\title{
Molecular Phylogenetics of the Metazoan Clade Lophotrochozoa \\ By
}

Yale J. Passamaneck

B.A., University of California, Santa Cruz, 1996

Submitted in partial fulfillment of the requirements for the degree of

Doctor of Philosophy

at the
MASSACHUSETTS INSTITUTE OF TECHNOLOGY
and the

WOODS HOLE OCEANOGRAPHIC INSTITUTION

September 2003

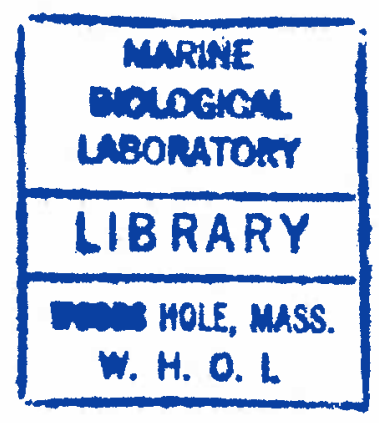

(C) 2003 Woods Hole Oceanographic Institution. All rights reserved.

The author hereby grants to MIT and WHOI permission to reproduce paper and electronic copies of this thesis document in whole or in part and to distribute them publicly.

Signature of Author

$$
\begin{array}{r}
\text { Joint Program in Biological Oceanography } \\
\text { Massachusetts Institute of Technology } \\
\text { and Woods Hole Oceanographic Institution } \\
\text { September } 2003
\end{array}
$$

Certified by

$$
\begin{array}{r}
\text { Kenneth M. Halanych, } \mathrm{PhD} . \\
\text { Thesis Supervisor }
\end{array}
$$

Accepted by

John Waterbury, Ph.D.

Chair, Joint Program for Biological Oceanography

Massachusetts Institute of Technology and Woods Hole Oceanographic Institution 


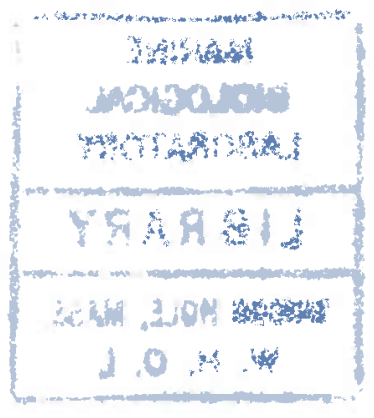




\title{
Molecular Phylogenetics of the Metazoan Clade Lophotrochozoa
}

\author{
By \\ Yale J. Passamaneck \\ Submitted in partial fulfillment of the requirements for the degree of \\ Doctor of Philosophy \\ at the \\ MASSACHUSETTS INSTITUTE OF TECHNOLOGY \\ and the \\ WOODS HOLE OCEANOGRAPHIC INSTITUTION
}

September 2003

\section{ABSTRACT}

DNA sequencing and phylogenetic analyses were conducted to investigate evolutionary relationships between taxa within the metazoan clade Lophotrochozoa. Chapter 1 presents an introduction to phylogenetics of the Metazoa and the clade Lophotrochozoa. Chapter 2 analyzes higher level relationships between the major groups within the phylum Mollusca using sequences of the nuclear ribosomal large-subunit RNA gene (LSU rDNA). Results presented provide the first molecular evidence for a close relationship between the Scaphopoda and Cephalopoda. Phylogenetic trees with this topology were found to have likelihood scores significantly better than those for phylogenies constrained to fit the Diasoma hypothesis grouping Scaphopoda and Bivalvia as sister taxa. Chapter 3 utilizes LSU rDNA sequences to analyze relationships between diverse phyla within the clade Lophotrochozoa. LSU rDNA sequences were found to provide greater resolution than has been provided by previous analyses of the nuclear small-subunit ribosomal RNA gene (SSU rDNA). Analysis of LSU rDNA sequences recovered the monophyly of several phyla, such as Mollusca and Annelida, whose members are found to be paraphyletic using SSU rDNA sequences alone. Results also suggest that the clade Platyzoa, including rotifers and platyhelminthes, may have arisen within the Lophotrochozoa, rather than as a sister group to lophotrochozoans. Chapter 4 investigates the Hox gene complement of the bryozoan Bugula turrita. Six Hox genes were recovered, including an ortholog of the posterior class gene Post2, which is a synapomorphy for the Lophotrochozoa. The identification of a Post 2 ortholog provides evidence of a close relationship between the Bryozoa and other lophotrochozoan phyla.

Thesis Supervisor: Kenneth M. Halanych

Title: Assistant Scientist, Biological Oceanography, Woods Hole Oceanographic Institution 


\section{Acknowledgements}

I would like to thank my advisor, Ken Halanych for inspiring this project and providing support and advice throughout its development and execution. I would also like to than my committee members, John Finnerty, Mark Hahn, Lauren Mullineaux, and Hazel Sive for their support and guidance during the course of my research. Eric Webb generously served as the chair of my thesis defense and provided valuable advice during this process, as well as whenever I had questions about molecular biology during the course of my research.

To all the members of the Halanych lab, Thomas Dahlgren, Annette Govindarajan, Rob Jennings and Nan Trowbridge, thank you for your friendship, support and good humor. Thank you as well to all the members of the Shank and Finnerty labs for welcoming and sharing their knowledge and resources with me.

My sincere thank to all those who provided me with tissue samples and DNA extractions. Akiko Okusu, Thomas Dahlgren, David Mark Welch, Monica Medina, Chris Schander, Tim Shank, and Janet Voight, your generosity made his work possible.

To all the members of the Scheltema lab, Amelie Scheltema, Chris Schander, Akiko Okusu, Dimitri Ivanov, and Benoit Dayrat, thank you for stimulating and enlightening conversations about aplacophoroans and other mollusks.

My thanks to all those at the Bay Paul Center for Molecular Evolution at the Marine Biological Laboratory who lent their expertise and time to aid my research: Mitch Sogin, Hilary Morrison, Andrew McArthur, Monica Medina, and Jennifer Wernegreen. My thanks as well to Patrick Degnan and Adam Lazarus for always being willing to warm up the spectrophotometer form me.

My thanks to Dennis Willows and all at Friday Harbor Laboratories for supporting me in my work there and providing me unique teaching opportunities. Special thanks to Billie Swalla for inviting me to TA for her, as well as for her support and friendship.

To Nora, thank you for teaching me to sequence DNA, for being my editor, for all your peptalks and motivation, and for being my source of joy. My enduring thanks to my parents for their support and love, and to David and Tess Eakin for welcoming into their family.

This work was supported by a grant from the National Science Foundation, DEB-0075618 "Genomic approaches to metazoan evolution; lophotrochozoans and Hox genes" to Kenneth Halanych. Bryozoan Hox research was supported by a Doctoral dissertation Improvement Grant from the National Science Foundation, DEB-0104984 "Phylogenetic inference from bryozoan Hox genes" to Kenneth Halanych and Yale Passamaneck. Additional support was provided by the Woods Hole Oceanographic Institution Education Office. 


\section{Table of Contents}

Title page

Abstract 3

$\begin{array}{ll}\text { Acknowledgements } & 4\end{array}$

Table of Contents

$\begin{array}{ll}\text { Chapter } 1 & 6\end{array}$

Introduction to metazoan phylogenetics and the clade Lophotrochozoa.

Charper 2

Investigation of Molluscan Phylogeny Using Large-Subunit and Small-Subunit

Nuclear rRNA Sequences, and Analysis of Rate Variation Across Lineages.

Chapter 3

Assessing Lophotrochozoan phylogeny with combined LSU and SSU ribosomal RNA gene sequences.

Chapter 4

A Survey of Hox genes in the bryozoan Bugula turrita.

Chapter 5

Conclusions

Appendix

A brief review of metazoan phylogenetics and future directions in Hox-research.

Bibliography 


\section{Chapter 1}

Introduction to metazoan phylogenetics and the clade

\section{Lophotrochozoa}


The work presented in this thesis explores the phylogenetic relationships between major groups within the metazoan clade Lophotrochozoa. This clade, which encompasses a many animal phyla, including bryozoans, brachiopods, annelids and mollusks, was first identified from analyses of nuclear ribosomal small-subunit gene (SSU rDNA) sequences (Halanych et al., 1995). Although the clade has been supported by additional markers, such as Hox genes (de Rosa et al., 1999), resolution of relationships among lophotrochozoan phyla remains uncertain. The Lophotrochozoa encompasses a broad diversity of body plans, developmental modes and life histories. A greater understanding of the evolutionary relationships amongst taxa within the clade is crucial to understanding the origins of morphological and developmental novelties. The work presented here builds upon the current body of knowledge by employing sequence data from the nuclear ribosomal large-subunit gene (LSU rDNA) and Hox genes to explore the evolution of lophotrochozoans.

To appreciate the context in which this thesis has developed, it is valuable to understand historical and current views of metazoan evolution. Traditionally, hypotheses of metazoan evolution have been based upon researchers' knowledge of the animals under study and their personal interpretation of similarities between them. The dominant view has long been one of increasing complexity over the course of metazoan evolution (e.g. Haeckel, 1874; Hyman, 1940) (Figure 1), where animals moved from a simple organization with two cell layers (diplobastic) to a more advanced state with three cell layers (triploblastic). 


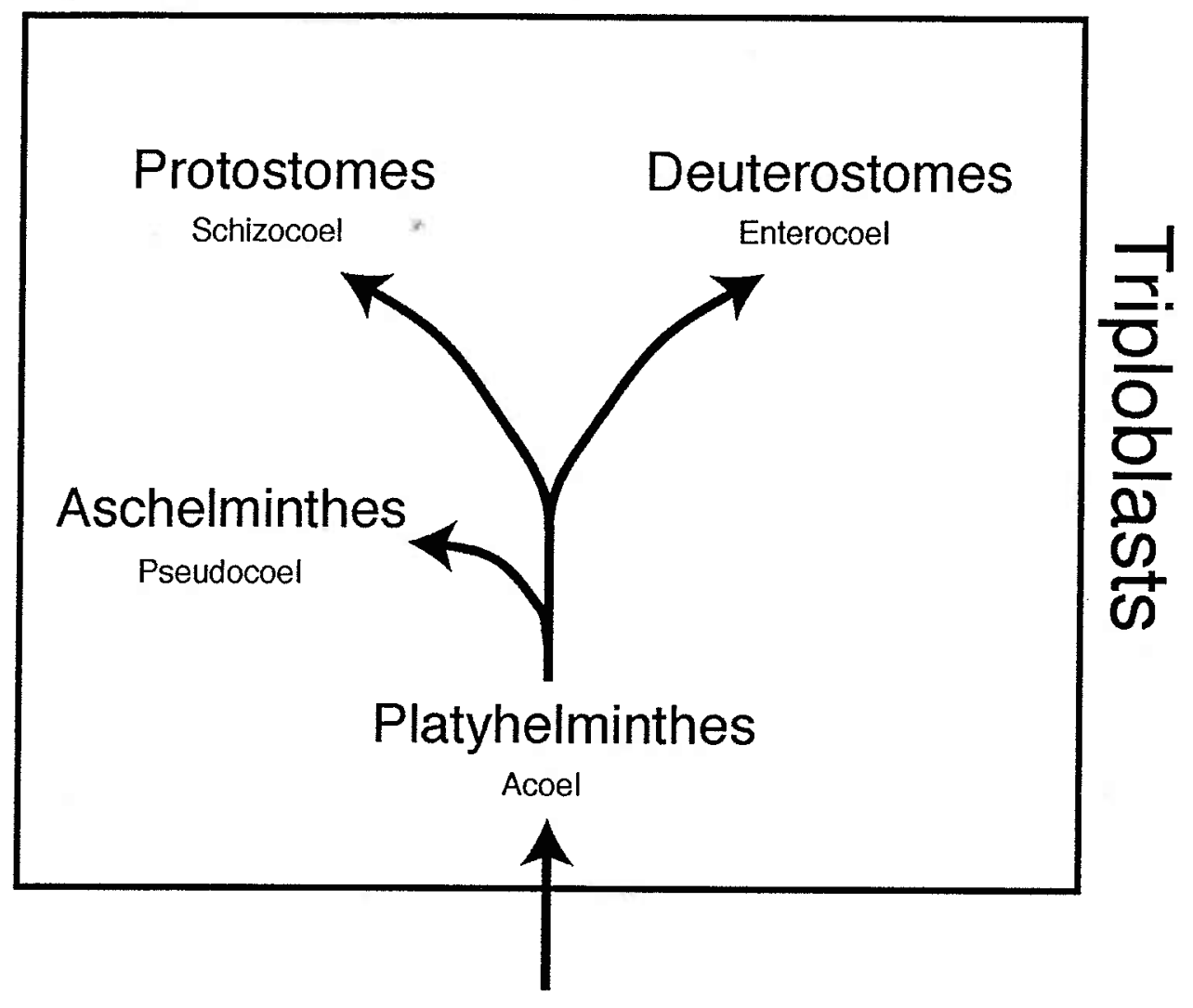

Cnidarians, Ctenophores

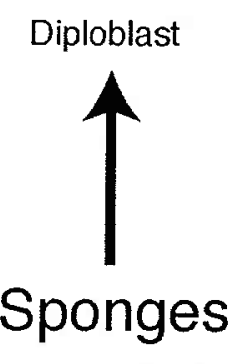

Cellular Grade

Figure 1: Traditional view of metazoan phylogeny, based upon interpretation of increasing morphological complexity. Tissue organization or pattern of coelom fomation is listed for each group. Modified from Halanych and Passamaneck (2001). 
Under this view, relationships among bilaterian triploblasts were defined based upon the nature and origin their coelomic cavities, with organisms having more complex coeloms being viewed as more derived. Platyhelminthes were descibed as acoelomate, and therefore the most primitive of bilaterian triploblasts. Several taxa, such as rotifers and nematodes, have simple body cavities derived from the embryonic blactocoel. Such animals have been described as pseudocoelomate, and grouped together by some authors under the name Aschelminthes (e.g. Hyman, 1951).

Taxa with fully developed coeloms surrounded by mesodermal tissue were viewed as the most advanced metazoans. Among such taxa a further distinction was drawn based upon the mode of coelom formation. Deuterostomes were characterized by coelom formation through invagination of the endoderm, termed enterocoely, while protostomes formed coeloms by means of schizocoely, a splitting of mesodermal bands.

Other researchers have also posited the phylogenetic significance of features such as cleavage pattern during early development (e.g. Siewing, 1976; 1980), fate of the blastopore in relation to the mouth and anus of the adult (Grobben, 1908), and larval type (e.g. Jägersten, 1972; Nielsen, 1985). However, each of these hypotheses is limited by the potential bias in the investigator's perspective on what small set characters are phylogenetically important. The major problem with these approaches is that reliance on a small number of features to infer evolutionary relationships limits the potential for rigorous comparison of alternative hypotheses.

With the advent of cladistics, Willi Hennig (1966) provided the groundwork for a systematic approach to analyzing the evolutionary relationships between metazoan phyla that answers the limitation of traditional analyses. Cladistics bases determination of 
phylogenetic relationships upon the identification of synapomorphies, shared derived characters present in related organisms and absent in unrelated organisms. Identification of synapomorphies allows determination of monophyletic clades of organisms.

In recent, years cladistic methods have been employed to analyze several large datasets of metazoan morphological and embryological datasets. Cladistic analyses by Eernissee et al., (1992) provided evidence contradicting the widely held Articulata hypothesis, which viewed annelids and arthropods as sharing a common segmented ancestor. More recent analyses (e.g. Zrzavy et al., 1998; Giribet et al., 2000; Peterson and Eernissee, 2001) have incorporated large datasets that include nearly all known extant metazoan phyla. While there are many similarities in the results from each of these studies, the position of some taxa, such as the lophophorate taxa (brachiopods, phoronids, and bryozoans), varies depending upon what characters are chosen and how they are coded. Recently, Jenner (2001) has urged caution in analysis of morphological characters, as many studies have included characters from previous studies without critical appraisal as to whether these characters are coded correctly.

Resurgent interest in the evolution of development during the last decade may provide a valuable tool for identifying phylogenetically informative characters. More detailed understanding of ontogenetic processes and the molecular mechanisms underlying them has the potential to aid determination of homology between structures. For example, recent evidence suggests that the molecular mechanisms underlying formation of the blastopore are conserved across bilaterians (Arendt et al., 2001). These findings are important because comparisons of blastopore fate are predicated on a presumption that all blastopores are homologous. Detailed studies of cell fate have also 
helped to establish the homology of cell lineages among taxa with spiral cleavage (Henry, 2002). Spiral cleavage may therefore have had a single origin during the course of metazoan evolution. While utilizing such an approach may be produce phylogenetically informative results, great care must be exercised, as homologous processes often do not produce homologous structures (Abouheif et al., 1997; Wray and Abouheif., 1998).

Recent advances in DNA sequencing techniques have provided the ability of use gene sequences as an independent dataset for inferring evolutionary relationships among metazoans. To date, many molecular phylogenetic analyses of the relationships between metazoan phyla have relied upon sequence of the nuclear small-subunit ribosomal RNA gene (SSU rDNA or 18S rDNA; e.g. Field et al., 1988; Halanych et al, 1995; Aguinaldo et al., 1997; Giribet et al., 2000; Peterson and Eernissee, 2001). SSU rDNA has been valuable because portions of the gene sequence appear to evolve quite slowly, creating the potential for conservation of changes accrued during the diversification of metazoan phyla. Such conserved changes would then allow insight into the relationships between phyla. Analysis of SSU sequence has provided independent verification of many hypotheses of metazoan evolution, including the monophyly of the Bilateria (Field et al., 1988), and the division of Bilateria into protostome and deuterostome lineages (Lake, 1990). However, SSU sequence has also revealed unexpected relationships.

One dramatic finding has been that the three lophophorate phyla (bryozoans, brachiopods, and phoronids) are more closely related to protostome annelids and mollusks, than they are to deuterostomes, as has traditionally been believed (Halanych et al., 1995; Table 2). Halanych et al. (1995) named this new clade "Lophotrochozoa", for the lophophore of bryozoans, brachiopods, and phoronids, and the trochophore type larva 


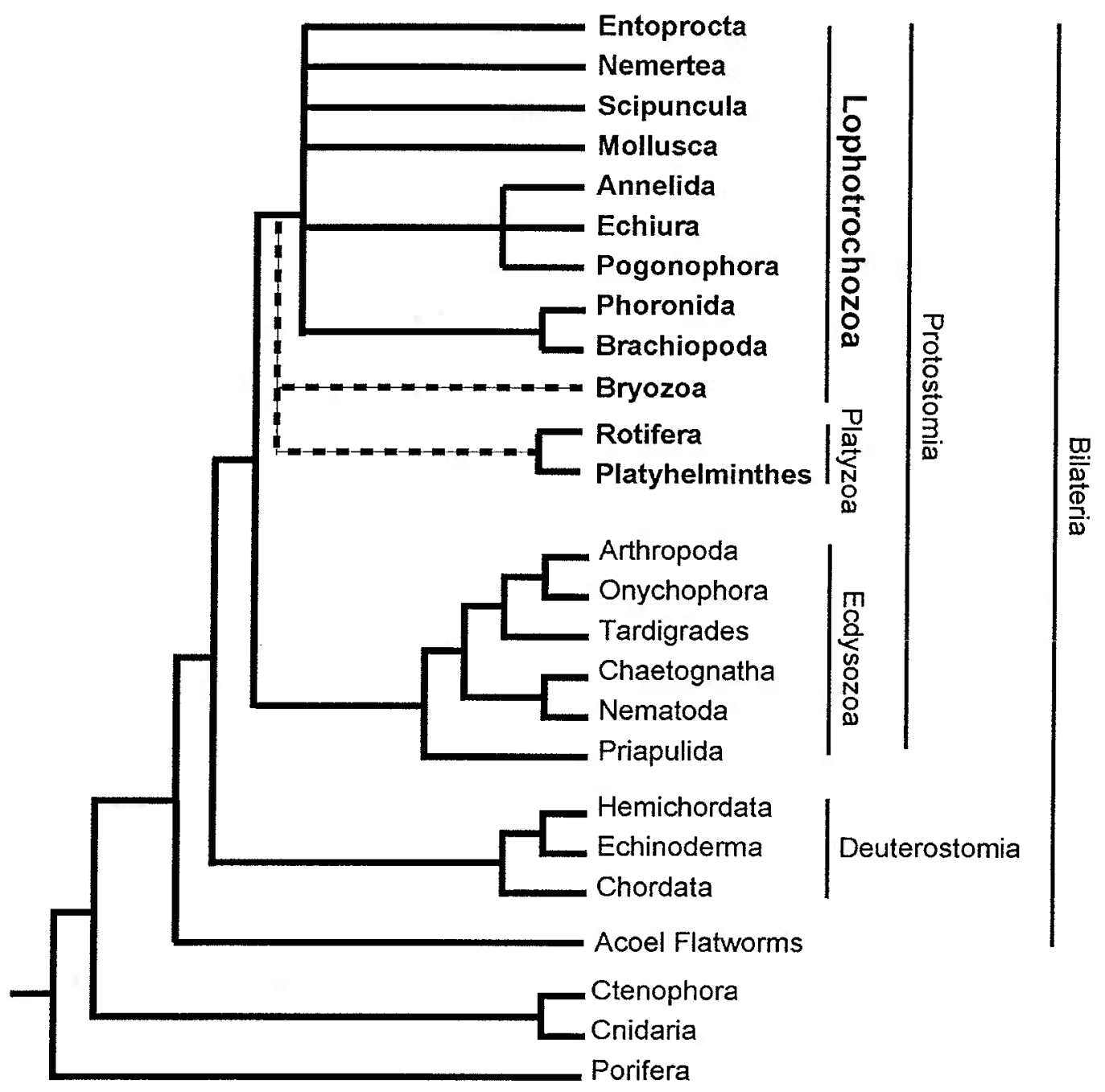

Figure 2: Current understanding of evolutionary relationships among metazoan phlya. Members of the clade Lophotrochozoa are highlighted. Phyla with uncertain phylogentic affinities in the tree are denoted with dashed branches. Relationships presented in the tree are primarily derived from analyses of small-subunit ribosomal rRNA gene (SSU rDNA) sequences. Modified from Halanych and Passamaneck (2001). 
shared by annelids and mollusks. The results presented in this study also suggested that lophophorates might not comprise a monophyletic clade, as the bryozoan sequence branched basally to that of the other lophotrochozoans. The relationships between brachiopods, phoronids, annelids and mollusks were not resolved in this study.

Subsequent analysis of SSU sequence from additional taxa suggests that the clade Lophotrochozoa encompasses a broad diversity of metazoan phyla, including sipunculans, nemerteans, and entoprocts (e.g. Winnepenninckx et al., 1995; Mackey et al., 1996). Rotifers and platyhelminthes also appear to be closely related to lophotrochozoans, either as members of the clade (as discussed in Chapter 3), or as members of a sister group termed the Platyzoa (Giribet et al., 2000). Despite the diversity of the Lophotrochozoa, the relationships among the phyla within the group have not been extensively studied, and are not well understood. While SSU rDNA provided the initial evidence for the clade Lophotrochozoa, it does not appear to be able to resolve relationships among phyla within the clade.

Although the utility of SSU rDNA for elucidating metazoan evolution has been criticized (Abouheif et al., 1998), simulation studies have suggested that additional sequence with evolutionary properties like that of SSU rDNA for each taxon would be sufficient to increase resolution (Halanych, 1998). Multiple copies of the SSU gene are present in the genome of metazoans, however, their sequences remain homogeneous through a process of concerted evolution (Hillis and Dixon, 1991). Other molecular markers must therefore be explored to obtain additional sequence data for phylogenetic reconstructions. 
The nuclear large-subunit ribosomal RNA gene (LSU rDNA) provides a potential source of information for metazoan phylogenetics because it has properties similar to that of SSU rDNA (Hillis and Dixon, 1991). Both are part of the ribosomal DNA tandem repeat, and like SSU rDNA, LSU rDNA displays rate heterogeneity among sites. Highly conserved sites therefore allow for design of universal primers for amplification and sequencing, while changes accumulated at less conserved sites may hold information regarding the evolutionary relationships among taxa. Several recent studies have evidenced the utility of LSU sequence for analyzing phylum level relationships within the Metazoa, particularly when combined with SSU sequence (Medina et al., 2001; Winchell et al., 2002; Mallatt and Winchell, 2002).

In the following chapters I present work done to assess the ability of LSU rDNA and Hox sequences to inform our understanding of lophotrochozoan phylogenetics. Chapter 2 focuses on higher-level relationships within the phylum Mollusca. The Mollusca represents the most diverse of lophotrochozoan phyla, in terms of both morphology and numbers of species. Despite this diversity, the relationships between the major groups of mollusks has received relatively little attention from the standpoint of molecular phylogenetics. Work presented here provides the first molecular evidence of a close evolutionary relationships between scaphopods and cephalopods. This finding challenges the widely held Diasoma hypothesis, which suggests scaphopods to be closely related to bivalves. Chapter 2 also explores heterogeneity in the rate of LSU evolution between molluscan taxa, and its potential impact of phylogenetic reconstruction.

Chapter 3 utilizes LSU sequence to investigate the relationships among lophotrochozoan phyla. LSU sequence is found to improve resolution of phylum level 
relationships from the standpoint that most phyla are recovered as monophyletic. Although bootstrap branch support values are low, this finding is a dramatic advance over analyses of SSU sequence alone, which generally fail to recover the monophyly of phyla such as the Mollusca and Annelida. Results in Chapter 3 also suggest that rotifers and platyhelminthes may have emerged as part of the lophotrochozoan radiation, rather than diverging prior to it.

Chapter 4 of the thesis utilizes Hox gene sequences to explore the phylogenetic affinities of the enigmatic phlyum Bryozoa. The Bryozoa are part of the Lophotrochozoa, as it was originally defined. However, recent analyses of SSU sequences have failed to recover a close relationship between bryozoans and other lophotrochozoans, and have called the phylogenetic position of the Bryozoa into question. Recent identification of Hox genes which appear to be present only in lophotrochozoans presents the possibility that these genes may have utility as synapomorphies for members of the clade (de Rosa et al., 2001). In this chapter evidence is presented for a bryozoan ortholog of one such gene, Post2, which is also present in annelids, mollusks, brachiopods, nemerteans, and platyhelminthes. This finding provides strong evidence of a close relationship between the Bryozoa and other lophotrochozoans. The potential utility of Hox genes in elucidating metazoan phylogenetics in discussed further in Halanych and Passamaneck (2001), which is included as an Appendix to this thesis. 


\section{Chapter 2}

Investigation of Molluscan Phylogeny Using Large-Subunit and Small-Subunit Nuclear rRNA Sequences, and Analysis of Rate Variation Across Lineages. 


\begin{abstract}
The Mollusca represent one of the most morphologically diverse animal phyla, prompting a variety of hypotheses on relationships between the major lineages within the phylum based upon morphological, developmental, and paleontological data. Analyses of small-ribosomal RNA (SSU rRNA) gene sequence have provided limited resolution of higher-level relationships within the Mollusca. Recent analyses suggest large-subunit (LSU) rRNA gene sequences are useful in resolving deep-level metazoan relationships, particularly when combined with SSU sequence. To this end, LSU ( $3.5 \mathrm{~kb}$ in length) and SSU $(\sim 2 \mathrm{~kb})$ sequences were collected for 33 taxa representing the major lineages within the Mollusca to improve resolution of intraphyletic relationships. In contrast to phylogenetic analyses base on SSU, the Polyplacophora, Gastropoda, and Cephalopoda were each recovered as monophyletic clades with the LSU + SSU dataset. Analyses of LSU sequences strongly contradict the widely accepted Diasoma hypotheses that bivalves and scaphopods are closely related to one another. The data are consistent with recent morphological analyses suggesting scaphopods are more closely related to gastropods and cephalopods than to bivalves. While the Bivalvia were not recovered as monophyletic clade in analyses of the SSU, LSU, or LSU + SSU, the ShimodairaHasegawa test showed that likelihood scores for these results did not differ significantly from topologies where the Bivalvia were monophyletic. Although the LSU and combined LSU + SSU datasets appear to hold potential for resolving branching order within the recognized molluscan classes, low bootstrap support was found for relationships between the major lineages within the Mollusca. LSU + SSU sequences also showed significant levels of rate heterogeneity between molluscan lineages. The dataset also presents the first published DNA sequences from a neomeniomorph
\end{abstract}


aplacophoran, a group considered critical to our understanding of the origin and early radiation of the Mollusca. 


\section{Introduction}

Recent phylogenetic research on major metazoan lineages has relied heavily on the nuclear small subunit ribosomal rRNA gene (SSU rRNA or 18S), and prompted reevaluation of traditional theories of animal evolution (e.g. Halanych et al., 1995; Agiunaldo et al., 1997; Balavoine and Adoutte, 1998). Although rate variation between sites within SSU rRNA has made the gene useful for resolving relationships between organisms with varying degrees of relatedness, SSU rRNA alone has not been sufficient to resolve some higher-level relationships among metazoans. For example, major relationships within the Mollusca have proven difficult to resolve with SSU rRNA gene data (Winnepenninckx et al., 1996; Steiner and Hammer, 2000). Winnepenninckx et al., (1996) suggested two hypotheses to account for this lack of resolution. Rates of evolution within the gene may be inappropriate for the relationships being investigated, because changes accumulated during divergence of the molluscan classes have been subsequently masked by multiple substitutions. Alternatively, the Mollusca may have diversified rapidly, not allowing sufficient changes in SSU to permit accurate reconstruction of major relationships.

Simulations by Halanych (1998) have suggested that in such cases where SSU rRNA alone is inadequate to resolve relationships, additional sequence data with similar properties may provide greater signal and thus greater resolving power. The largesubunit (LSU) rRNA gene is linked to the SSU gene in a tandem repeat, having a shared evolutionary history. Several recent studies (Medina et al., 2001; Winchell et al., 2002; Mallatt and Winchell, 2002) have investigated the utility of LSU rRNA gene sequence for resolving higher-level relationships within the Metazoa. Each of these studies has 
shown that combined datasets of LSU and SSU may provide greater resolution of higherlevel relationships among metazoans than is achieved by analysis of SSU sequences alone. The present study investigates the ability of a combined LSU + SSU dataset to provide information regarding class level relationships within the Mollusca not available from SSU sequence alone.

The Mollusca represent one of the most diverse metazoan phyla both in terms of species number as well as in range of body plans. The diversity of the phylum is represented by seven or eight extant clades, commonly recognized as "classes". The Neomeniomorpha and Chaetodermomorpha (often referred to collectively as the Aplacophora), along with the Polyplacophora, are believed to be basally divergent lineages of the Mollusca (Wingstrand, 1985; Salvini-Plawen and Steiner, 1996). Together the three groups are referred to as the Aculifera (Scheltema, 1993). The Conchifera, comprised of the Monoplacophora, Bivalvia, Scaphopoda, Gastropoda, and Cephalopoda, appear to have arisen from a univalved common ancestor (Wingstrand, 1985).

Although the Aculifera are widely agreed to have diverged prior to the diversification of the Conchifera, relationships between the basal molluscs have been variously interpreted. Based upon morphological data, the Chaetodermomorpha (=Caudofoveata) have been described as the earliest diverging lineage within the Mollusca (SalviniPlawen, 1972; 1980; 1985) (Figure 3A). Cladistic analyses of morphological datasets have evidenced the Neomeniomorpha (=Solenogastres) as the most basal of extant lineages (Salvini-Plawen and Steiner, 1996; Haszprunar, 2000) (Figure 3B). Under either scenario the Aplacophora and Aculifera are viewed as paraphyletic grades, with the Polyplacophora branching as the sister group to the Conchifera to form the Testaria 
(Salvini-Plawen, 1972; 1980). Alternative interpretations of morphological and developmental characters have maintained the monophyly of the Aculifera, with the Neomeniomorpha and Chaetodermomorpha as members of a monophyletic Aplacophora forming the sister group to the Polyplacophora (Scheltema, 1993; 1996; Ivanov, 1996) (Figure 3C).

The Conchifera has been divided into two major clades, the Diasoma containing the Bivalvia and Scaphopoda, and the Cyrtosoma (sensu lato) including the Monoplacophora, Gastropoda, and Cephalopoda (Figure 3D). This widely accepted view (e.g. Brusca and Brusca, 1992; Meglitsch and Schram, 1991) is based primarily on paleontological evidence (Runnegar and Pojeta, 1974). The term Cyrtosoma is used herein to refer only to the Gastropoda and Cephalopoda, due to the likely paraphyly of the Monoplacophora (sensu Wingstrand, 1985). The Diasoma hypothesis, based upon inferred common origins of bivalves and scaphopods has come into question. Waller (1998) has proposed close relationship between the Scaphopoda and Cephalopoda based upon inferred developmental commonalities (Figure 3E). A cladistic analysis by Haszprunar (2000) also contradicts the Diasoma hypothesis, finding the Scaphopoda to be the sister group to the Cyrtosoma (Figure 3F).

To gain further understanding of molluscan diversification, we have sequenced LSU and SSU genes for all extant major lineages of the Mollusca, except monoplacophorans. Herein we evaluate the phylogenetic signal present in these rRNA genes, and their utility in resolving higher level molluscan relationships. Analyses found short internal branch lengths and variability in branching order among the major molluscan lineages. High levels of rate heterogeneity were also found between taxa sampled. However, 
reconstructions grouping scaphopods with cephalopods were found to have likelihood scores significantly better than those for reconstructions constrained to fit the Diasoma + Cyrtosoma hypothesis of conchiferan evolution. 
A

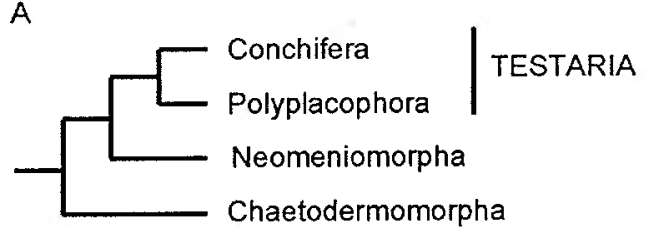

C

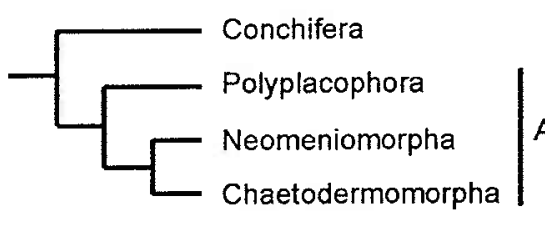

ACULIFERA

$E$

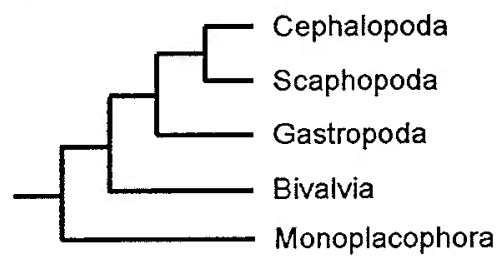

B

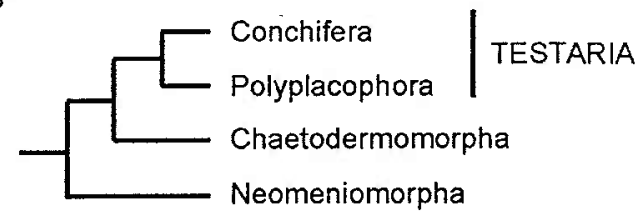

D

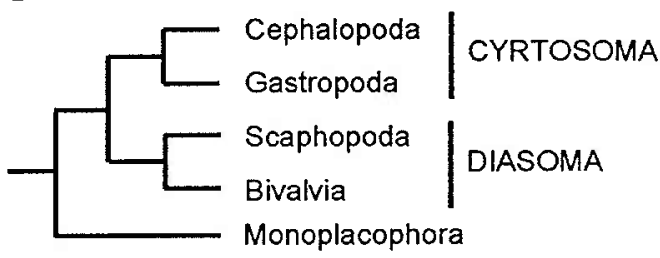

F

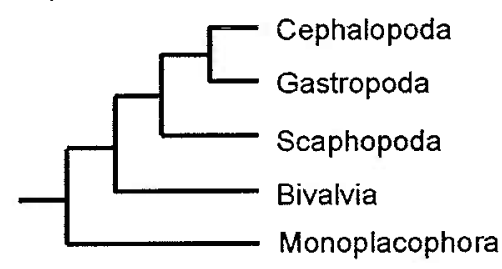

Figure 3: Hypothesis of molluscan class relationships. (A)-(C) Hypotheses of basal molluscan relationships. (A) Basal position of Chaetodermomorpha (Salvini-Plawen, 1972, 1980, 1985); (B) Basal position of Neomeniomorpha (Salvini-Plawen and Steiner, 1996; Haszprunar, 2000); (C) Aculifera hypothesis (Scheltema, 1993, 1996; Ivanov, 1996). (D)-(F) Hypotheses of Conchiferan relationships. (D) Diasoma and Cyrtosoma hypothsis (Runnegar and Pojeta, 1974); (E) Scaphopoda as sistergroup of Cephalopoda (Waller, 1998); (F) Scaphopoda as sistergroup of Cephalopoda + Gastropoda (Haszprunar, 2000). 


\section{Materials and Methods}

\section{Taxon sampling}

Molluscan taxa were chosen from available material to provide the broadest representation of extant lineages. Genomic DNA was isolated from 32 mollusk and 1 outgroup taxa (Table 1) using the DNeasy Tissue Kit (Qiagen), with an additional two sequences obtained from GenBank. Monica Medina kindly provided tissue and LSU rDNA sequence for Dialula sp. Akiko Okusu kindly provided samples of Cryptoplax japonica, Dentalium octangulatum, Ischnochiton comptus, and Nordotis discus. Janet Voight kindly provided samples of Arboliopsis sp., Benthoctopus yaquinae, Graneledone pacifica, Histioteuthis sp., and Vampyroteuthis infernalis from the collection of the Field Museum of Natural History. DNA extractions of molluscan samples were taken from mantle or muscle tissue, with the exception of Chaetoderma sp. and Helicoradomenia sp. where, due to size, whole animals were used. DNA extraction for the outgroup taxon Cerebratulus lacteus was taken from sperm. Outgroups were chosen based on knowledge of lophotrochozoan phylogeny (e.g. de Rosa et al., 1999; Giribet et al., 2001; Peterson and Eernisse, 2001) and the presence of low nucleotide substituion rates.

SSU sequence for Crassostrea gigas available from GenBank was combined with LSU sequence from $C$. virginica collected for this study. A 381 nucleotide fragment of C. virginica SSU (accession number L78851) was $98 \%$ similar to that of C. gigas, suggesting minimal difference in the complete sequence of the gene from the two species. 
Table 1: Taxa sampled for SSU and LSU rDNA sequences

\begin{tabular}{|c|c|c|c|}
\hline \multirow[b]{2}{*}{ Species } & \multirow[b]{2}{*}{ Collection location } & \multicolumn{2}{|c|}{ Accession numbers } \\
\hline & & LSU & SSU \\
\hline \multicolumn{4}{|l|}{ Mollusca } \\
\hline \multicolumn{4}{|l|}{ Aplacophora } \\
\hline Helicoradomenia acredema & $18^{\circ} \mathrm{N}$ - East Pacific Rise & AY $145409^{2}$ & $\mathrm{AY} 145377^{\mathrm{a}}$ \\
\hline Chaetoderma sp. & Tjärnö, Sweden & AY $145397^{\mathrm{a}}$ & AY $145369^{a}$ \\
\hline \multicolumn{4}{|l|}{ Bivalvia } \\
\hline Arctica islandica & Maine & $\mathrm{AY} 145390^{\mathrm{a}}$ & AIU93555 \\
\hline Argopecten irradians & Cape Cod, MA & $\mathrm{AY} 145391^{\mathrm{a}}$ & L11265 \\
\hline Crassostrea virginica & North Falmouth, MA & $\mathrm{AY} 145400^{\mathrm{a}}$ & AB064942 \\
\hline Geukensia demissa & North Falmouth, MA & $\mathrm{AY} 145405^{\mathrm{a}}$ & L33450 \\
\hline Nuculuna pernula & Tjärnö MBL, Sweden & AY $145419^{a}$ & $\mathrm{AY} 145385^{\mathrm{a}}$ \\
\hline Phaxas pellucidus & Tjärnö MBL, Sweden & AY $145420^{\mathrm{a}}$ & $\mathrm{AY} 145386^{\mathrm{a}}$ \\
\hline Placopecten magellanicus & $?$ & AF342798 & X53899 \\
\hline Solemya velum & Cape Cod, MA & AY $145421^{a}$ & AF 120524 \\
\hline Yoldia limulata & Cape Cod, MA & AY $145424^{\mathrm{a}}$ & $\mathrm{AF} 120528$ \\
\hline \multicolumn{4}{|l|}{ Cephalopoda } \\
\hline Arbaliopsis sp. & FMNH $962-69^{b}$ & $\mathrm{AY} 145389^{\mathrm{a}}$ & AY $145364^{\mathrm{a}}$ \\
\hline Benthoctopus yaquinae & FMNH $278119^{b}$ & AY $145393^{\mathrm{a}}, \mathrm{AY} 145394^{\mathrm{a}}$ & AY $145366^{\mathrm{a}}$ \\
\hline Graneledone pacifica & FMNH $278306^{b}$ & AY $145407^{2}$ & AY $145376^{\mathrm{a}}$ \\
\hline Histioteuthis sp. & FMNH $962-69^{b}$ & AY $145410^{\mathrm{a}}$ & AY $145378^{a}$ \\
\hline Loligo paeli & Woods Hole, MA & AY $145415^{\mathrm{a}}, \mathrm{AY} 145416^{\mathrm{a}}$ & AY $145383^{a}$ \\
\hline Nautilus pompilius & MBL, Woods Hole, USA & $\mathrm{AY} 145417^{\mathrm{a}}$ & AY $145384^{a}$ \\
\hline Vampyroteuthis infernalis & FMNH $286569^{b}$ & $\mathrm{AY} 145422^{\mathrm{a}}, \mathrm{AY} 145423^{\mathrm{a}}$ & AY $145387^{\mathrm{a}}$ \\
\hline \multicolumn{4}{|l|}{ Gastropoda } \\
\hline Arion silvaticus & Sandwich, MA & AY $145392^{\mathrm{a}}$ & AY $145365^{\mathrm{a}}$ \\
\hline Boonea seminuda & Woods Hole, MA & AY $145395^{a}$ & AY $145367^{\mathrm{a}}$ \\
\hline Deroceras reticulatum & Connecticut & AY145404 ${ }^{a}$ & $\mathrm{AY} 145373^{\mathrm{a}}$ \\
\hline Diaulula sandiegensis & California & $\mathrm{AY} 144352^{\mathrm{a}}$ & AY $145374^{\mathrm{a}}$ \\
\hline Gibbula magnus & Vigo Harbor, Spain & AY145406 ${ }^{\mathrm{a}}$ & AY $145375^{\mathrm{a}}$ \\
\hline Haminoea solitaria & West Falmouth, MA & $\mathrm{AY} 145408^{\mathrm{a}}$ & AF249221 \\
\hline Ilyanassa obsoleta & North Falmouth, MA & $\mathrm{AY} 145411^{\mathrm{a}}$ & AY $145379^{a}$ \\
\hline Lepetodrilus elevatus & $9^{\circ} \mathrm{N}$ - East Pacific Rise & $\mathrm{AY} 145413^{\mathrm{a}}$ & AY $145381^{a}$ \\
\hline Nordotis discus & Japan & AY $145418^{a}$ & AF082177 \\
\hline \multicolumn{4}{|l|}{ Polyplacophora } \\
\hline Chaetopleura apiculata & North Falmouth, MA & AY $145398^{a}$ & AY $145370^{\mathrm{a}}$ \\
\hline Cryptoplax japonica & Japan & $\mathrm{AY} 145402^{\mathrm{a}}$ & AY $145371^{8}$ \\
\hline Ischnochiton comptus & Japan & AY $145412^{a}$ & $\mathrm{AY} 145380^{a}$ \\
\hline Leptochiton acellus & Kristineberg MRS, Sweden & AY $145414^{\mathrm{a}}$ & AY $145382^{a}$ \\
\hline \multicolumn{4}{|l|}{ Scaphopoda } \\
\hline Antalis entalis & Tjärnö MBL, Sweden & AY $145388^{a}$ & AY $145363^{\mathrm{a}}$ \\
\hline Dentalium octangulatum & Japan & $\mathrm{AY} 145403^{\mathrm{a}}$ & $\mathrm{AY} 145372^{\mathrm{a}}$ \\
\hline
\end{tabular}




\section{Nemertea}

Cerebratulus lacteus

Woods Hole, MA

AY $145396^{a}$

AY $145368^{a}$

Brachiopoda

Terebratalia transversa

$?$

U12650

AF342802

a Sequences collected for this study

${ }^{b}$ Voucher numbers of Field Museum of Natural History samples provided by Janet Voight. 


\section{Data Collection}

All oligonucleotide primers used in this study are listed in Table 2. LSU fragments were amplified using the primers F63.2 and R3264.2 and SSU fragments were amplified using the primers $18 \mathrm{e}$ and $18 \mathrm{p}$. Molluscan specific primers were designed to avoid contamination of extraneous genomic DNA in Helicoradomenia sp. and Chaetoderma sp. extractions. For these species, the SSU region was amplified as two overlapping fragments, using the primer pairs 18e and Mollusc18R1, and Mollusc18F1 and 18p. LSU was amplified in these species using F63.2 and Mollusc28R2, which amplified all but $\sim 400$ bases at the 3 ' end of the gene.

Both genes were isolated using a long PCR protocol to facilitate amplification of nearly complete gene fragments. PCR reactions contained $15 \mu 13.3 \times$ rTth buffer, $2.5 \mu 1$ $10 \mu \mathrm{M}$ primer, $5 \mu 12 \mathrm{mM}$ dNTPS, $0.4 \mu 1 \mathrm{rTth}$ (PE Applied Biosystems), $1 \mu 1$ Vent polymerase (New England BioLabs) (diluted 1:100 in a buffer composed of 50\% glycerol, 20mM HEPES, 10mM KCL, 1mM DTT, 0.1 $\mathrm{mM} \mathrm{Na}_{2}$ EDTA, 0.0025\% Tween20 , and $0.0025 \%$ NP-40), with genomic DNA and water to a final volume of $45 \mu 1$. Following a 5 minute denaturation, $5 \mu \mathrm{l}$ of $25 \mathrm{mM} \mathrm{Mg}(\mathrm{OAc})_{2}$ was added to each reaction. PCR involved 30 cycles of denaturation at $94^{\circ} \mathrm{C}$ for $30 \mathrm{sec}$, annealing at $45-55^{\circ} \mathrm{C}$ for 1 min, and extension at $65^{\circ} \mathrm{C}$ for $12 \mathrm{~min}$ LSU or $8 \mathrm{~min}$ for SSU. A final extension was carried out at $72^{\circ} \mathrm{C}$ for $10 \mathrm{~min}$. PCR products were cleaned with QIAquick PCR Purification Kit (Qiagen) and incubated at $70^{\circ} \mathrm{C}$ for 10 minutes in the presence of $T a q$ polymerase (Promega) and $0.4 \mathrm{mM}$ dATP to create adenine overhangs. PCR fragments were cleaned a second time with the QIAquick PCR Purification Kit and cloned using the pGEM-T Vector System (Promega). 
Table 2: Primers used for PCR amplification and sequencing

\begin{tabular}{|c|c|c|}
\hline Primer & Reference & Sequence $5^{\prime}>3^{\prime}$ \\
\hline \multicolumn{3}{|c|}{ PCR amplification } \\
\hline \multicolumn{3}{|l|}{ LSU } \\
\hline F63.2 & Medina (personal communication) & ACCCGCTGAAYTTAAGCATAT \\
\hline $\mathrm{R} 3264.2$ & Medina (personal communication) & TWCYRMCTTAGAGGCGTTCAG \\
\hline Mollusc28R2 & Present study & GCGAGGTTTCCGTCCTCGC \\
\hline \multicolumn{3}{|l|}{ SSU } \\
\hline $18 \mathrm{e}$ & Hillis \& Dixon, 1991 & CTGGTTGATCCTGCCAGT \\
\hline $18 \mathrm{p}$ & Halanych et al., 1998 & TAATGATCCTTCCGCAGGTTCACCT \\
\hline Mollusc18F1 & Present study & TTTAGCCACRCGAGAWTGA \\
\hline Mollusc18R1 & Present study & GTTATTGCTCAWTCTCGYG \\
\hline \multicolumn{3}{|l|}{ Sequencing } \\
\hline \multicolumn{3}{|l|}{ LSU } \\
\hline $28 \mathrm{ee}$ & Hillis \& Dixon, 1991 & ATCCGCTAAGGAGTGTGTAACAACTCACC \\
\hline $28 \mathrm{ff}$ & Hillis \& Dixon, 1991 & GGTGAGTTGTTACACACTCCTTAGCGG \\
\hline $28 \mathrm{gg}$ & Hillis \& Dixon, 1991 & GACGAGGCATTTGGCTACCTTAAG \\
\hline $28 \mathrm{nn}$ & Present study & GGAACCAGCTACTAGATGGTTCG \\
\hline $28 \mathrm{~F} 1-2$ & Present study & GYWGGGACCCGAAAGATGGTGAAC \\
\hline $28 \mathrm{~F} 2-2$ & Present study & GCAGAACTGGCGCTGAGGGATGAAC \\
\hline $28 \mathrm{~F} 4$ & Present study & CGCAGCAGGTCTCCAAGGTGMACAGCCTC \\
\hline $28 \mathrm{~F} 5$ & Present study & CAAGTACCGTGAGGGAAAGTTG \\
\hline $28 \mathrm{R} 2$ & Present study & GAGGCTGTKCACCTTGGAGACCTGCTGCG \\
\hline $28 \mathrm{~V}$ & Hillis \& Dixon, 1991 & AAGGTAGCCAAATGYCTCGTCATC \\
\hline $28 \mathrm{X}$ & Hillis \& Dixon, 1991 & GTGAATTCTGCTTCACAATGATAGGAAGAGCC \\
\hline $28 \mathrm{MT} 4.1$ & Present study & TCCTTGGTCCGTGTTTCAAGACG \\
\hline $28 \mathrm{R} 3$ & Present study & GATGACGAGGCATTTGGCTACC \\
\hline 28R4 & Present study & GAGCCAATCCTTATCCCAAAGTTACGGATC \\
\hline \multicolumn{3}{|r|}{ ( } \\
\hline $18 \mathrm{~h}$ & Hillis \& Dixon, 1991 & AGGGTTCGATTCCGGAGAGGGAGC \\
\hline $18 \mathrm{~L}$ & Halanych et al., 1998 & GAATTACCGCGGCTGCTGGCACC \\
\hline $18 \mathrm{M}$ & Halanych et al., 1998 & GAACCCAAAGACTTTGGTTTC \\
\hline $18 \mathrm{M0}$ & Halanych et al., 1998 & GAAACCAAAGTCTTTGGGTTC \\
\hline 180 & Halanych et al., 1998 & GGAATRATGGAATAGGACC \\
\hline $18 Q$ & Halanych et al., 1998 & TGTCTGGTTAATTCCGATAAC \\
\hline $18 \mathrm{Q} 0$ & Halanych et al., 1998 & GTTATCGGAATTAACCAGACA \\
\hline $18 \mathrm{R}$ & Present study & GTCCCCTTCCGTCAATTYCTTTAAG \\
\hline $18 \mathrm{~F} 3$ & Present study & CGAAGACGATCAGATACCG \\
\hline \multicolumn{3}{|l|}{ Vector } \\
\hline M13f & & GTAAAACGACGGCCAGT \\
\hline $\mathrm{M} 13 \mathrm{r}$ & & CAGGAAACAGCTATGAC \\
\hline
\end{tabular}


Sequencing was conducted with BigDye Terminator v2.0 Sequencing Reaction chemistry (Applied Biosystems), using the primers listed in Table 2. Sequencing reactions were purified using Centri-Sep (Princeton Separations) purification columns. Sequencing reactions were analyzed using an ABI 377 automated sequencer (Applied Biosystems) using $48 \mathrm{~cm}$ plates and $4.75 \%$ Long Ranger (FML BioProducts) polyacrylamide gels. For each taxon, each gene was sequenced in both directions.

\section{Phylogenetic analyses}

Sequences were aligned by the profile alignment function of ClustalW (Thompson et al., 1994), using previously aligned sequences from the Ribosomal Database Project II (Maidak et al., 2001) as guides. Alignments were checked manually with MacClade 4 (Maddison and Maddison, 2000), and regions that could not be unambiguously aligned were excluded.

In order to better understand the relative contribution of each rDNA gene, analyses were carried out on SSU data alone, the LSU data alone, and the combined LSU + SSU data. To evaluate consistency in results between phylogenetic reconstruction methods, minimum evolution (ME), maximum parsimony (MP), and maximum likelihood (ML) analyses were conducted using PAUP* version 4.0 b10 (Swofford, 2002). Appropriate models for maximum likelihood analyses were determined using the hierarchical likelihood ratio test (LRT) implemented in Modeltest (Posada and Crandall, 1998).

Support in the datasets for previously published hypotheses of relationships between molluscan clades was evaluated by explicit hypothesis testing. Unresolved trees conforming to a priori hypotheses were used to constrain maximum likelihood heuristic searches with TBR. Resultant trees were compared with unconstrained maximum 
likelihood trees using the Shimodaira-Hasegawa test (Shimodaira and Hasegawa, 2000) implemented in PAUP*4.0b10. 


\section{Results}

\section{Alignment and Base Composition}

Total lengths of the alignments, number of unambiguously aligned characters included in analyses, number of variable characters, and number of parsimony informative characters for the SSU, LSU and LSU + SSU data are shown in Table 3.

Stationarity of base frequencies is an assumption of parsimony and likelihood based methods of phylogenetic reconstruction (Swofford et al., 1996). Therefore, the relative nucleotide composition of the datasets was evaluated using the "basefreqs" command in PAUP. The LSU + SSU dataset shows high proportions of A and G among most of the sampled taxa (Table 4). This pattern is reflected in the dataset for each gene when analyzed separately (not shown). Five of the cephalopods sampled (Arboliopsis, Benthoctopus, Graneledone, Loligo, and Vampyroteuthis) differed from this pattern, having high levels of $\mathrm{G}$ and low levels of $\mathrm{T}$. Inclusion of these taxa results in significant $(\mathrm{P}<<0.0001)$ rejection of $\mathrm{c}^{2}$ test of homogeneity of base frequencies across taxa, as implemented in PAUP*4.0b10. This result is exhibited in both the SSU and LSU datasets, suggesting the variation in nucleotide usage is lineage specific, rather than gene specific. Such a pattern might be expected in genes which are linked and share evolutionary history. However, Winchell et al. (2002) found LSU sequences displayed differences in base proportions across deuterostome lineages, while SSU sequences did not. Exclusion of the nucleotide biased cephalopods from the datasets results in acceptance of stationarity of base frequencies under the $c^{2}$ test $(P=0.7704)$ in the LSU + SSU dataset (Table 4), as well as in the SSU and LSU datasets individually (not shown). 
Table 3: Total, Included, Variable, and Parsimony Informative characters for alignmentsof SSU, LSU, and combined LSU + SSU datasets

\begin{tabular}{lrrrr}
\hline & Total & Included & Variable & Informative \\
\hline SSU & 2605 & 1603 & 651 & 399 \\
LSU & 4076 & 2615 & 1054 & 517 \\
LSU + SSU & 6681 & 4218 & 1705 & 916 \\
\hline
\end{tabular}

Table 4: Average base frequencies in the combined LSU + SSU dataset with $c^{2}$ tests of stationarity for complete and trimmed dataset

Data set with all taxa

\begin{tabular}{cccccc} 
& A & C & G & T & \# Sites \\
\cline { 2 - 6 } Mean & 0.2606 & 0.2276 & 0.2899 & 0.2219 & 3513
\end{tabular}

$\mathrm{c}^{2}=350.866$ (d.f. $\left.=102\right), \mathrm{P}=0.00000000$

Arboliopsis, Benthoctopus, Graneledone, Loligo, and Vampyroteuthis alone

\begin{tabular}{cccccc} 
& A & C & G & T & \# Sites \\
\cline { 2 - 6 } Mean & 0.2329 & 0.2629 & 0.3147 & 0.1896 & 3627
\end{tabular}

$\mathrm{c}^{2}=0.377 \cdot(\mathrm{d} . \mathrm{f} .=12), \mathrm{P}=0.99999995$

Data set without Arboliopsis, Benthoctopus, Graneledone, Loligo, and Vampyroteuthis

\begin{tabular}{|c|c|c|c|c|c|}
\hline & $\mathrm{A}$ & $\mathrm{C}$ & $\mathrm{G}$ & $\mathrm{T}$ & \# Sites \\
\hline Mean & 0.2729 & 0.2223 & 0.2808 & 0.2240 & 3629 \\
\hline \multicolumn{6}{|c|}{$c^{2}=76.977$ (d.f. $\left.=87\right), P=0.77037135$} \\
\hline
\end{tabular}


Datasets including sequences for all cephalopods sampled were initially analyzed with minimum evolution (ME) (Figure 4) using LogDet-Paralinear distances (Lake, 1994; Lockhart et al., 1994), which is less biased by variability in base frequencies across taxa than are parsimony (Lockhart et al., 1994) and likelihood (Swofford et al., 1996) based methods. Monophyly of the Cephalopoda was strongly supported (bootstrap support $=100 \%$ ) by ME analysis of the LSU + SSU dataset (Figure 4), as well by the individual SSU and LSU datasets (not shown). Nautilus and Histioteuthis, having base frequencies consistent with other mollusks sampled, were retained as representatives of the Cephalopoda for parsimony and likelihood analyses. Therefore, subsequent discussion will assume that nucleotide biased cephalopod lineages were not included in the analyses unless otherwise stated.

\section{Relative Rates}

Variation in relative rates of nucleotide substitution across taxa and its potential impact on phylogenetic reconstructions are well-documented issues with rDNA genes (e.g. Stiller and Hall, 1999; Philippe et al., 2000; Peterson and Eernisse, 2001). To help identify taxa with relatively elevated rates of nucleotide substitution, we conducted relative rates tests of all pairwise comparisons of the ingroup taxa to the reference outgroup taxa using the HYPHY program (Muse and Kosakovsky Pond, 2002) with a Tamura-Nei (1993) model. A Tamura-Nei model was the best fit to the data as determined in Modeltest. The analysis found for 432 of the $528(82 \%)$ ingroup comparisons showed significant rate variation $(\mathrm{P}<0.05$; including all cephalopod taxa) for at least one of the two outgroups. Additionally, 70\% (371/528) of the comparisons 


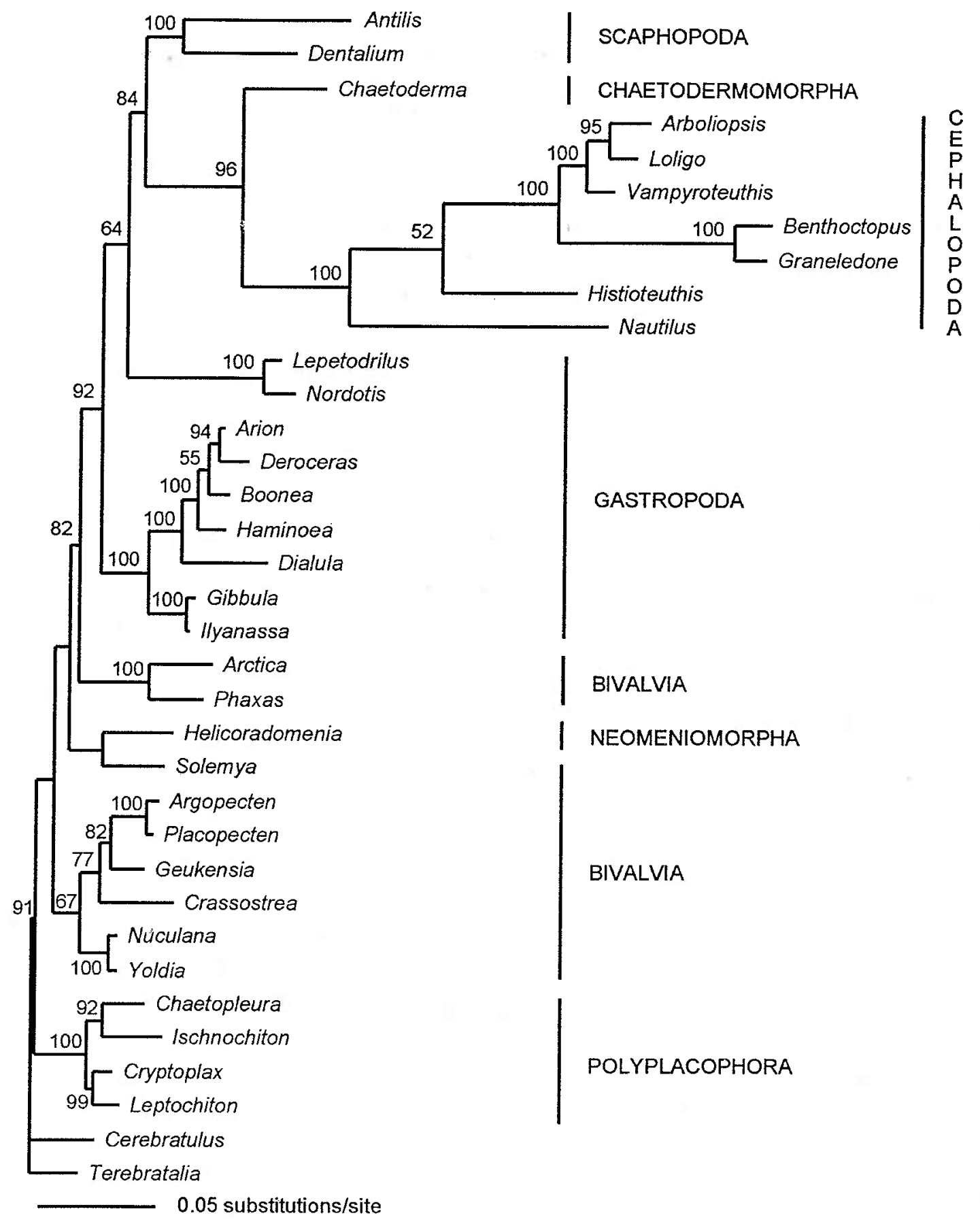

Figure 4: ME tree of the combined LSU+SSU dataset, including all seven cephalopods, calculated using LogDet-Paralinear distances. Bootstrap values from 1000 replicates are shown for nodes with support values of $<50 \%$. 


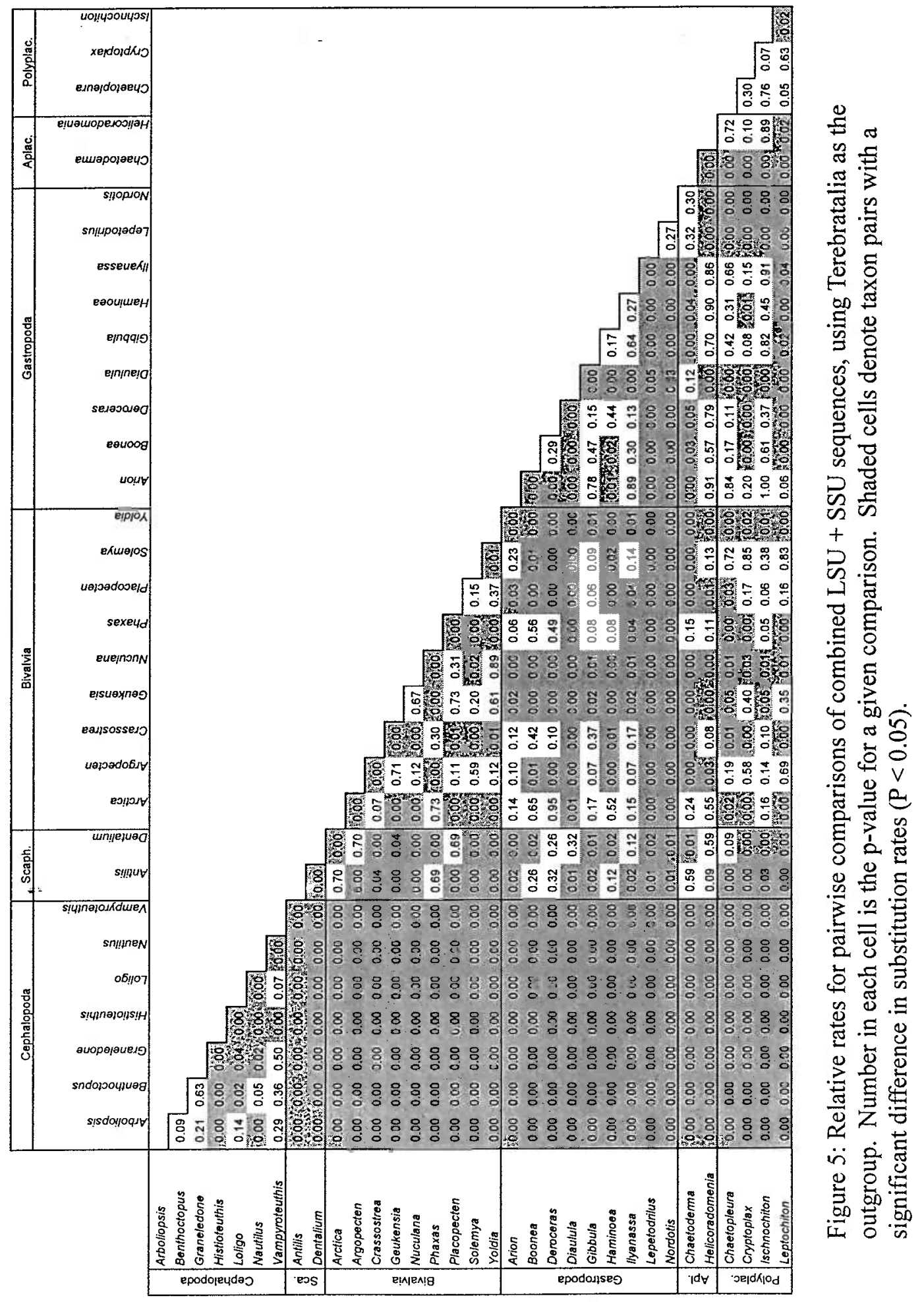


showed significant variation for both outgroups. As an example of the results, Figure 5 shows the relative rates test result when the brachiopod, Terebratalia, was used as outgroup. Clearly, rate variation across taxa is a serious concern for these data. However, exclusion of all the taxa that showed significantly elevated rates of nucleotide substitution would eliminate representation from several mollusk clades (e.g. cephalopods, chaetoderms, and scaphopods), rendering the dataset useless for trying to gain a deeper understanding about mollusk phylogeny.

\section{Phylogenetic Reconstruction}

The reconstructed topologies for the SSU dataset alone are shown in Figues 6 and 7 , the LSU dataset alone in Figures 8 and 9, and the LSU + SSU dataset in Figures 10 and 11. For each dataset, MP (A) and ML (B) are presented with the parameter and search details in the figure legends. Because available evidence suggests the phylogenetic signal in the SSU alone is limited for mollusks (e.g., Winnepenninckx et al., 1996; Steiner and Hammer, 2000), and in an effort to maximize the amount of available data, the discussion herein will emphasize the LSU + SSU data.

Several features are immediately obvious on inspection of the resultant trees: internal branch-lengths are short, bootstrap support tends to be higher near the tips of the tree, the exact topology is dependent upon the reconstruction method, and variation in nucleotide substitution rates is notable. Despite these pitfalls, the data still represent the most comprehensive molecular perspective of mollusk phylogeny to date and provide insight on several long-standing hypotheses about molluscan evolution.

Consistent with expectations, many of the traditionally recognized molluscan "classes" were found to be monophyletic in the best trees recovered under all or most 
reconstruction conditions (e.g. Gastropoda, Cephalopods, Polyplacophora, and Scaphopods; admittedly the taxon sampling for some of these groups is limited). The representatives of the Cephalopoda and Scaphopoda were found to cluster together in all analyses, although this clade often included Chaetoderma branching with the Cephalopoda (Figures 6, 7, 10, and 11). The Aculifera, Conchifera, and Bivalvia were not recovered as monophyletic clades under any analysis. The Polyplacophora usually clustered with bivalves (e.g. Figures 8-11) contrary to both the Aculifera and Conchifera hypotheses. In the case of the Bivalvia, Arctica, and Phaxas consistently branched closest to one another but separate from the other bivalves. Interestingly, Arctica and Phaxas also have higher rates of nucleotide substitution than other bivalves.

To assess the impact of the relatively quickly evolving cephalopod sequences, ML analysis of the LSU + SSU dataset was conducted with Nautilus and Histioteuthis excluded. Branching order among the Polyplacophora + Bivalvia + Gastropoda was not affected, however representatives of the Scaphopoda, Neomeniomorpha, and Chaetodermomorpha branch most closely with outgroup taxa (not shown). Exclusion of outgroup taxa from the LSU + SSU dataset produced similar topologies, with the exception that Helicoradomenia branches with the Polyplacophora (not shown). 


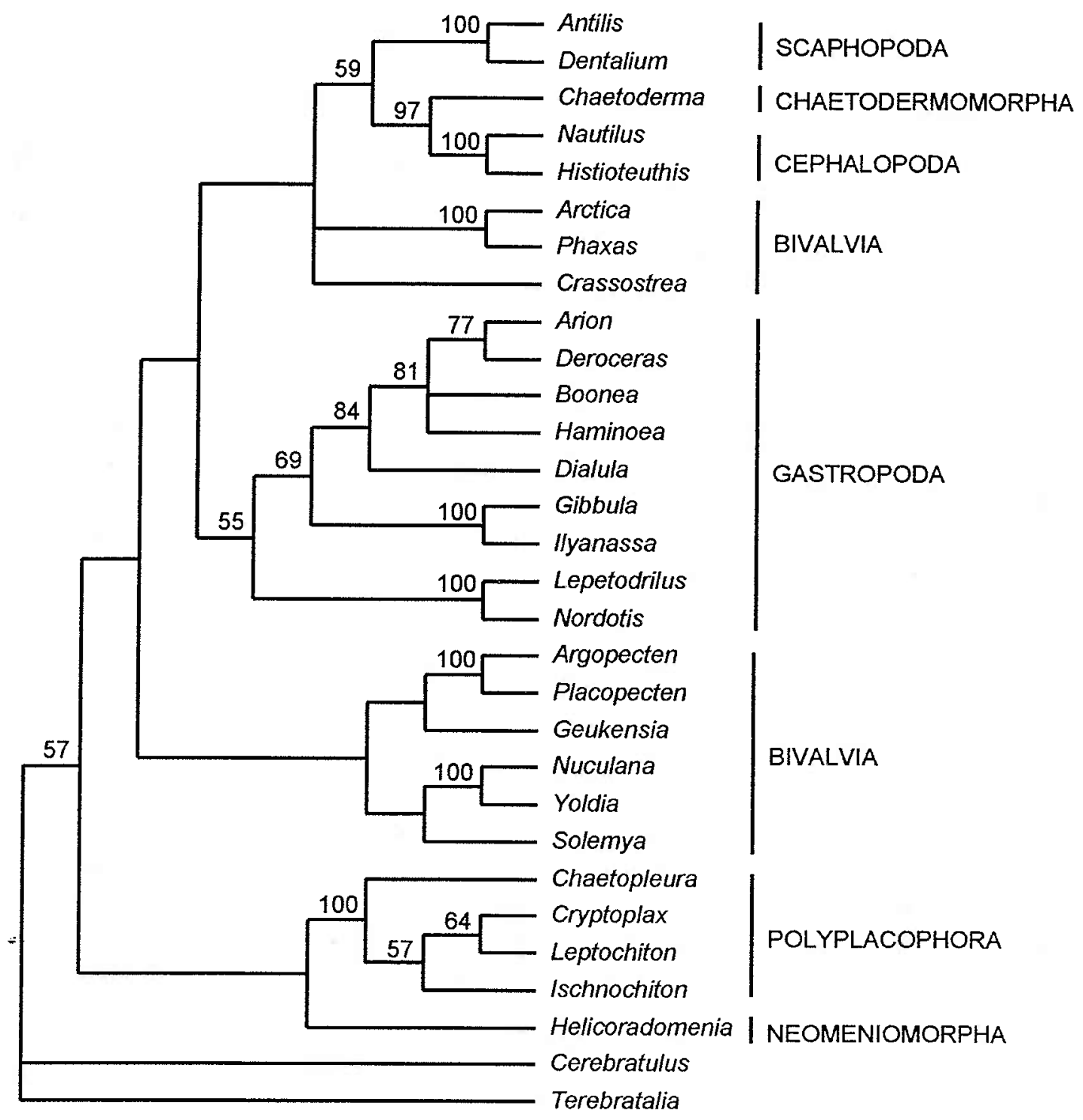

Figure 6: Maximum parsimony (MP) analysis of the SSU dataset, with Nautilus and Histioteuthis as representatives of the Cephalopoda. MP analysis using heuristic search with TBR of 1000 sequence additions replicates. Majority rule consensus of 9 best trees found. Score $=1578$. Bootstrap values are shown above nodes where support was $>50 \%$ from 1000 replicates. 


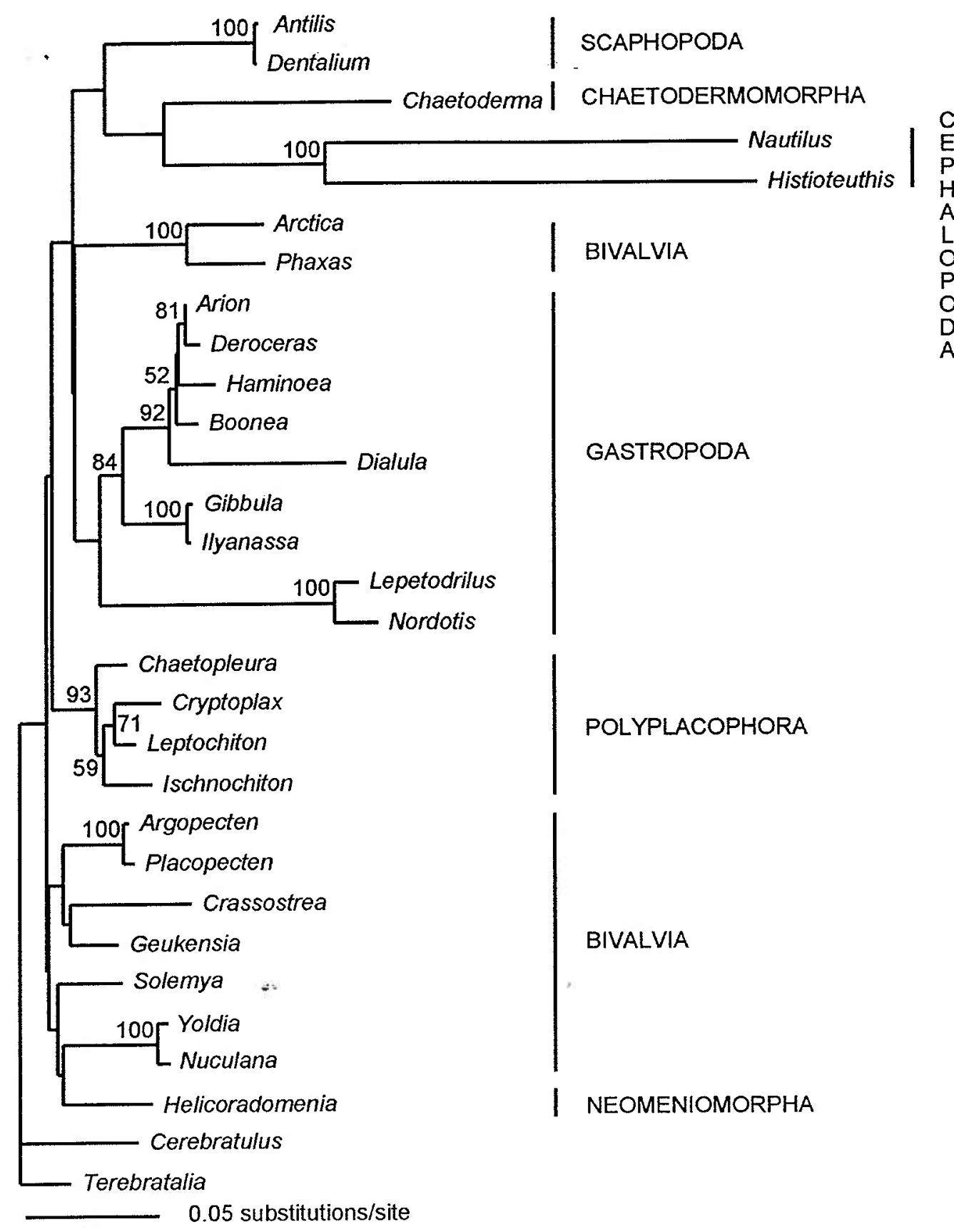

Figure 7: Maximum likelihood (ML) analysis of the SSU dataset, with Nautilus and Histioteuthis as representatives of the Cephalopoda. ML analysis using heuristic search with TBR of 100 replicates. Analysis performed under the Tamura-Nei $(\operatorname{TrN})$ model with proportion of invariant sites ( $\mathrm{Pinv}=0.3487$ ) and gamma distribution of among site rate variation $(G=0.5887)$ estimated from the data. Score $-\operatorname{lnL}=$ 9165.6521 Bootstrap percentages based on 100 replicates. 


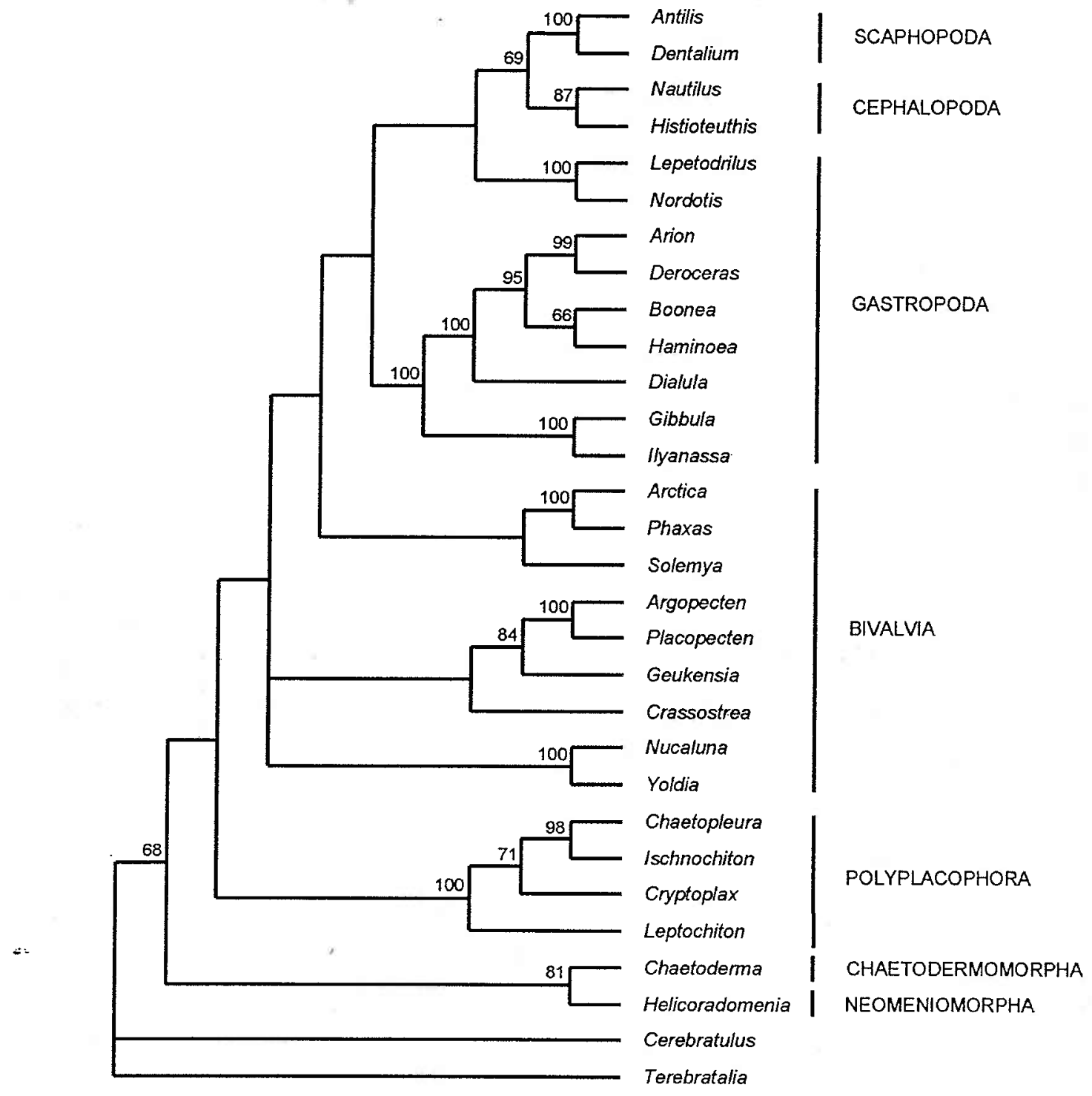

Figure 8: Maximum parsimony (MP) analysis of the LSU dataset, with Nautilus and Histioteuthis as representatives of the Cephalopoda. MP analysis using heuristic search with TBR of 1000 heuristic sequence additions replicates. Majority rule consensus of 3 best trees found. Score $=2570$. Bootstrap percentages based on 1000 replicates. 


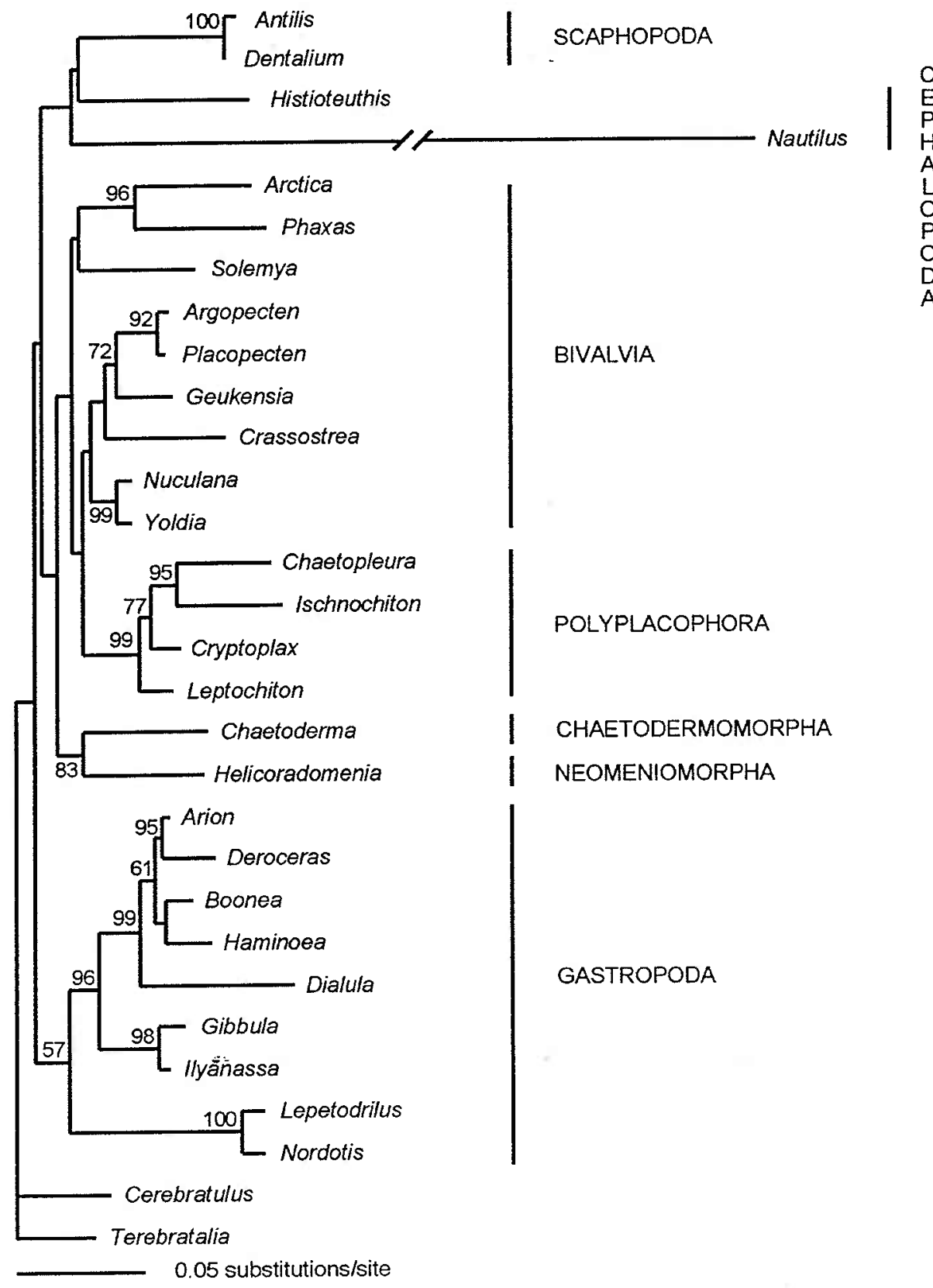

Figure 9: Maximum likelihood (ML) analysis of the LSU dataset, with Nautilus and Histioteuthis as representatives of the Cephalopoda. ML analysis using heuristic search with TBR of 100 heuristic replicates under the $\operatorname{TrN}+\mathrm{I}+\mathrm{G}$ model. Pinv $=0.3313, \mathrm{G}=0.4520$. Score $-\mathrm{lnL}=14825.2782$. Bootstrap percentages based on 100 replicates. 


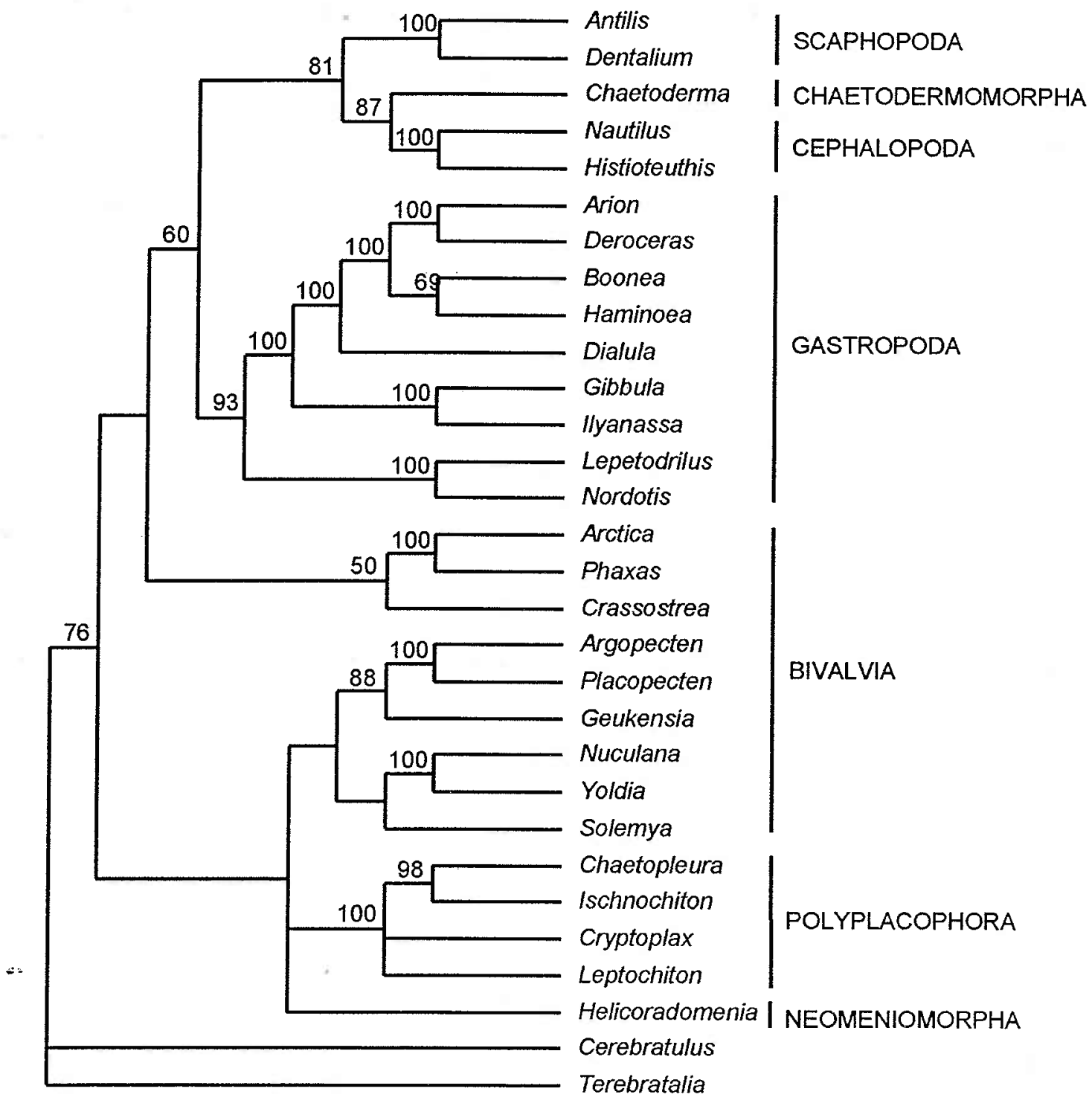

Figure 10: Maximum parsimony (MP) analysis of the combined LSU+SSU dataset, with Nautilus and Histioteuthis as representatives of the Cephalopoda. MP analy sis using heuristic search with TBR of 1000 heuristic sequence additions replicates. Consensus of 2 best trees found. Score $=4181$.

Bootstrap percentages based on 1000 replicates. 


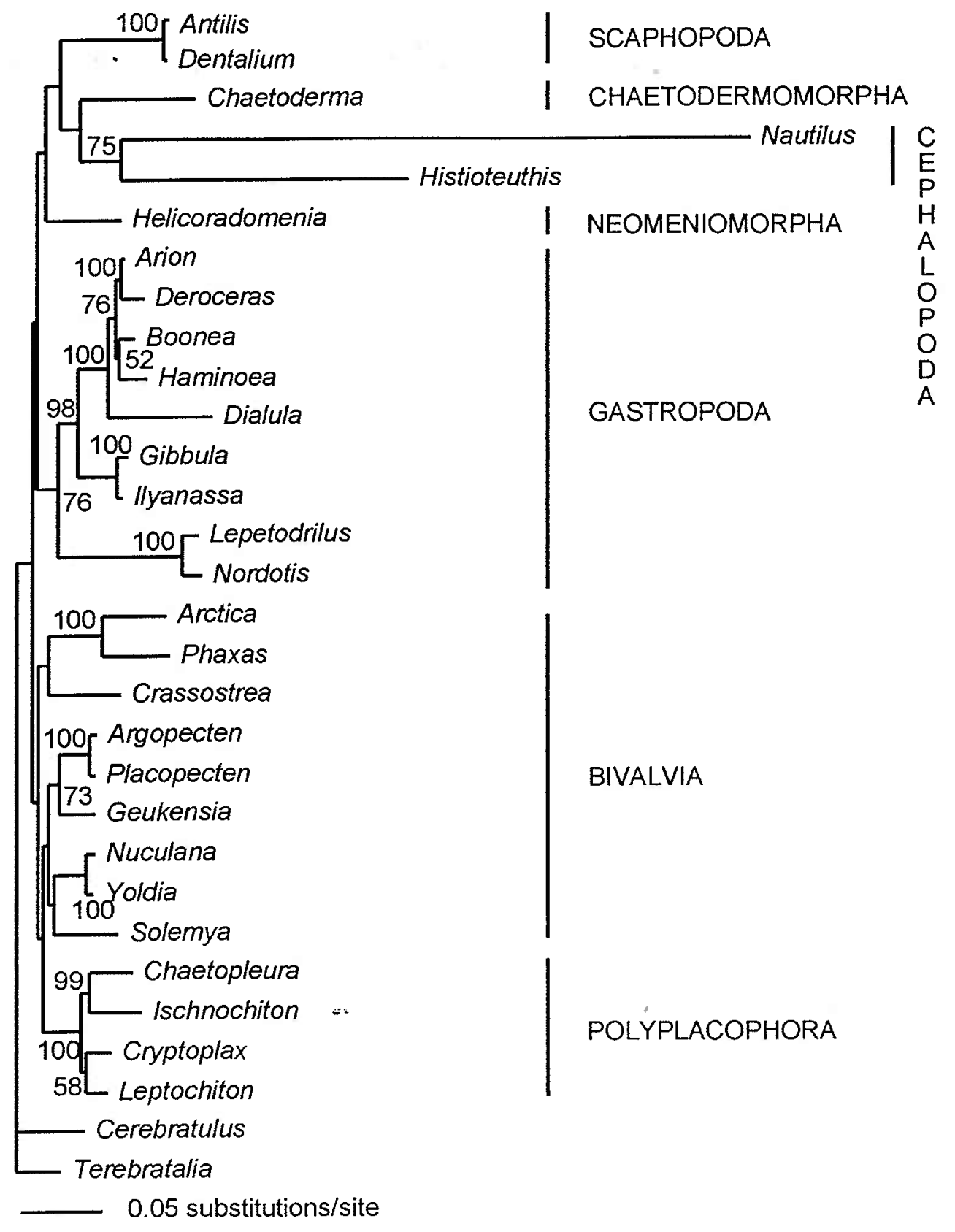

Figure 11: Maximum likelihood (ML) analysis of the combined LSU+SSU dataset, with Nautilus and Histioteuthis as representatives of the Cephalopoda. ML analysis using heuristic search with TBR of 100 heuristic replicates under the $\operatorname{TrN}+\mathrm{I}+\mathrm{G}$ model. Pinv $=0.3373, \mathrm{G}=0.4956$. Score $-\ln \mathrm{L}=$ 24200.9917. Bootstrap percentages based on 100 replicates. 


\section{Hypothesis testing}

Even when internal branch lengths are short and bootstrap support for nodes is low, sufficient phylogenetic signal may still exist in the dataset to allow competing hypotheses to be evaluated. To this end, the Shimodaira-Hasegawa (SH) test was used to assess support for alternative hypotheses of molluscan evolution. SH tests did not rejec any alternative a priori hypotheses regarding the basal radiation of the Mollusca (Table 5). Within the Conchifera, the hypothesis of the Diasoma (Bivalvia + Scaphopoda) (Runnegar and Pojeta, 1974) is rejected by the LSU data. The hypothesis of the Diasoma and Cyrtosoma (Gastropoda + Cephalopoda) as sister groups is also rejected by analyses of both the LSU and LSU + SSU datasets. The optimal LSU tree also differs significantly from one where Bivalvia branches basally among the Conchifera, with Scaphopoda more closely related to the Cyrtosoma. The LSU + SSU ML tree also differed significantly from a tree constrained to fit the tradition division of the Conchifera into Diasoma and Cyrtosoma clades. Trees constrained such that the Bivalvia formed a monophyletic clade did not differ significantly from unconstrained results for the three datasets (Table 5).

The SH test was used to evaluate consistency between trees recovered for the three SSU, LSU, and LSU + SSU datasets under ML analyses. Likelihood scores for the LSU and SSU ML trees differed significantly, when tested under the respective datasets and associated models (Table 5). However, LSU + SSU likelihood scores did not differ significantly from those of either the SSU or LSU ML trees. 
Table 5: Shimodaira-Hasegawa test of support for alternative a priori hypotheses, $P$ values

\begin{tabular}{|c|c|c|c|}
\hline & SSU & LSU & $\mathrm{LSU}+\mathrm{SSU}$ \\
\hline \multicolumn{4}{|l|}{ Molluscan relationships: } \\
\hline Molluscan monophyly & 1.000 & 1.000 & 1.000 \\
\hline \multicolumn{4}{|l|}{ Basal molluscan relationships: } \\
\hline Aculifera (Aplacophora + Polyplacophora) & 0.107 & 0.112 & 0.190 \\
\hline Testaria (Chaetodermomorpha basal) & 0.088 & 0.090 & 0.180 \\
\hline Testaria (Neomeniomorpha basal) & 0.072 & 0.069 & 0.151 \\
\hline \multicolumn{4}{|l|}{ Conchiferan relationships } \\
\hline Bivalve monophyly & 0.254 & 0.251 & 0.366 \\
\hline Diasoma (Bivalvia + Scaphopoda) & 0.084 & $0.021^{*}$ & 0.109 \\
\hline (Bivalvia + Scaphopoda $)+($ Gastropoda + Cephalopoda $)$ & 0.090 & $0.009^{*}$ & $0.047^{*}$ \\
\hline$((($ Gastopoda + Cephalopoda $)+$ Scaphopoda $)+$ Bivalvia $)$ & 0.107 & $0.029^{\star}$ & 0.096 \\
\hline$((($ Scaphopoda + Cephalopoda $)+$ Gastropoda $)+$ Bivalvia $)$ & 0.108 & 0.073 & 0.188 \\
\hline \multicolumn{4}{|l|}{ ML unconstrained analyses } \\
\hline SSU ML tree & 1.000 & $0.000^{*}$ & 0.068 \\
\hline LSU ML tree & $0.000^{*}$ & 1.000 & 0.224 \\
\hline $\mathrm{LSU}+\mathrm{SSU}$ ML tree & 0.291 & 0.076 & 1.000 \\
\hline
\end{tabular}

* $\mathrm{P}<0.05-$ Hypotheses in bold are rejected under the given dataset.

Note. - Analyses carried out using the dataset listed at the top of each column, using the appropriate likelihood model as calculated with Modeltest. 


\section{Discussion}

The LSU + SSU data provided high bootstrap support for some relationships within the major molluscan clades, but showed limited ability to confidently recover relationships between these clades. Recent studies employing LSU + SSU datasets to investigate metazoan phylogenetics.(Medina et al., 2001; Winchell et al., 2002; Mallatt and Winchell, 2002), have suggested the utility of LSU, particularly when combined with SSU, in elucidating major events in metazoan diversification. In each of these cases findings from the LSU + SSU data generally agreed with those from SSU alone, with LSU + SSU providing greater bootstrap support. In the case of the Mollusca however, we find the SSU trees to be significantly different from the LSU and LSU + SSU trees (Table 5).

In assessing relationships among the major molluscan groups, we observed a high level of variability in the resultant topologies. Variability in branching order among the major molluscan groups may be a function of 1) high levels of rate heterogeneity between lineages represented in the dataset, and/or 2) a rapid radiation of the major molluscan groups. A majority of the pairwise relationships between LSU + SSU sequences showed significant rate differences regardless of outgroup choice. For example, within the Bivalia, Arctica and Phaxas display unstable placement in the trees and have substitution rates significantly different from those of other bivalves sampled. Such rate heterogeneity has previously been found for SSU sequences from bivalves (Steiner and Müller, 1996; Steiner and Hammer, 2000) and is suggested to explain problems recovering the monophyly of the Bivalvia. Our findings show significant rate variation across the major molluscan lineages, as well within the recognized classes. The potential 
for rate heterogeneity between lineages to produce artifacts is well known, particularly the case of long-branoh attraction (Felsenstein, 1978).

Lack of the resolution in the relationships between the major lineages of the Mollusca may also be interpreted as evidence of a rapid radiation. Most of the major clades in the Mollusca first appear in the fossil record during the Cambrian (Runnegar and Pojeta, 1985), which has been viewed as a period of diversification and cladogenesis thoughout the Metazoa (Valentine, 1994). Under such a scenario the amount of change accumulated in rRNA gene sequences may have been insufficient to allow reliable reconstruction of the radiation and/or changes may have accumulated mainly at rapidly evolving sites in the gene and been subsequently masked by additional substitutions.

Rate heterogeneity may be a general characteristic of molluscan genomic evolution, rather than a phenomenon specific to the rRNA genes sequenced here. Studies of mitochondrial gene order show numerous transpositions and inversions of protein coding and tRNA genes between bivalves, gastropods, and cephalopods (Wilding et al., 1999; Kurabayashi and Ueshima, 2000; Tomita et a1., 2002). Within mollusks, and within some clades of mollusks, such as gastropods (Kurabayashi and Ueshima, 2000), greater variation in mitochondrial gene rearrangements has been observed than between the polyplacophoran Katharina tunicata and the brachiopod Terebratulina retusa (Stechmann and Schlegel, 1999). In some cases these rearrangements appear to have occurred between closely related species over relatively short time scales (Rawlings et al., 2001). Rate heterogeneity in gene sequence evolution will need to be a careful consideration for future studies of molecular phylogenetics within the Mollusca. 
Despite variability between reconstructions, several relationships between the major lineages of the Mollusca were consistently found in the analyses. A close relationship between the Scaphopoda and Cephalopoda was recovered in nearly all reconstructions, with likelihood scores under the LSU and LSU + SSU datasets being significantly better than those for placing the Diasoma, grouping the Bivalvia + Scaphopoda, as sister group to the Cyrtosoma, containing Gastropoda and Cephalopoda. These findings suggest a reassessment of the view that scaphopods and bivalves are closely related to one another, as in the Diasoma hypothesis (Runnegar and Pojeta, 1974). Although these results may be questioned because of the high substitution rates within the cephalopod sequences sampled, they are supported by recent analyses of molluscan morphological characters. Waller (1998) has suggested the Bivalvia diverged prior to the common ancestor of the Gastropoda, Scaphopoda, and Cephalopoda, with scaphopods and cephalopods being most closely related to one another. Alternatively, cladistic analysis by Haszprunar (2000) also support the monophyly of Gastropoda + Scaphopoda + Cephalopoda, with the scaphopods as sistergroup to the Gastropoda + Cephalopoda.

The polyplacophorans and aplacophorans are widely viewed as being the most basal molluscan lineages, although the relationship between these groups has been variously interpreted (Salvini-Plawen, 1972; 1980; Salvini-Plawen and Steiner, 1996; Scheltema, 1993). In the results presented here, a basal position for the Polyplacophora was recovered only under MP analyses of the SSU and LSU datasets. In ML and MP analyses of the LSU+SSU dataset, and ML analysis of the LSU dataset, reconstructions placed the polyplacophorans close to bivalves. While likelihood scores for ML trees did not differ significantly from those of trees where the Polyplacophora branches basally to 
the Conchifera, the results presented here bear further investigation. Corroboration of this relationship with other molecular markers would require a reinterpretation of morphological evolution in the Mollusca (e.g. the homology of sclerites in polyplacophorans and aplacophorans). The close relationship recovered for LSU sequences of Helicoradomenia and Chaetoderma suggests the monophyly of Aplacophora, though this finding is not recovered with the SSU or LSU + SSU data. The branching of Chaetoderma with scaphopods and cephalopods under analyses of the SSU and SSU + LSU datasets deserves further scrutiny given the accelerated rates of evolution in these lineages. Aplacophorans have previously been suggested to be secondarily simplified through a process of progenesis (Scheltema, 1993). Yochelson (1978) likewise suggested aplacophorans to be derived, rather than direct descendents of primitive molluscs.

This study represents the most comprehensive molecular sampling of the Mollusca to date, including taxa from all the major molluscan lineages except the monoplacophorans. Given the short length of deep internal and the instability of nodes connecting the major lineages, it is expected that additional taxon sampling of ribosomal genes will provided limited additional resolution. Investigations of protein coding genes and genomic organization may provide valuable future directions improving our understanding of molluscan relationships. 


\section{Chapter 3}

Assessing Lophotrochozoan phylogeny with combined LSU and SSU ribosomal RNA gene sequences 


\begin{abstract}
The clade Lophotrochozoa, which includes mollusks, annelids, brachiopods, flatworms and their allies, encompasses the greatest body plan diversity of the three major bilaterian lineages. Lophotrochozoan interphyletic relationships are not well understood in part because analyses on the topic have been limited to morphology and/or small ribosomal subunit (SSU) data. To further elucidate the clade's phylogenetic history, we have analyzed DNA sequences of the large-subunit ribosomal RNA (LSU) gene from a diversity of lophotrochozoans. Unlike SSU data alone, the LSU and combined LSU + SSU datasets recover the monophyly of most recognized lophotrochozoan phyla, a prerequisite of evaluating interphyletic relationships. The data show Bryozoa diverged prior to the diversification of other lophotrochozoans, suggesting a cryptic early evolution of the lineage leading to bryozoans. Lophophorata, an exclusive Bryozoa/Brachiopoda/Phoronida clade, is significantly rejected as is a Bryozoa/Entoprocta clade. Contrary to previous reports, Platyzoa (including platyhelminthes, rotifers, and acanthocephalans) appears to be derived within lophotrochoazoans rather than a sister group to the Lophotrochozoa. In the LSU and LSU + SSU data, entoprocts and cycliophorans form a clade sister to Platyzoa. The monophyly of taxa possessing "trochophore" larvae was not recovered.
\end{abstract}




\section{Introduction}

The Lophotrochozoa encompasses the greatest body-plan diversity of the three major Bilaterian clades, however, relationships within the clade are poorly resolved hindering our understanding of metazoan evolution. The clade, initially identified with small nuclear ribosomal subunit (SSU) sequences (Halanych et al., 1995), comprises all descendents of the common ancestor of the lophophorates (Brachiopoda, Phoronida and Bryozoa), mollusks and annelids. Subsequent studies (e.g., Mackey et al., 1996; Balavoine, 1997; De Rosa et al., 1999; Mallatt and Winchell, 2002; Peterson and Eernisse, 2001) have supported the clade and included additional protostomes (e.g., platyhelminthes, sipunculans, nemerteans, and entoprocts). The present study aimed to more thoroughly resolve lophotrochozoan phylogeny providing a comparative framework.

Previous studies of lophotrochozoan relationships have relied heavily on SSU data, morphological cladistic analyses, or a combination of the two (e.g., Eernisse, 1997; Zrzavry et al., 1998; Giribet et al., 2000). Unfortunately, SSU data do not even cluster taxa into well-recegnized monophyletic units (e.g., Mollusca, Nemertea, Brachiopoda). Utilizing morphological characters to recover relationships between phyla is inherently problematic. Organisms were separated into distinct "phyla" primarily because features grouping organisms together were lacking. More importantly, choice and definition of morphological characters that are applicable across phyla can be subjective (Jenner, 2001). For example, both spiral cleavage pattern and trochophore larvae are still used as important phylogenetic characters, yet they have subjective definitions that group 
different taxa. Nonetheless, some progress has been made in understanding lophotrochozoan relationships.

Herein, we build on previous data by examining combined SSU and large nuclear ribosomal subunit (LSU) data to address three hypothesized lophotrochozoan taxa that shape our overall understanding of the group's evolution: Lophophorata, Platyzoa, and Trochozoa. Hyman (1959) grouped the bryozoans, brachiopods, and phoronids together as the "Lophophorata" based on inferred homology of the ciliated feeding structure. Although the monophyly of this group has not been demonstrated and evidence suggests that not all "lophophores" are homologous (Halanych, 1996; Nielsen, 2001), the "Lophophorata" has been perpetuated in invertebrate textbooks and is commonly accepted. Molecular sequences support protostome affinities (Field et al., 1988; Halanych et al., 1995; Schtemann and Schlegel, 1998; de Rosa et al., 1999), but the exact placement of Bryozoa (a.k.a., Ectoprocta) has been contentious. To date, molecular analyses of bryozoan affinities have relied upon SSU sequences, which do not recover bryozoan monophyly and place them as basal members of the Lophotrochozoa (e.g., Halanych et al., 1995; Giribet et al., 2000; Peterson and Eernisse, 2001). Nielsen (1985) has suggested bryozoans to be most closely related to entoprocts, but this has not been evidenced by molecular data.

Platyzoa was originally diagnosed as ciliated non-segmented acoelomates or pseudocoelomates lacking a vascular system (i.e., Platyhelminthes, Rotifera, Acanthocephala, Gastrotricha, and Ganthostomulida; Cavalier-Smith, 1998). Although traditionally viewed as basal lineages within Bilateria, interpretations of platyhelminth 
and rotifer cleveage as spiral or "modified spiral" suggest an evolutionary relationship with spiralian lophotrochozoans such as mollusks, annelids, echiurans, sipunculans, and entoprocts (Boyer et al 1998; Gilbert 1989). Recent analyses of SSU sequences and combined SSU + morphological datasets have suggested Platyzoa represents a sister clade to the Lophotrochozoa (Giribet et al., 2000), or a grade which diversified basal to the last common ancestor of the Lophotrochozoa (Peterson and Eernisse, 2001). Our understanding of Platyzoa has been altered by recent analyses that place the acoelomorph playhelminthes outside Platyzoa at the base of Bilateria (Ruiz-Trillo et al., 2002). Although Cycliophora were initially hypothesized to have evolutionary affinities to the Entoprocta (Funch and Kristensen, 1995; 1997), SSU analyses (Winnepenninckx et al., 1998) suggest a close relationship with the Syndermata (acanthocephalans and rotifers, Ahrlichs, 1995; Garey et al., 1996). Lastly, the hypothesized grouping Nemertea and Platyhelminthes (a.k.a. Parenchyma; Nielsen, 2001), based up simplicity of body organization, is of interest with respect to the Platyzoa concept.

The term "Trochozoa" refers to taxa that have a certain type of ciliated larvae, a trochophore. The term was originally applied specifically to annelids (Hatschek, 1878), but it has been loosely applied to several other protostome lineages causing confusion in the literature. Recognizing this problem, Peterson and Eernisse (2001) use several different terms to define nested clades with trochophore or trochophore-like larvae. The Neotrochozoa (i.e., annelids including echiurids, mollusks, and sipunculans) is the most restrictive clade recognized, whereas the Eutrochozoa (Nemertea \& Neotrochozoa) and Trochozoa (Entoprocta \& Eutrochozoa) are more inclusive. Whether these form natural 
(i.e., monophyletic) units, influences our understanding of 1) the early history of larval forms and 2) the evolutionary plasticity of characters considered important to phylogeny (e.g., metatroch and apical tuft).

Deciphering the relationships within the Lophotrochozoa requires critical evaluation of phylogenetic hypotheses such as the Lophophorata, Platyzoa, and Trochozoa, among others. However, recovering the monophyly of individual lophotrochozoan phyla is prerequisite to evaluating interphyletic relationships - on this point SSU data have failed. Previous simulation study (Halanych, 1998) and recent phylogenetic analyses (Medina et al., 2001; Mallatt and Winchell, 2002; Winchell et al., 2002) suggested that combined LSU + SSU data offer more resolution than SSU data alone. To this end, we examined approximately $5 \mathrm{~Kb}$ of nuclear rRNA gene sequence for 36 lophotrochozoan taxa. Compared to SSU data, both LSU + SSU data and LSU data alone more consistently recover recognized phyla as monophyletic, allowing us to begin elucidating interphyetic relationships. The Lophophorata is significantly rejected, but data are more equivocal on "Trochozoa" hypotheses. The monophyly of the Platyzoa is not rejected, but LSU + SSU data suggest this clade is derived within the Lophotrochozoa rather than a basal sister :lineage. This placement has profound repercussions for our interpretation of metazoan morphological evolution. 


\section{Materials and Methods}

Taxon sampling

Thirty-six taxa were chosen to provide broad representation of extant

lophotrochozoan lineages (Table 6). Two deuterostomes and three ecdysozoans with low rates of nucleotide substitution were chosen as outgroups (de Rosa et al., 1999; Giribet et al., 2000; Peterson and Eernisse 2001; Mallatt and Winchell, 2002). LSU data were collected from 20 taxa. SSU data were also collected for taxa not in GenBank.

\section{Data Collection}

Genomic DNA was isolated using the DNeasy Tissue Kit (Qiagen). Primer sequences utilized for PCR and sequencing are provided in Chapter 2. Both genes were amplified using a long PCR protocol. PCR reactions contained $15 \mu 13.3 \mathrm{x}$ rTth buffer, $2.5 \mu 110 \mu \mathrm{M}$ primer, $5 \mu 12 \mathrm{mM}$ dNTPS, $0.4 \mu \mathrm{l}$ rth (PE Applied Biosystems), $1 \mu \mathrm{l}$ Vent polymerase (New England BioLabs) (diluted 1:100 in a buffer composed of 50\% glycerol, 20mM HEPES, 10mM KCL, 1 mM DTT, 0.1mM Na ${ }_{2}$ EDTA, 0.0025\% Tween20 , and $0.0025 \%$ NP-40), with genomic DNA and water to a final volume of $45 \mu \mathrm{l}$. Following a 5 minute denaturation, $5 \mu 1$ of $25 \mathrm{mM} \mathrm{Mg}(\mathrm{CAc})_{2}$ was added to each reaction. PCR involved 30 cycles of denaturation at $94^{\circ} \mathrm{C}$ for $30 \mathrm{sec}$, annealing at $45-55^{\circ} \mathrm{C}$ for 1 min, and extension at $65^{\circ} \mathrm{C}$ for $12 \mathrm{~min}$ LSU or $8 \mathrm{~min}$ for SSU. A final extension was carried out at $72^{\circ} \mathrm{C}$ for 10 min. PCR products were cleaned with QIAquick PCR Purification Kit (Qiagen) and incubated 10 minutes at $70^{\circ} \mathrm{C}$ with $\mathrm{Taq}$ polymerase (Promega) and $0.4 \mathrm{mM}$ dATP to create adenine overhangs. Fragments were cleaned a second time and cloned using the pGEM-T Vector System (Promega). 
Sequencing used BigDye Terminator v2.0 Sequencing Reaction chemistry (Applied Biosystems) on an ABI 377 automated sequencer (Applied Biosystems). For each taxon, each gene was sequenced in both directions.

Phylogenetic analyses

Sequences were aligned by the profile alignment function of ClustalW (Thompson et al., 1994), using existing alignments from the Ribosomal Database Project II (Maidak et al., 2001) as guides. Alignments were checked manually with MacClade 4 (Maddison and Maddison, 2000), and regions of questionable alignment were excluded.

To better understand relative contributions of each rDNA gene, analyses were carried out on SSU data alone, LSU data alone, and combined LSU + SSU data. Due to the need for brevity, we mainly focus on the combined analyses. Maximum likelihood (ML) analyses were conducted in PAUP* version $4.0 \mathrm{~b} 10$ (Swofford, 2002), with appropriate models determined by Modeltest (Posada and Crandall, 1998). Details of phylogenetic reconstructions are given in the figure legends. Support for previously published lophotrochozoan hypotheses was evaluated using the Shimodaira-Hasegawa (1999) test implemented in PAUP*4.0b10. 
Table 6. Species ąnd GenBank accession numbers

\begin{tabular}{|c|c|c|}
\hline Species & LSU & SSU \\
\hline \multicolumn{3}{|l|}{ Mollusca } \\
\hline Arion silvaticus & AY145392 & AY 145365 \\
\hline Chaetopluera aplicata & AY 145398 & AY145370 \\
\hline Ilyanassa obsoleta & AY 145511 & AY145379 \\
\hline Leptochiton acellus & AY 145414 & AY 145382 \\
\hline Nucalana pernula & AY 145419 & AY145385 \\
\hline Placopecten magellanicus & AF342798 & X53899 \\
\hline \multicolumn{3}{|l|}{ Nemertea } \\
\hline Amphiporus sp. & AF342786 & AF 119077 \\
\hline Cerebratulus lacteus & AY145396 & AY145368 \\
\hline Oerstedia dorsalis & AY210465* & AY210448* \\
\hline Tubulanus annulatus & AY210473* & AY $210452 *$ \\
\hline \multicolumn{3}{|l|}{ Sipuncula } \\
\hline Apionsoma misakianum & AY210454* & AY210440* \\
\hline Phascolion strombi & AY210468* & AY210449* \\
\hline Phascolopsis gouldii & AF342795 & AF342796 \\
\hline \multicolumn{3}{|l|}{ Bryozoa } \\
\hline Alcyonidium diaphanum & AY21045* & \\
\hline Alcyonidium gelatinosum & & X91403 \\
\hline Bugula turrita & AY210457* & AY210443* \\
\hline Crisia sp. & AY210458* & AY210443* \\
\hline \multicolumn{3}{|l|}{ Entoprocta } \\
\hline Barentsia gracilis & AY210456* & AY210442* \\
\hline \multicolumn{3}{|l|}{ Brachiopoda } \\
\hline Glottidia pyramidata & AY210459* & U12647 \\
\hline Laqueus californianus & AY210460* & U08323 \\
\hline Neocrania anomola & AY210463* & U08328 \\
\hline Terebratalia transversa & $\therefore$ AF342802 & $\mathrm{AF} 025045$ \\
\hline \multicolumn{3}{|l|}{ Phoronida } \\
\hline $\begin{array}{l}\text { Phoronis vanvouverensis } \\
\text { Echiura }\end{array}$ & AF342797 & AY210450* \\
\hline Arhynchite pugettensis & AY210455* & AY210441* \\
\hline Urechis caupo & AF342804 & AF342805 \\
\hline \multicolumn{3}{|l|}{ Annelida } \\
\hline Eisenia fetida & AF212166 & X79872 \\
\hline Nereis succinea & AY210464* & AY210447* \\
\hline Proceraea cornuta & AF212165 & AF212179 \\
\hline Riftia pachyptila & AY210470* & AF 168745 \\
\hline \multicolumn{3}{|l|}{ Platyhelminthes } \\
\hline Dugesia tigrina & U78718 & AF013157 \\
\hline Sytlochus zebra & AF342800 & AF342801 \\
\hline
\end{tabular}


Acanthocephala

$\begin{array}{lll}\begin{array}{l}\text { Oligacanthorhynchus tortuosa } \\ \text { Oncicola } \text { sp. }\end{array} & \text { AY210466* } & \text { AF064817 } \\ \begin{array}{l}\text { Rotifera } \\ \text { Philodona roseola }\end{array} & \text { AY210467* } & \text { AF064818 } \\ \text { Sinantherina socialis } & \text { AY210469* } & \text { AF154567 } \\ \text { Cy } & \text { AY210471* } & \text { AY210451* }\end{array}$

Cycliophora

Symbion sp. (from Homarus

americanus)

Symbion pandora

AY210472*

Myzostomida

Myzostoma polycyclus

Ecdysozoa

Limulus polyphemus

Misumenops asperatus

Halicryptus spinulosus

Deuterostomia

Antedon serrata

Florometra serratissima

Ptychodera flava

Y14811

AY210462* AY210446*

AF212167 U91490

AY210461* AY210445*

AF342789 AF342790

AF212168

D14357

AF278681

AF278681

* New sequences 


\section{Results}

The number of aligned, unambiguously aligned, variable, and informative characters for each dataset are given in Table 7. ML trees for the LSU + SSU, LSU and SSU datasets are presented in Figures 12-14, respectively. Phylogenetic reconstructions from the LSU and LSU + SSU datasets recover the monophyly of the nearly all lophotrochozoan phyla. Although the bootstrap support for these nodes is weak, this result is a substantial improvement over the situation with SSU data alone (compare Figures 12 and 14). This boost in signal is clearly due to the LSU data, which recovered a tree (Figure 13) much more consistent with our current understanding of animal relationships than the SSU topology. SSU reconstructions have also been maligned because of the potential for long-branch attraction (e.g., Maley and Marshall, 1998). Interestingly, all the long branches clump together in the SSU tree, but not in the LSU or $\mathrm{LSU}+\mathrm{SSU}$ tree suggesting that rate effects may be less severe in these datasets. Table 8 gives the results of the Shimodaira-Hasegawa tests for LSU + SSU data, LSU, and SSU data sets. The most striking result, and consistent with the recovered tree topologies, the monophyly of the Lophophorata was not suppoited in either the LSU or LSU + SSU datasets (Table 8). In all analyses, Bryozoa consistently fell out basal to other lophotrochozoans, including brachiopods and phoronids. The resultant non-monophyly of Brachiopoda in the LSU + SSU analysis bears further investigation. Additionally, the hypothesis that Bryozoa is sister to Entoprocta was rejected for both the LSU and LSU + SSU data sets. Neither result appeared to be affected by the presence of Myzostoma 
within the Bryozoa, as bryozoan monophyly was not significantly rejected under either data set.

In both the LSU and LSU + SSU analyses a clade was recovered which included the Entoprocta, Cycliopohora, Platyhelminthes, Syndermata (Rotifera + Acanthocephala), and Nemertea. Within this clade the Entoprocta + Cycliophora appear as each others closest relatives and form a sister group to the Platyzoa. Although the nemertean Tubulanus branches within the Brachiopoda in the LSU tree, the Nemertea are recovered as monophyletic in the LSU + SSU analysis. An SH test found the LSU + SSU analysis uniting Platyhelminthes + Syndermata had a likelihood score significantly better than that of a tree where the Platyhelminthes and Nemertea are sister taxa.

The data are more equivocal about the reality of various "trochozoan" hypotheses. LSU data place sipunculans as the sister to annelids, which includes echiurids and siboglinids (a.k.a. pogonophorans). However, the placement of mollusks relative to this clade still is not clear. 


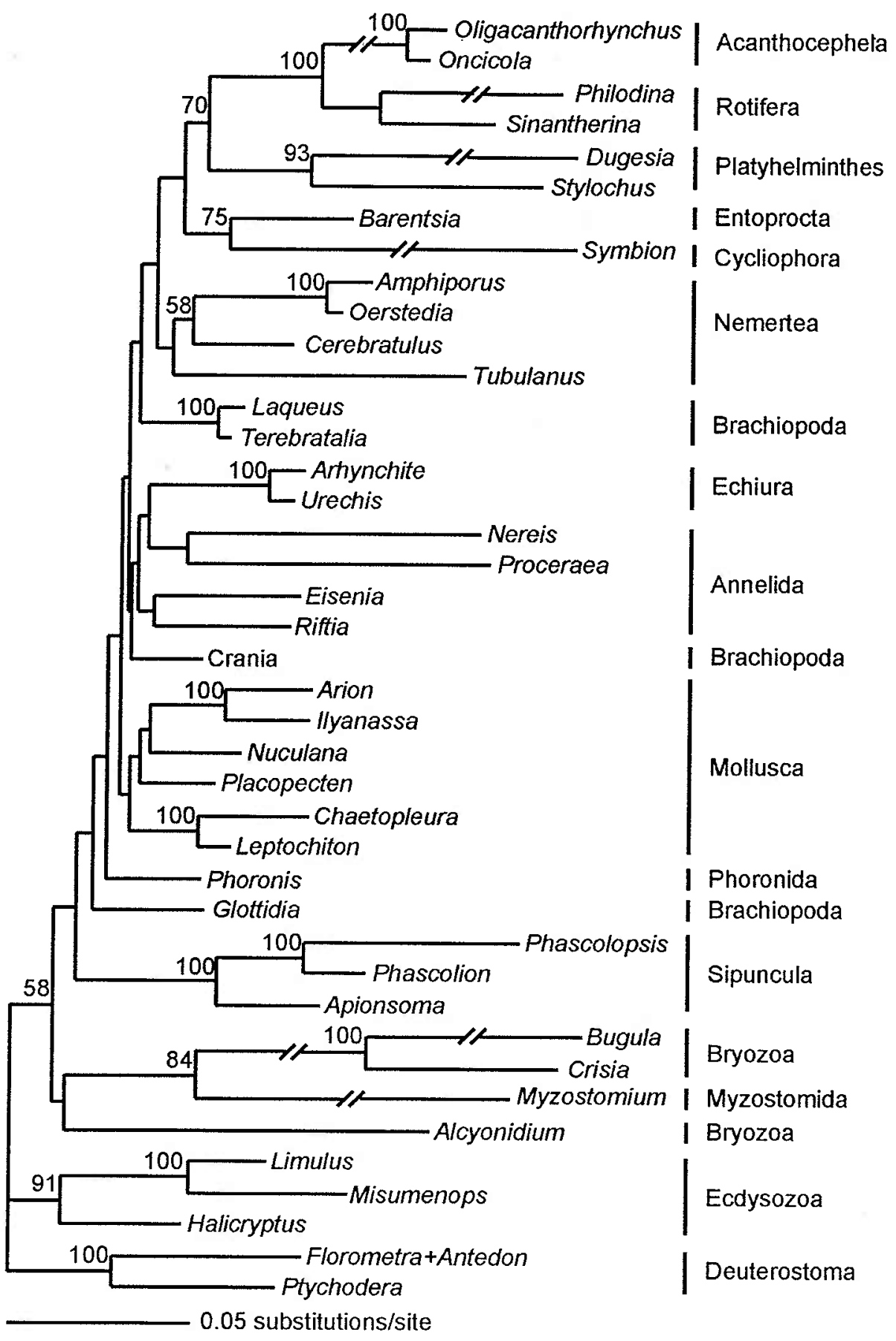

Figure 9: ML tree for the combined LSU + SSU dataset. 100 hueristic replicates were performed using the Symmertical Model (Zharkikh, 1994) with equal base frequencies and estimation of gamma parameter shape distribution $(G=0.5750)$ and proportion of invariant sites $(I=0.3234)$. ML bootstrap (100) replicates) values are shown above nodes with values $>50 \%$. 


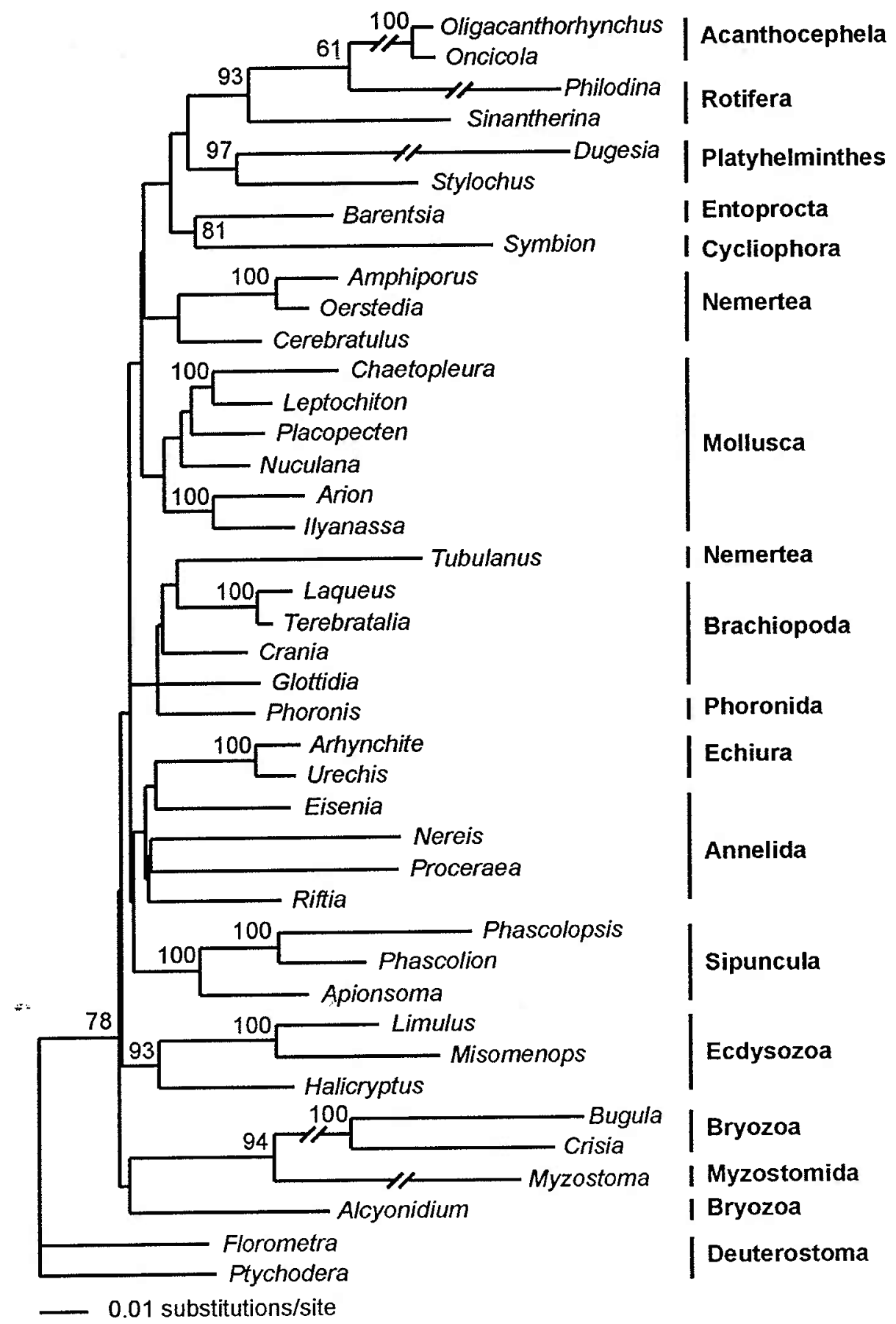

Figure 10: ML tree for the LSU dataset. 100 hueristic replicates were performed using the Transition Model with equal base frequencies and estimation of gamma parameter shape distribution $(G=0.5229)$ and proportion of invariant sites $(\mathrm{I}=0.3228)$. ML bootstrap ( 100 replicates) values are shown above nodes with values $>50 \%$. 


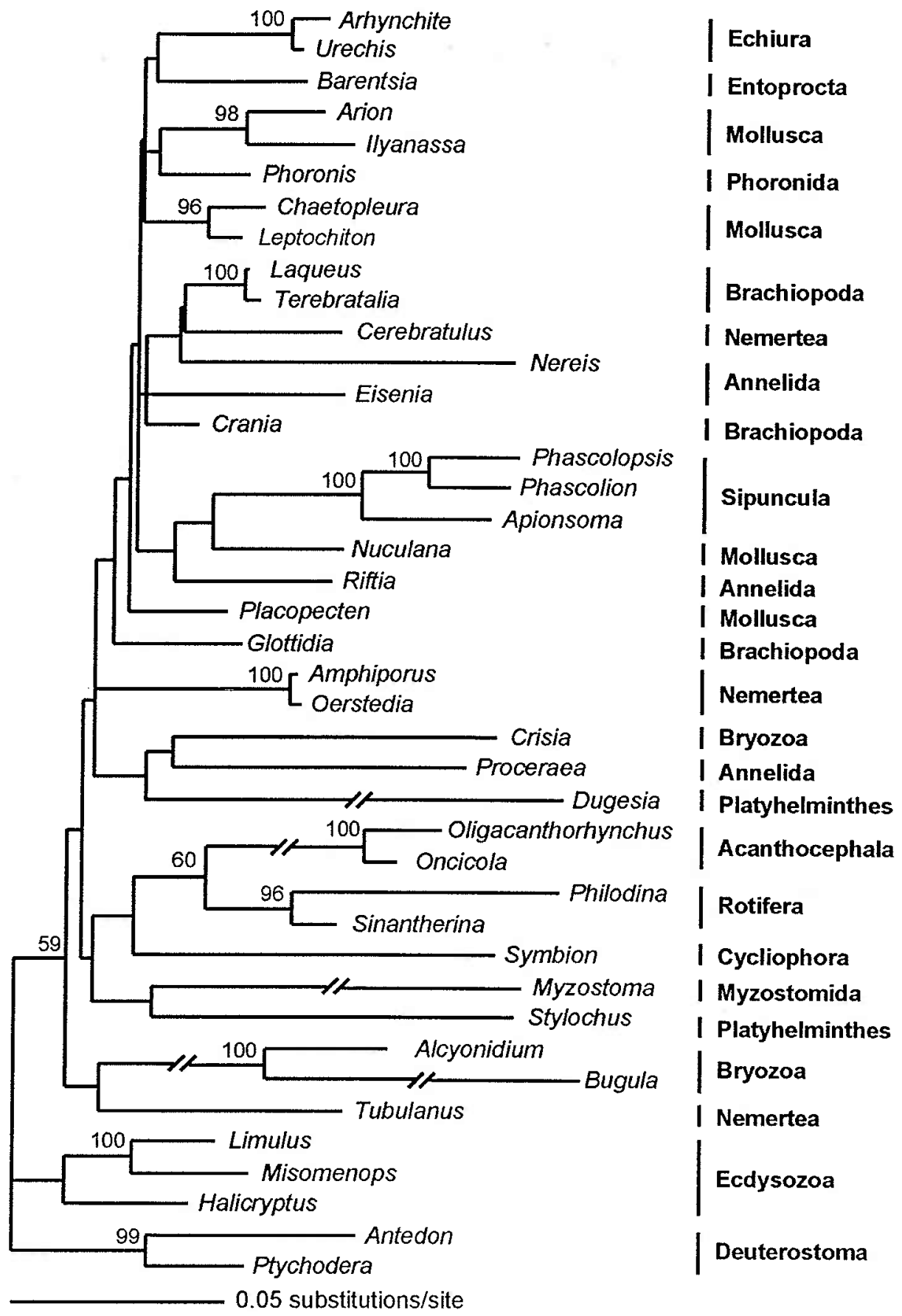

Figure 11: ML tree for the SSU dataset. 100 hueristic replicates were performed using the Tamura-Nei (Tamura and Nei 1993) model with equal base frequencies and estimation of gamma parameter shape distribution $(G=0.6199)$ and proportion of invariant sites $(I=0.3112)$. ML bootstrap (100 replicates) values are shown above nodes with values $>50 \%$. 
Table 7: Total, unambigouosly aligned, variable and parsimony informative characters

\begin{tabular}{lrrrr} 
& Total & Unambiguous & Variable & Informative \\
\cline { 2 - 5 } SSU & 2048 & 1508 & 783 & 499 \\
LSU & 4611 & 2370 & 1183 & 804 \\
LSU+SSU & 6659 & 3878 & 1966 & 1303 \\
\hline
\end{tabular}

Table 8: Shimodaira-Hasegawa test results

\begin{tabular}{llll} 
& SSU & LSU & LSU +SSU \\
\hline Lophophorata monophyly & 0.128 & $\mathbf{0 . 0 0 5} *$ & $\mathbf{0 . 0 4 1 *}$ \\
Bryozoa + Entoprocta monophyly & 0.173 & $\mathbf{0 . 0 1 3}$ & $\mathbf{0 . 0 1 7}$ \\
Bryozoa monophyly & 0.312 & 0.052 & 0.275 \\
Platzoa sister group of Trochozoa & 0.212 & 0.059 & 0.133 \\
Parenchyma monophyly & 0.050 & 0.362 & $\mathbf{0 . 0 1 1}$ \\
Neotrochozoa monophyly & 0.164 & 0.443 & 0.269 \\
Eutrochozoa monophyly & 0.056 & 0.220 & 0.165 \\
Trochozoa monophyly & 0.066 & 0.114 & 0.269 \\
\hline
\end{tabular}

$* \mathrm{P}<0.05-$ Hypotheses in bold are rejected under the given dataset.

Note. - Analyses carried out using the dataset listed at the top of each column, using the appropriate likelihood model as calculated with Modeltest. 


\section{Discussion}

The LSU data greatly improve the phylogenetic signal recovered for lophotrochozoan interphyletic relationships over SSU data alone. LSU sequences recover monophyly of nearly all recognized phyla sampled, including mollusks and annelids which have consistently appeared as polyphyletic in studies using SSU alone (e.g. Giribet et al., 2000; Eernisse, 1997; Peterson and Eernisse, 2001). This increase in resolution provides a tool by which we can begin to decipher deep-level relationships within Lophotrochozoa.

This study provides the most conclusive evidence to date that Lophophorata is not monophyletic. While the position of the Bryozoa differs between the LSU and LSU + SSU trees, both reconstructions place bryozoans basal to other lophotrochozoans.

Alternative hypotheses regarding the origin of the Bryozoa are not supported by ML reconstructions and SH tests of the LSU and LSU + SSU datasets. The "Lophophorata" hypothesis which unites bryozoans with brachiopods and phoronids (Hyman, 1959), is rejected under SH tests of both the LSU and LSU + SSU datastets. Likewise, grouping of the Bryozoa and Entoprocta as sister taxa (Nielsen, 2001) is not supported. These results confirm previous arguments (Halanych, 1996; Nielsen, 1987 - among others) that the similarities in feeding mechanics, ciliation patterns, and gross morphology in bryozoans, brachiopods, phoronids, and other tentacular suspension feeders (e.g. pterobranch hemichordates) are the product of convergent evolution rather than common ancestry. This recognition renders the term "lophophorates" descriptive of function rather than history. 
Moreover, given the results herein, Bryozoa diverged by at least the early Cambrian period. Such an early divergence is at odds with the fossil record, as the Bryozoa have not been found from before the Ordovician, despite being well preserved in later sediments (Lehmann and Hillermer, 1983). Apparently, Bryozoa went through an extended period of cryptic evolution, unrecorded in the fossil record. A late evolution of a calcified skeleton is one possible explanation for this discontinuity between the molecular data and the fossil record.

Analyses of both the LSU and LSU + SSU datasets supports the monophyly of the Platyzoa, and places the group well within the Lophotrochozoa. Despite the placement of the Nemertea near the Platyhelminthes, the rejection of the Parenchyma hypothesis under the SH test of the LSU + SSU dataset strengthens support for the monophyly of the Platyzoa. SSU datasets have found the Platyzoa to branch basally to the Lophotrochozoa (Giribet et al., 2000; Peterson and Eernisse, 2001) supporting, in a general sense, that bilaterians evolved from simple to complex. In contrast, LSU and LSU + SSU data suggest that the morphology of Platyzoans represent secondary simplification of body form. Drawing on recent studies that show platyhelminthes are polyphyletic (with acoelmorphs as basal bilaterians), we favor that both possibilities of bilaterian evolution are correct. However in the specific case of platyzoans, it will be critical to sample gnathostomulids and gastrotrichs to test Cavalier-Smith's (1998) ideas. Although a basal divergence is not rejected by the SH test of the LSU or LSU + SSU trees, the placement of the Platyzoa as a derived clade within the Lophotrochozoa provides a markedly different interpretation of bilaterian evolution which warrants further investigation. 
One putative member of the Platyzoa whose evolutionary affinities are drawn into question is the cycliophoran Symbion. Analyses of SSU data, including those presented here, have suggested that cycliophorans are closely related to rotifers and acanthocephelans. In contrast, the recovery of Cycliophora and Entoprocta as sister taxa in the LSU and LSU + SSU analyses is consistent with the evolutionary relationship hypothesized when this enigmatic taxon was first described (Funch and Kristensen, 1995; 1997), as well as with the results of morphological cladistic analysis (Zrzavy et al., 1998).

The recovered LSU and LSU + SSU topologies suggest that trochozoans represent an evolutionary grade rather than a distinct clade, although hypotheses supporting the monophyly of trochozoan taxa are not rejected under SH tests. If the trochophore larva is a plesiomorphy of the Lophotrochozoa (excepting the Bryozoa) it appears to have been lost or highly modified in some descendent lineages, such as phoronids, brachiopods, and platyzoans. The sister relationship of the Annelida and Sipuncula in the LSU tree supports the presence of the trochophore in the common ancestor of these two groups. A close relationship between annelids and sipunculans has also been suggested based upon similarities in mitochondrial gene arrangement (Boore and Staton, 2002).

LSU sequence data presented here provide improved resolution of lophotrochozoan relationships. Unlike SSU data, LSU and LSU + SSU sequences recover the monophyly of most recognized lophotrochozoan phyla, a prerequisite to evaluating interphyletic relationships. Several findings have important implications for our understanding of developmental and morphological evolution. In particular, the finding of a derived Platyzoa closely related to entoprocts provides support for secondary simplification of the 
group, perhaps due to a neotonic origin. Increased attention on the evolutionary origin of the Bryozoa will also be of particular interest given their possible early divergence during protostome diversification. 


\section{Chapter 4}

A Survey of Hox genes in the bryozoan Bugula turrita 


\begin{abstract}
The present study surveys the complement of Hox genes present in the genome of the bryozoan Bugula turrita. Although the clade Lophotrochozoa was defined as including bryozoans, recent studies have not reliably recovered the position of the Bryozoa among metazoans. Hox genes sequences have the potential to provide an additional set of evidence for the phylogenetic position of bryozoans. Hox genes appear to have undergone independent duplication events in each of the three major bilaterian clades: lophotrochozoans, ecdysozoans, and deuterosotmes. Two Hox gene paralogs, Postl and Post2, appear to have arisen subsequent to the divergence of the Lophotrochozoa and can therefore serve as a synapomorphy for members of the clade. Six Hox genes were identified from Bugula turrita, including an ortholog of Post 2 . The identification of a bryozoan Post 2 ortholog provides novel evidence for a close evolutionary relationships between bryozoans and other lophotrochozoans.
\end{abstract}




\section{Introduction}

The Bryozoa remain among the most enigmatic of metazoan phyla with respect to their phylogenetic position (Giribet 2002). Bryozoans have traditionally been viewed as closely related to brachiopods and phoronids. Together these three groups are referred to as lophophorates, based upon the inferred homology of their ciliated tentacular feeding structures (Hyman, 1959; Willmer, 1990). Inference of the phylogenetic position of lophophorates based upon morphological and embryological characters has been complicated by the fact that they display a mosaic of archetypal protostome and deuterostome conditions. Differing interpretations of developmental and morphological traits has lead to the assignment of lophophorates as protostomes (Gutmann et al., 1978), deuterostomes (Zimmer, 1973), intermediates between the two groups (Salvini-Plawen, 1982; Seiwing, 1976), or an independent radiation (Willmer, 1990).

However, detailed structural and functional analyses of bryozoan tentacles suggest that they are not homologous to the lophophores of phoronids and brachiopods (Nielsen and Riisgard, 1998), as widely believed (e.g. Brusca and Brusca, 1990; Willmer, 1990; Knoll and Carroll, 1999). As the lophophore is the primary feature uniting bryozoans with brachiopods and phoronids, failure to establish the homology of this structure undermines the validity of the Lophophorata hypothesis (Halanych, 1996; de Rosa et al., 2001). Nielsen has suggested that bryozoans may be most closely related to entoprocts, on the basis of developmental similarities between the two groups (Nielsen, 1971; 2001).

Several recent studies have utilized cladistic methods to reconstruct metazoan phylogenies from explicit matrices of morphological and developmental character states 
(e.g. Zrzavy et al., 1998; Peterson and Eernissee, 2001). The placement of bryozoans within these studies varies based the characters chosen and the way these characters were chosen (Jenner, 2001). Zrzavy et al. (1998) coded bryozoans as possessing a lophophore, and recovered the bryozoans as an outgroup to Phoronida + Brachiopoda + Deuterostomia. In a recent study, Peterson and Eernissee (2001) did not code bryozoans as having a lophophore, and found bryozoans to be closely related to spiralian protostomes such as mollusks and annelids and entoprocts.

With the advent of molecular phylogenetics there arose the potential for an independent set of characters for analyzing the relationship between bryozoans and other metazoan phyla. Using small-subunit ribosomal gene (SSU rDNA) sequence, Halanych et al., (1995) found, bryozoans, brachiopods and phoronids to be more closely related to the protostome annelids and mollusks than to deuterostomes. Based upon these results, the clade Lophotrochozoa was defined as "the last common ancestor of the three traditional lophophorate taxa, the mollusks, and the annelids, and all of the descendents of that common ancestor." Halanych et al., (1995) did not recover lophophorates as monophyletic, instead finding that the bryozoan sequence branched basally to the other lophotrochozoans sequenced. Although this study utlilized only a single bryozoan, analysis of SSU sequnces from additional bryozoan species has also failed to recover lophophorate monophyly (Giribet et al., 2001).

Subsequent sampling has suggested that the Lophotrochozoa encompasses a broad assemblage of invertebrates, such as nemerteans, sipunculans, and entoprocts (e.g. Mackey et al., 1996). Platyhelminthes and rotifers may also be members of the clade, or 
closely related sister taxa (Giribet et al., 2000; Chapter 3). Despite broad sampling of SSU rDNA sequences from metazoan taxa, relatively few representatives of the Bryozoa have been sequenced and included in subsequent analysis. Additionally, most bryozoan SSU rDNA sequences that have been sampled appear to have relatively high substitution rates. This raises the concern that placement of bryozoan sequences in phylogenetic reconstructions may be impacted by artifacts such as long-branch attraction (Felsenstein, 1978).

As discussed in Chapter 3, sampling of SSU and large-subunit (LSU) rDNA sequences from three bryozoans allowed rejection of the two most prominent hypotheses of bryozoan relationships, uniting bryozoans with brachiopods + phoronids or with entoprocts. However the placement of bryozoans among bilaterian phyla was variable depending upon the dataset used and which taxa were included. It would therefore be advantageous to have additional sequence data to evaluate the relationship between bryozoans and other metazoans, in particular lophotrochozoans.

Hox genes appear to provide a valuable set of evidence regarding the relationships between the major clades of bilaterian metazoans (de Rosa et al., 1999; Halanych and Passamaneck, 2001; Balavoine et al., 2002). Hox genes are well known for their organization in a linked cluster along the chromosome, in most bilaterians that have been investigated. The genes within the cluster arose from serial duplications that created paralogs (Holland, 1999; Lundin, 1999). Several of these genes appear to have arisen prior to the divergence of the three major bilaterian clades (Finnerty and Martindale, 1998). The anterior class genes labial(lab)l/Hoxl and proboscopedia(pb)/Hox2, Hox3, 
and the medial class genes Deformed(Dfd)/Hox 4 and Sex combs reduced(Scr)/Hox 5 all appear to have direct orthologs present in lophotrochozoans, ecdysozoans and deuterostomes. In contrast, posterior class genes, and perhaps some medial genes appear to have undergone independent duplications over the course of bilaterian diversification. Identification of paralog groups which are restricted to a clade can therefore serve as a synapomorphy for that clade (Telford, 2000b).

de Rosa et al. (1999) identified 5 Hox genes (the medial class genes Lox5, Lox2, Lox4, and the posterior class genes Post1, and Post2) in brachiopods, annelids and mollusks which they suggested did not have clear orthologs among Hox genes from either ecdysozoans or deuterostomes. If these genes are inferred to have arisen subsequent to the divergence of Lophotrochozoa from Ecysozoa and Deuterostomia, then they genes would represent synapomorphies for lophotrochozoans. Although some of these genes may have orthologs among ecdysozoans (Telford 2000a;2000b), each appears to have peptide motifs present only among lophotrochozoans.

Identification of lophotochozoan specific Hox genes of Hox gene peptide motifs from bryozoans would provide strong evidence for a close relatiunship between bryozoans and other lophotrochozoans. The current study utilized degenerate primer PCR surveys to screen for Hox genes in the bryozoan Bugula turrita. Regions flanking the homeodomain of several genes of interest were also amplified using ligation mediated PCR (Balavoine, 1996). Orthologs of two lophotrochozoan Hox genes, Lox5 and Post2, were identified from Bugula turrita, supporting the hypothesis of a close relationship between bryozoans 
and other lophotrochozoans. Attempts were also made to establish chromosomal linkage of Bugula turrita Hox genes by means of Southern blotting. 


\section{Methods .}

\section{Genomic DNA}

Colonies of Bugula turrita were collected from docks in Eel Pond, Woods Hole, Massachusetts. Colonies were held in filtered seawater overnight to allow clearance of gut contents prior to extraction of genomic DNA. Colony fragments were sorted under light microscopy to avoid contamination by epibionts such as nematodes and caprellid amphipods. Genomic DNA was extracted using the DNEasy Tissue Kit (QIAGEN), following manufacturers protocols.

\section{Homeodomain amplification}

Homeodomains were amplified using the forward primer Hox1F-ELEKEF (GCTCTAGARYTNGARAARGARTT) (Balavoine and Telford, 1995) and the reverse primer Hox2R-WFQNRR (CGGGATCCCKNCKRTYTYGRAACCA) (Balavoine, 1996). The forward primer PostF RKKRKPY-PostF (MGIAARAARMGIAARCCNTA) and the reverse primer WFQNRRMK-HoxR (YTTCATICKICKRTTYTGRAACCA) were used to screen for posterior class genes. Polymerase chain reaction was conducted using Taq polymerase (Promega) using a "touchdown" approach. PCR conditions involved an initial denaturation $\left(94^{\circ} \mathrm{C}, 2 \mathrm{~min}\right)$ then 30 touchdown amplification cycles $\left(94^{\circ} \mathrm{C}, 30 \mathrm{sec} ; 55^{\circ} \mathrm{C}\right.$ (minus $\left.\left.0.5^{\circ} \mathrm{C} / \mathrm{cycle}\right) 45 \mathrm{sec} ; 72^{\circ} \mathrm{C}\right)$ followed by a final extension

$\left(72^{\circ} \mathrm{C}, 5 \mathrm{~min}\right)$. PCR products were cloned using pGEM-T Vector System (Promega). Clones were purified using Qiaprep (QIAGEN) minprep kit and sequenced on an ABI 377 automated sequencer (Applied Biosystems), using Big Dye Terminator Sequencing Reaction chemistry (Applied Biosystems). 


\section{Identification of full homeodomains and flanking regions}

Sequences of complete homeodomains and flanking regions were obtained using the ligation mediated PCR technique (LM-PCR), as described by Balavoine (1996). Seminested LM-PCR was conducted using specific primers designed from homeodomain fragments identified during degenerate screens. Gene specific primers used for seminested LM-PCR are listed in Table 9.

\section{Phylogenetic analysis}

Amino acid sequences for Hox gene homeodomains and flanking regions were aligned by eye using MacClade 4.0 (Maddison and Maddison 2000). Bayesian likelihood analyses were conducted using MrBayes version 2.0 (Huelsenbeck and Ronquist, 2001), with a JTT model of amino acid replacement (Jones et al., 1992). 1,000,000 replicates were conducted of four chains. Trees were retained every 100 replicates, and analysis was conducted with a burnin of 200,000 replicates. Minimum evolution and parsimony analyses were conducted using PAUP* version 4.0 bl0 (Swofford 2002). For minimum evolution analyses distance measure were based upon mean pairwise character differences. 1,000 replicate heuristic searches were performed. Minimum evolution bootstrap analysis employed 1,000 replicates, with 10 heuristic search replicates per bootstrap replicate. Parsimony analysis was conducted with 1,000 replicate heuristic searches. Parsimony bootstrap analysis employed 1,000 replicates, with 10 heuristic search replicates per bootstrap replicate. For all minumum evolution and parsimony analysis the maximum number of rearrangements was limited to $10,000,000$ per replicate due to computational limitations. 


\section{Southern mapping .}

Attempts were made to establish chromosomal linkage and gene order of Bugula turrita Hox genes using Southern hybridization. PCR fragments covering the homeodomain and flanking regions of Btu-Dfda (1093 nucleotides), Btu-Dfdb ( 750 nucleotides), Btu-Lox5 (566 nucleotides), and Btu-Post2 (1050 nucleotides) were used as template for the production of single-stranded digoxigenin-labeled probes by asymmetric PCR. Primers used for amplification of PCR fragments and probes are listed in Table 10. Probes were labeled with digoxigenin (DIG) using the PCR DIG Probe Synthesis Kit (Roche Diagnostics Corporation). Probe efficacy was tested by hybridization to membranes with serial dilutions of probe PCR template. Southern hybridization experiments were conducted using 10ug of genomic DNA digested using one of the following restriction enzymes: Pac I, Pst $I$, Sph I. Genomic DNA digests were separated using pulse field gel electrophoresis. Separated digests were transferred to membranes and screened using gene specific probes. 
Table 1: Gene specific primers used for semi-nested ligation-mediated PCR

\begin{tabular}{llll} 
Gene & Direction & Primer name & Sequence $\left(5^{\prime}>3^{\prime}\right)$ \\
\hline BtDfda & Forward & BtDfdaF1 & TAGATATTTAACAAGACGGAGA \\
BtDfda & Forward & BtDfdaF2 & CGGAGAAGAATAGAAATTGCTCAC \\
BtDfda & Reverse & BtDfdaR1 & GTCTTTCTGAGAGATCGAGAGTG \\
BtDfda & Reverse & BtDfdaR2 & ATCGAGAGTGTGAGCAATTTC \\
& & & \\
BtDfdb & Forward & BtDfdbF1 & CACTATAACAGATATTTGACTCG \\
BtDfdb & Forward & BtDfdbF2 & CGAAGAAGACGTATCGAAATAGCC \\
BtDfdb & Reverse & BtDfdbR1 & CTG TCT TYC ACT GAG TGT CAG G \\
BtDfdb & Reverse & BtDfdbR2 & GTGTCAGGGTATGGGCTATTTCG \\
& & & \\
BtLox5 & Forward & BtLox5F1 & CAGATATYTAACAAGACGGCG \\
BtLox5 & Forward & BtLox5F2 & GCGTAGAATAGAAATTGCTC \\
BtLox5 & Reverse & BtLox5R1 & GGCGCTCCGTTAAACCGAG \\
BtLox5 & Reverse & BtLox5R2 & ACCGAGAGTATGAGCAATTTC \\
& & & \\
BtPost2 & Forward & BtPost2F1 & TACACACGCTACCAAACRATGG \\
BtPost2 & Forward & BtPost2F2 & GGAAACAGAGTTCATAAACAATTC \\
BtPost2 & Reverse & BtPost2R1 & CTTTAACTTGCCGTTCGGTCAGTC \\
BtPost2 & Reverse & BtPost2R2 & GTCTTAGTCTGCAGGAGATTTCCC \\
\hline
\end{tabular}

Table 2: Gene specific primers used for DIG probe construction

\begin{tabular}{llll} 
Gene & Direction & Primer name & Sequence $\left(5^{\prime}>3^{\prime}\right)$ \\
\hline $\begin{array}{l}\text { BtDfda } \\
\text { BtDfda }\end{array}$ & $\begin{array}{l}\text { Forward } \\
\text { Reverse }\end{array}$ & $\begin{array}{l}\text { BtDfdaF3* } \\
\text { BtDfdaR3 }\end{array}$ & $\begin{array}{l}\text { CCTGGGCCACCCCAACTACTAATGAAAGCAGC } \\
\text { CCAGCACCTAAATGCACAAGTACATTGG }\end{array}$ \\
$\begin{array}{lll}\text { BtDfdb } \\
\text { BtDfdb }\end{array}$ & $\begin{array}{l}\text { Forward } \\
\text { Reverse }\end{array}$ & $\begin{array}{l}\text { BtDfdbF3* } \\
\text { BtDfdbR3 }\end{array}$ & $\begin{array}{l}\text { ATGAAACATCGATTGCTTATTAGGG } \\
\text { CCACATAATATTACATGAAGTAGGACAAC }\end{array}$ \\
BtLox5 & Forward & BtLox5F3* & GAATTGAATGTTCTTAGTAATGTTGCC \\
BtLox5 & Reverse & BtLox5R3 & CCAGTCAGTTTGGCAATATTGTTCTC \\
& & & \\
BtPost2 & Forward & BtPost2F4* & CCTGCACATGTATTTGACCATTAG \\
BtPost2 & Reverse & BtPost2R3 & CCTCCGTGATGATAAGGTAAAGCAAC \\
\hline
\end{tabular}

* Primers used for asymmertic amplification of single-stranded probes 


\section{Results}

Identification of Bugula Hox genes

Six unique Hox genes were cloned from Bugula turrita. Orthology of isolated genes to Hox genes in other metazoans was initially determined by comparison of inferred amino acid sequence of homeodomains. Initial assignment of orthology was based upon identification of peptide residues that appear to be conserved among members of specific paralog groups (de Rosa et al., 1999) (Figure 15). Based upon these comparisons, the Hox genes isolated from Bugula turrita represent members of the proboscepedia $(p b)$, Hox3, Deformed (Dfd) (2 copies were identified), Lox5, and Post2 paralog groups. Bugula turrita Hox genes were designated with the prefix "Btu-", and were named Btu$p b, B t u-H o x 3, B t u-D f d a, B t u-D f d b, B t u-L o x 5$, and Btu-Post2 respectively.

Sequence of the complete homeodomain and flanking regions was obtained for Btu$D f d a, B t u-D f d b, B t u-L o x 5$, and Btu-Post2 using ligation mediated PCR (Balavoine, 1996). For Btu-Dfda 752 nucleotides 5' of the homeodomain and 160 nucleotides 3' of the homeodomain were sequenced; for Btu-Dfdb, 74 nucleotides 5 ' and 489 nucleotides 3'; for Btu-Lox5, 366 nucleotides 5'and 20 nucleotides 3'; for.Btu-Post2, 767 nucleotides. 5'and 88 nucleotides 3 '. 


\section{Proboscopedia / PG2}

\begin{tabular}{|c|c|c|c|}
\hline Btu pb & & $---K--C-P-----A S-D----V-V$ & \\
\hline Nvi pb & TGSN & $\mathrm{PR}-\mathrm{L}-\mathrm{TA}-\mathrm{NT}-\mathrm{L}---------\mathrm{K}--\mathrm{C}-\mathrm{P}-\cdots---\mathrm{AS}-\mathrm{D}----\mathrm{V}-\mathrm{V}$ & \\
\hline Dme pb & ENGL & PR-I-TA--NT-L- - - & LSKTDDEDNKD \\
\hline Bfl Hox2 & QVNS & SR-L-TVF-NT-L-D-- & TKGRSEIGTDP \\
\hline
\end{tabular}

\section{Hox3 / PG3}

\begin{tabular}{|c|c|c|c|}
\hline Btu Hox 3 & & $-\longrightarrow--C-P---M-A L-S---\cdots$ & \\
\hline Lan Hox 3 & GEQP & 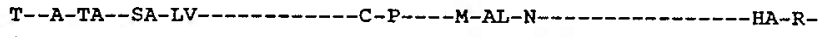 & RSKKSCSKNSS \\
\hline Nvi Hox 3 & GEKP & 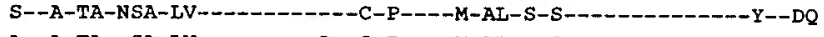 & RMKPNSEKELS \\
\hline Esc $\operatorname{Hox} 3$ & CEQP & 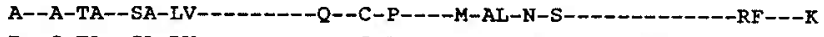 & KLKVNMDKSGC \\
\hline Lsa Hox 3 & LTGP & P--S-TA-SSA-IV-N- & KQKNLMEKIQL \\
\hline
\end{tabular}

Deformed / PG4

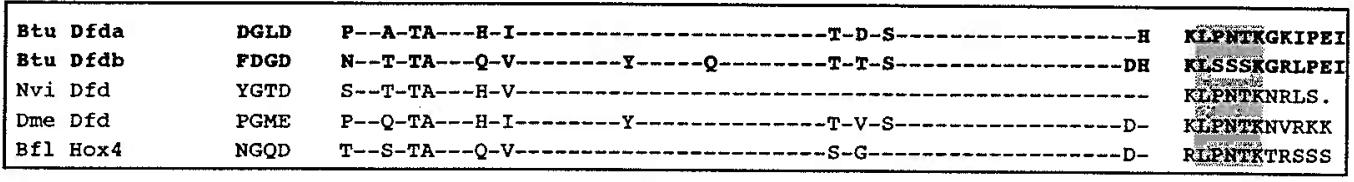

Lox5 / Fushi tarazu

\begin{tabular}{|c|c|c|c|}
\hline Btu Lox5 & TGYE & Q--T---C- & NIAKLTG. \\
\hline Lan Lox 5 & IGYE & 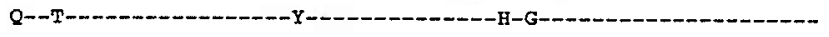 & NIPKLTGPNQK \\
\hline Nvi Lox 5 & FGFE & $\mathrm{Q}-\mathrm{T}-\mathrm{T}-\mathrm{C}-\mathrm{C}$ & NLSK... \\
\hline Esc Lox5 & TAYE & Q--T---D-F-n- & NVSKLTGPDKS \\
\hline Isa Hоx 6 & ANRE & Q--T- & NLQKLTGPNTK \\
\hline Fca Ftz & & 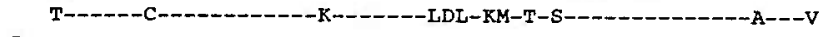 & KGHVVVATDLV \\
\hline Mta Ftz & GGFG & 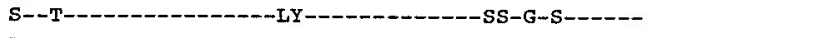 & \\
\hline Alo Ftz & SGQG & 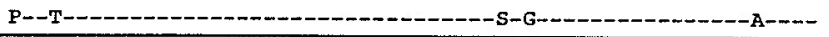 & KIKVDPNSAEG \\
\hline
\end{tabular}

Post2

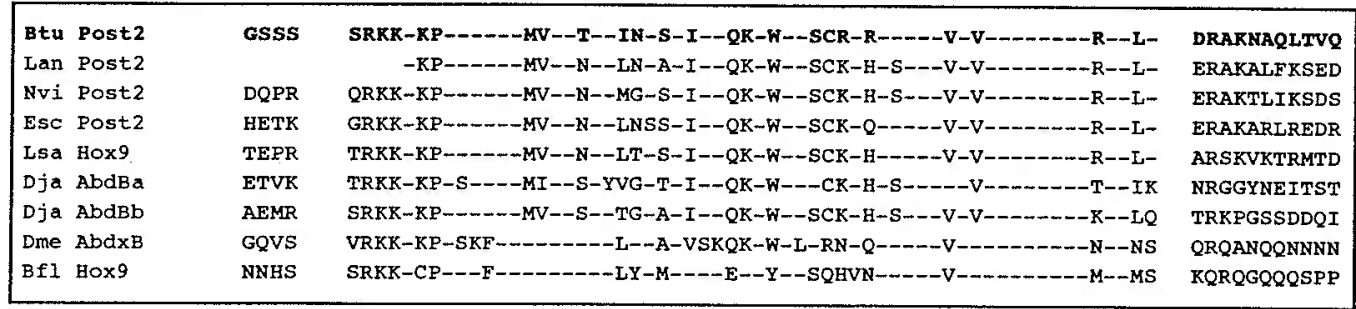

Figure 15: Alignment of Hox gene homeodomains and flanking regions. Dashes represent identity with the Droshiphila melanogastet Antp homeodomain alignment shown at the top of the alignment. Conserved peptide motif LPNTK in the C terminal flanking region of $D f d$ orthologs and the conserved peptide motif KLTPG in the C terminal flanking region of Lox 5 orthologs are highlighted. Species names are abbreviated as follows: Btu-Bugula turrita; Esc - Euprymna scolopes; Lan Lingula anatina; Lsa - Lineus sanguineus; Nvi - Nereis virens; Alo - Archegozetes longisetosus; Fca - Folsomia candida; Mta - Milnesium tardigradum; Dme - Drosophila melanogaster; Bfl Branchiostoma floridae. 


\section{Phylogenetic analysis}

Results from phylogenetic analyses of Hox gene homeodomain sequences are presented in Figure 13. Although the relationships among many Hox genes was not well resolved, the positions of Bugula Lox5 and Post 2 orthologs are worth noting. A monophyletic grouping of Btu-Lox5 with Lox 5 orthologs from the annelid Nereis and the brachiopod Laqueus received moderate support in both Bayesian likelihood and distance based analyses. A monophyletic clade of Post 2 orthologs, including Btu-Post 2 was strongly supported under both likelihood and distance criteria.

\section{Flanking regions}

Medial class genes (e.g. Dfd and Lox5) show high levels of similarity in Homeodomain sequence, with each each paralog group displaying only a few unique peptide residues. This complicates assignment of orthology, as the unique peptide residues shared among putative orthologous genes cannot be unequivocally distinguished as homologous rather than homoplasious. In these cases, assignment of gene orthology was bolstered by identification of conserved peptide motifs in the regions flanking the homeodomain. Across the Bilateria Dfd/Hox4 orthologs possess an "LPNTK" motif C terminal to the homeodomain. This peptide motif was also identified in the 3' flanking region of Btu-Dfda (Figure 12). At the same positions Btu-Dfdb contained the motif "LSSSK", However, Btu-Dfda and Btu-Dfdb shared a motif "PEI" in the flanking region, not observed in other Hox genes sampled. The peptide motif KLTG was identified C terminal to the homeodomain of Btu-Lox5. This region appears to be to the homologous to the KLTGP motif in the Lox 5 gene from other lophotrochozoans 


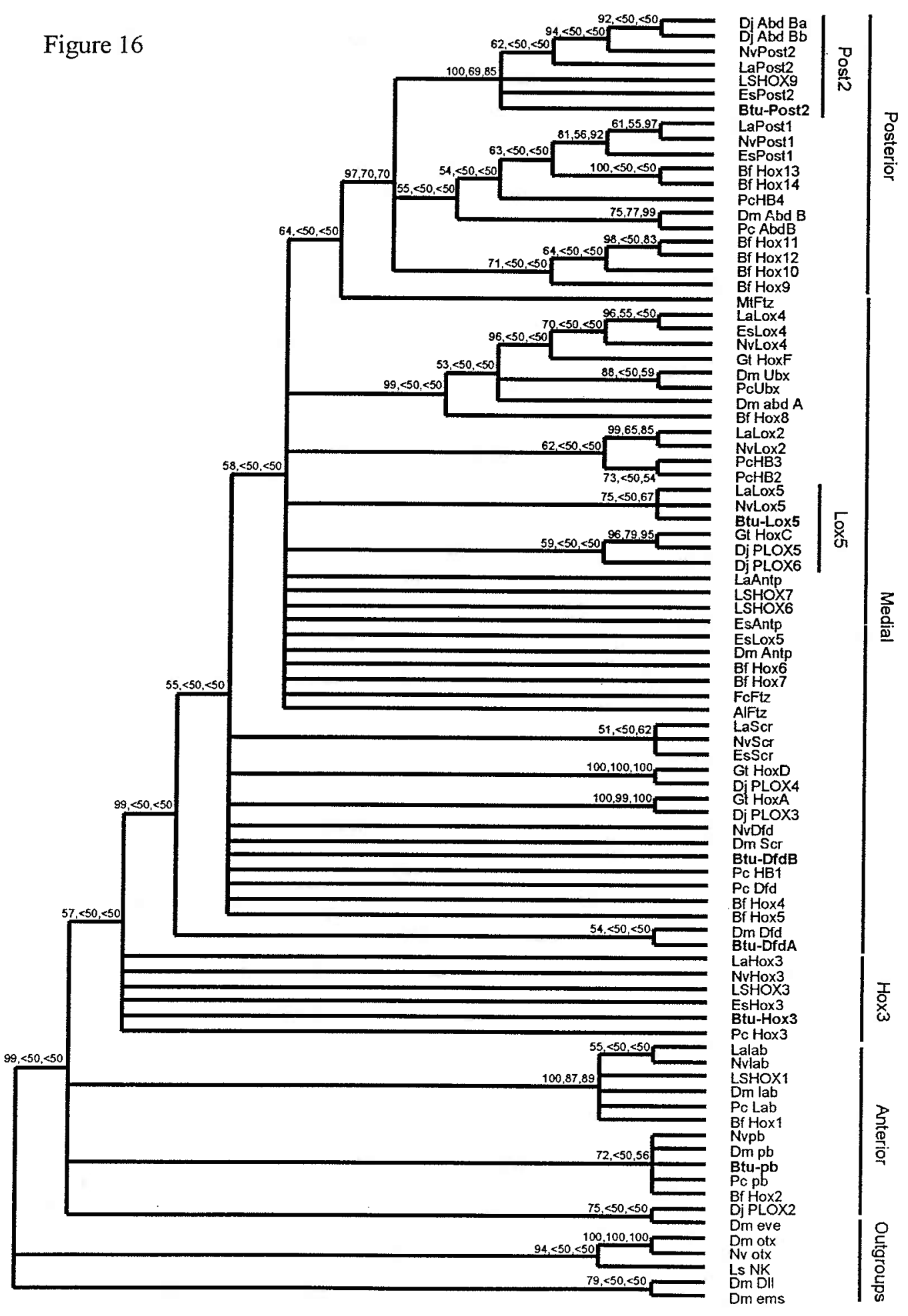


Figure 16: Phylogenetic reconstruction of Hox gene relationships. Bugula turrita Hox genes are highlighted. Tree shown is from Bayesian likelihood analysis using MrBayes: half compatibility concensus from $1,000,000$ replicates, burnin of 200,000 replicates. Percent support values above branches are from Bayesian likelihood, parsimony bootstrap (1000 replicates), and minimum evolution bootstrap (1000 replicates), respectively. 


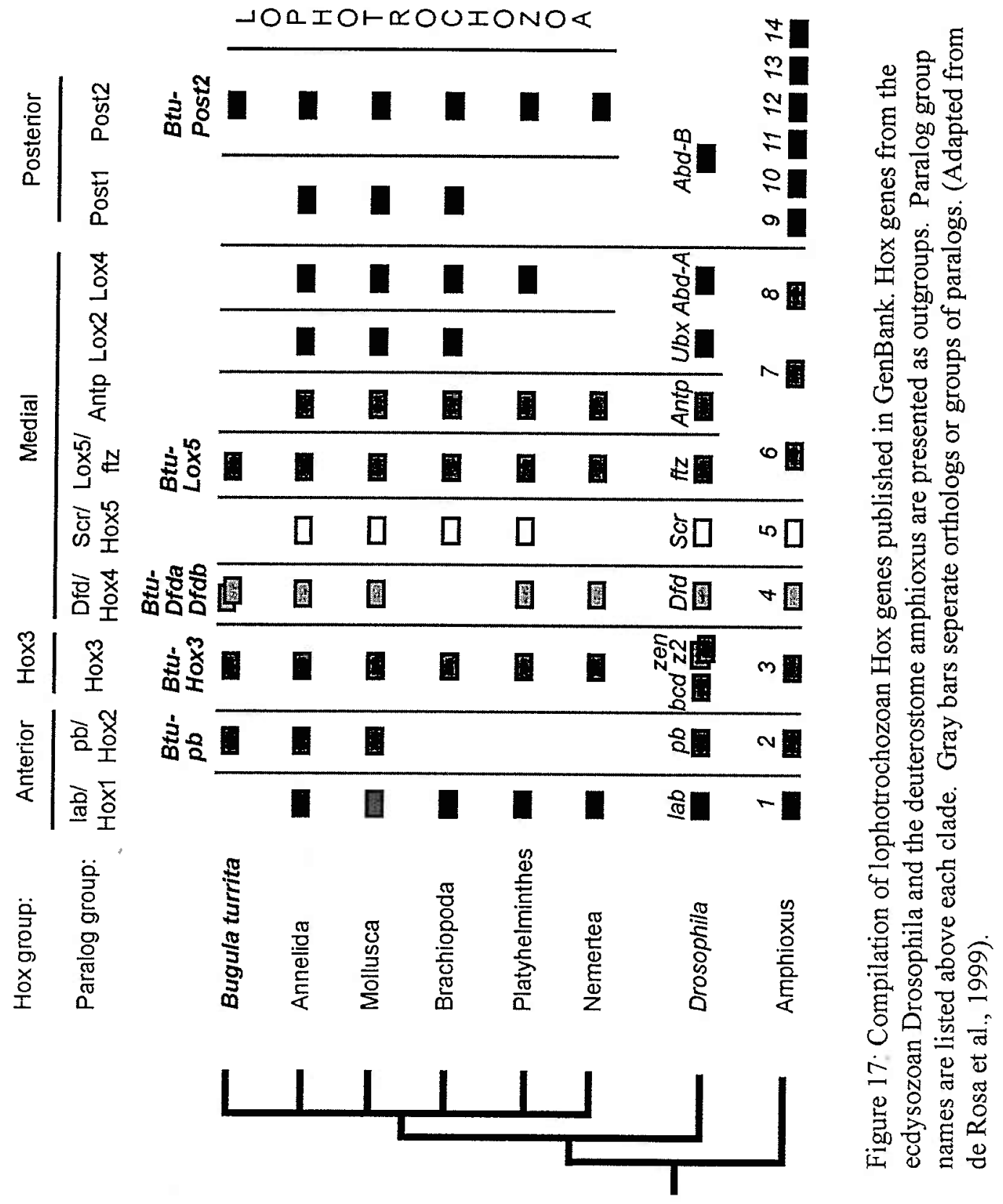




\section{Discussion}

The results presented here evidence that members of the anterior, Hox 3 , medial, and posterior Hox gene classes are present in the genome of the bryozoan Bugula turrita (Figure 15). The identification of Lox5 and Post2 orthologs are of particular interest, given their potential to inform us regarding the phylogenetic affinities of the Bryozoa.

Lox 5 was first identified in the leech Helobdella robusta (Kourakis et al., 1997). Subsequent identification of Lox5 orthologs in a brachiopod, a polychaete and a nemertean prompted suggestion that Lox 5 might represent a synapomorphy for the Lophotrochozoa, based not only similarity in homeodomain sequence, but also on the presence of a conserved peptide motif "KLTGP" C terminal of the homeodomain (de Rosa et al., 1999).

Telford $(2000 \mathrm{a} ; 2000 \mathrm{~b})$ has presented evidence that Lox5 did not arise through a duplication event within the lophotrochozoan lineage, but is an ortholog of ecysozoan $f t z$ genes, and perhaps also the deuterostome Hox6 genes. Given this, it is equally parsimonious to assume that the amino acid sequence any of these three genes may represent the ancestoral condition within bilaterians. The Lox 5 sequence may be primitive, rather than derived, and organisms possessing Lox5are not necessarily members of the lophotrochozoan clade (Telford, 2000b).

However, this analysis is based only upon analysis of the homeodomain, without reference to the sequence of flanking regions. As discussed above, Lox5 genes are characterized not only by similarities in homeodomain sequence, but also by the presence of the "KLTGP" peptide motif. This motif has not been identified in genes other than 
Lox5, and may therefore represent a synapomorphy for lophotrochozoans. Alternatively, the "KLTGP" motif may have been present in Lox $5 / f t z$ ortholog of the last common ancestor of protostomes, requiring a loss in ecdysozoans, or in the Lox5/ftz/Hox6 ortholog of the last common ancestor of bilaterians, requiring losses in both deuterostomes and ecdysozoans. Either scenario is less parsimonious than a single acquisition of the motif subsequent to the divergence of lophotrpochozoan and ecdysozoan lineages.

The identification of a Post 2 ortholog in Bugula turrita provides strong evidence for a close relationship between bryozoans and other lophotrochozoans. The monophyly of Post2 genes, including Btu-Post2, was recovered under all phylogenetic reconstruction criteria employed (Figure 16). Following Telford's (2000b) guideline for using paralogous genes as outgroups to root analyses, Post 2 is supported as having a derived condition relative to other posterior class Hox genes. Post 2 appears to have originated subsequent to the divergence of lophotrochozoans and ecdysozoans, and therefore represents a synapomorphy for the Lophotrochozoa. Btu-Post 2 thus provides evidence for the phylogenetic affinity between bryozoans and other lophotrochozoans.

In total, representatives of five Hox paralog groups were identified from Bugula turrita. Some Hox genes identified from other lophotrochozoans were not recovered from Bugula, including orthologs of lab/Hox1, Scr/Hox5, Antp/HB1, Lox2, Lox4, and Postl (Figure 17). This discrepancy maybe due to 1) an absence of these genes from the Bugula turrita genome, or 2) artifacts of the PCR based samplying method employed.

First, copies of these genes may not be present in the Bugula genome. This could be due to the fact that some genes had not arisen via tandem duplication prior to the diverge 
of the bryozoan lineage from other lophotrochozoans. Some of the genes listed above (i.e. lab/Hoxl, Scr/Hox5) have clear orthologs in all three major bilaterian clades, and thus clearly were present in the last common ancestor of lophotrochozoans. The origin of the other genes listed is less clear. $H B 1$ genes identified from several lophotrochozoans appear to be orthologs of Antp, and thus would also have been present in the lophotrochozoan stem lineage. Likewise, the phylogenetic affinities between Lox2 and Lox4 in lophotrochozoans and $U b x$ and $A b d-A$ in ecdysozoans suggests at least a single ancestor, if not both genes, arose prior to the divergence of lophotrochozoans and ecdysozoan lineages. Postl may have arisen from a duplication within lophotrochozoans, however the relationship between PostI and other posterior class Hox genes is not clearly resolved in the results presented here. Weak support for a clade including Post 1 and $A b d-B$ orthologs suggests Post 1 may have been present in the lophotrochozoan stem lineage. Given that most of the paralog groups listed above were likely present in the last common ancestors of Lophotrochozoa, some may have been lost within the bryozoan lineage, and thus would not be present in Bugula turrita.

Alternatively, the limited number of Hox genes recovered from Bugula turrita may be due to the use of PCR amplification with degenerate primers to screen for Hox genes. The full complement of Hox genes present in the Bugula turrita genome may not have been found due to bias in PCR amplification reactions. Despite the fact that primers were designed to target regions coding for highly conserved peptide motifs there may be variation between genes in codon usage or the amino acid sequence encoded for at these sites. Such variation may affect the efficacy of the PCR primers used, and lead to bias in 
the resultant pool of amplicons. With the advent of genomic techniques, screening of genomic libraries and sequencing of clones containing Hox genes may provide a valuable tool for studying the evolution of Hox genes. Such an approach would provide information on the conservation of a linked Hox cluster and gene order. If linkage of Hox genes is conserved, sequencing of the complete cluster would allow identification of Hox genes not recovered using degenerate PCR screens. 


\section{Chapter 5}

\section{Conclusions}


Thesis results and their significance

The work presented in this thesis focuses on the relationships between major groups of animals within the clade Lophotrochozoa. A summary of the results from this thesis is presented as an updated tree of metazoan relationships in Figure 18. Several aspects of this tree represent advances in our understanding of lophotrochozoan evolution, as compared with the state of knowledge prior to this work (Figure 2).

The utilization of large-subunit ribosomal RNA gene (LSU rDNA) sequence in chapters 2 and 3 of this thesis provides insight into the relationships between lophotrochozoan phyla, as well as within the Mollusca. In Chapter 2 LSU rDNA was sequenced from a broad sampling of mollusks. Analyses of these sequences have provided the first molecular evidence for a close relationship between scaphopods and cephalopods. Shimodaira-Hasegawa tests of alternative hypotheses call into question the traditional Diasoma hypothesis, which suggests scaphopods and bivalves are closely related to one another.

The rejection of Diasoma hypothesis is not unexpected, as recent work on shell ontogeny and expression of the gene engrailed does not have a bilobed shell during larval development (Wanniger and Haszprunar, 2001). This contradicts the Diasoma hypothesis, which was based upon a bilobed shell as a synapomorphy uniting scaphopods and bivalves (Runnegar and Pojeta, 1974). The presence of potential morphological and developmental synapomorphies joining scaaphopods and cephalopods is not yet apparent. Although Waller suggested a close relationship between scaphopod and bivalves based 


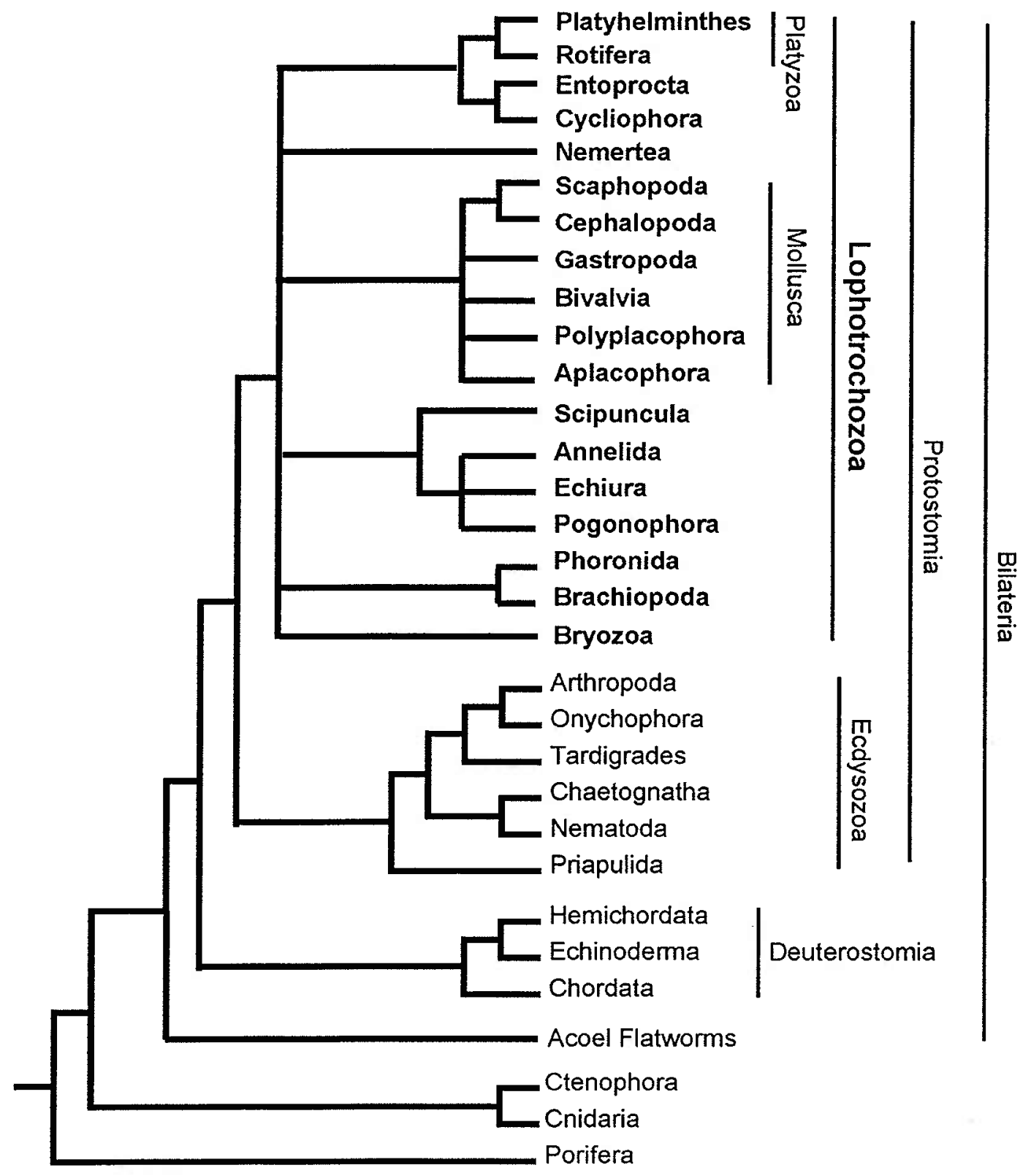

Figure 18: Updated view of metazoan phylogenetics, incorporating relationships among lophotrochozoan phyla identified in the current work. 
upon inferred ancestoral similarities, such characters have been criticized, and excluded form a recent cladistic analysis of the Mollusca (Haszprunar, 2000).

Chapter 3 evaluated the ability of LSU rDNA sequences to provide a more detailed understanding of the evolutionary relationships among lophotrochozoan phyla. Results presented suggest that rotifers and platyhelminthes may branch within the Lophotrochozoa, rather than forming a sister clade. This finding raises intriguing questions regarding the pattern of developmental evolution among metazoans, given earlier work suggesting rotifers and platyhelminthes to have derived from an entoproctlike larva. Although not sampled in the current study, loxosomid entoprocts are of particular interest. Hyman (1951) discussed similarities between the larvae of loxosomid entoprocts and rotifer trochi, including the morphology of the gut, protonephridia and eyes. If the relationship between Entoprocta and Platyzoa presented in Chapter 3 is corroborated using other markers, it would suggest that the Platyzoa may well have had a neotonic origin. Future comparative studies of embryological cell fate and morphological ultractructure may provide valuable insight into potential morphological homologies between theš̀ taxa.

The phylogenetic position of the Bryozoa was of particular interest, given previous work suggesting that they might branch basally to other lophotrochozoans. Analyses of LSU rDNA sequences, presented in Chapter 3, challenge the two dominant evolutionary hypotheses regarding bryozoans, either that they are closely related to brachiopods and phoronids, together forming the Lophophorata, or that they are sister to the spiralian entoprocts. However, identification of a Post 2 class Hox gene from the bryozoan Bugula 
turrita, as described in Chapter 4, provides strong evidence for a close relationship between bryozoans and other lophotrochozoans, upholding the phylogenetic validity of the clade as it was initially defined. These finding are consistent with recent work questioning the homology of the bryozoan tentacles to the lophophore of brachiopods and phoronids (Nielsen and Riisgård, 1998). It is therefore suggested that, to avoid the suggestion of homology, the term "lophophore" be reserved only for the tentacular feeding structure of phronids and brachiopods, and not that of bryozoans.

While the monophyly of the Lophotrochozoa (sensu stricto) is supported by analyses of combined analyses of LSU+SSU rDNA, as well as the presence of the synapomorphic Post2 Hox gene, the author considers the position of the Bryozoa within the Lophotrochozoa an open question. Results from the combined LSU+SSU rDNA analysis suggest that the Bryozoa may have diverged basally to the common ancestor of other lophotrochozoan lineages. This would suggest that bryozoans emerged much earlier than their first appearance in the fossil record during the Ordovician (Lehmann and Hillerman, 1983). This could be due to a period of cryptic evolution prior to the acquisition of a calcified skeleton and/or a colonial life-history. A small unitary and uncalcified bryozoan may have been as yet overlooked in the fossil record from Cambrian deposits. However, the rDNA results are confounded by long branch-lengths, which may well produce artifactual results. As yet, relatively few bryozoans have been sampled for higher-level phylogenetic analyses. The problem of long branch-lengths has previously been overcome in other taxa (e.g. nematodes; Aquinaldo et al., 1997) by employing broad taxanomic sampling to identify species with slower substitution rates. 


\section{Future directions}

It is evident in the updated tree presented in Figure 18 that many evolutionary relationships within the Lophotrochozoa remain uncertain. Although LSU sequence has provided an advance over previous studies using SSU data alone, in that the tree is consistent with morphological data supporting the monophyly of phyla, questions remain. Interphyletic branch lengths in the LSU tree are low, resulting in low bootstrap support for the recovered topology. While hypothesis testing allowed rejection of some competing hypotheses, many alternative trees had likelihood scores that did not differ significantly from that of the optimal tree recovered under an unconstrained analysis. Because of these short branch lengths at the base of the tree it is not expected that sampling of LSU sequences from additional taxa will appreciable improve our understanding of the lophotrochozoan radiation.

Resources would be better focused on identifying and sampling additional molecular markers that can be analyzed independently or in conjunction with rDNA data to improve resolution among lophotrochozoan phyla. A number of potential candidates already have been the focus of limited sampling and warrant further investigation. Mitochondrial genomes appear to provide a valuable source of phylogenetic information regarding distantly related taxa (Boore and Brown, 1998), and may prove a useful tool for investigating lophotrochozoan evolution. Already, studies have provided evidence regarding lophotrochozoan relationships based not only upon phylogenetic analyses of primary sequences data (e.g. Boore and Brown, 2000; Tomita et al., 2002), but also on the basis of similarity in gene arrangement along the mitochondrial genome (e.g. 
Stechmann and Schlegel, 1999). Investigation of mitochondrial genomes from bryozoans, entoprocts and platyzoans will be of particular interest.

Protein coding genes in the nuclear genome represent a large, and as yet poorly sampled, pool of potential molecular markers for phylogenetic reconstruction. Several genes have already demonstrated utility in analyses of metazoan phylogenetics, including intermediate filament proteins (Erber et al., 1998), elongation factor 2 (Regier and Schultz, 2001), and myosin heavy chain type II (Ruiz-Trillo et al., 2002). A broader taxanomic sampling of these genes may provide a valuable avenue for future research.

To date, investigations of higher-level metazoan phylogenetics have been limited by a lack of genes identified as having substitution rates suitable for reconstruction of phylumlevel relationships and the challenge of designing primers, which are functional across a broad range of distantly related taxa. The genes as listed above may provide a fruitful avenue of research in the short-term. With the increasing availability of high throughput sequencing a focus on genome-wide surveys may provide a valuable approach. Genome surveys would allow identification of genes that might otherwise not be easily amplified using degenerate primers, as well as enabling discovery of novel genes that may provide phylogenetic information. Further information may also be present regions of conserved genomic organization, as with mitochondrial genomes. Careful selection of organisms of genomic investigations will be crucial. Ideally, they will have relatively low substitution rates across their genome, maximizing conservation of phylogenetically informative sequence. 


\section{Molecules and morphology}

One aspect of this thesis, and phylogenetics in general, that bears further discussion is the relative merits of molecular and morphological datasets. While the focus of the present work is an investigation of molecular sequences, however, this is not meant to discount the potential importance of morphological and embryological characters. However, one advantage of molecular studies is that they provide an independent source of data that have the potential to identify cases of convergent morphologies which might otherwise be considered homologous (e.g. Wray, 1996).

In analyses of lophotrochozoan rDNA genes in Chapter 3 it was stated that the LSU data were superior to the SSU data in that they recovered the monophyly of many taxa considered to belong to the same phyla. The reasoning presented may seem somewhat circular, with LSU being preferred as it more closely fits a priori hypotheses. It is the author's opinion that the greatest confidence in phylogenetic relationships arises when independent datasets produce concordant results. The fact that the LSU results are more consistent with morphological hypothesis than are SSU analyses represents just such a case.

One are of potential conflict between molecular and morphological characters among lophotrochozoans is the evolution of cleavage pattern. Many lophotrochozoans are characterized by a pattern of spiral cleavage that appears to be homologous (Valentine, 1997; Henry, 2002). Based upon morphological analyses Peterson and Eernissee (2001) have suggested that the Spiralia represent a monophyletic clade within the Lophotrochozoa. However, results presented in Chapter 3 suggest that brachiopods and 
phoronids may branch among spiralian taxa such as annelids and mollusks. Peterson and Eernissee (2001) regard the possibility that radial cleavage in brachiopods and phoronids is secondarily derived from a spiral ancestor, rather than homologous to radial cleavage in non-lophotrochozoans "dubious". Given the variation in cleavage patterns among spiralians, including the effect of high yolk content on cleavage pattern in taxa such as cephalopods, it does not seem implausible to the author that a radial cleavage pattern could have been derived from an ancestor with spiral cleavage. Additional molecular phylogenetic evidence regarding the evolutionary relationship between spiralians and brachiopods and phoronids may provide valuable insight into the evolution of cleavage pattern.

\section{Final thoughts}

The results presented here provide new insights into our understanding of metazoan evolution. However, many questions remain regarding the evolution of the Lophotrochozoa remain. It is hoped that the current work will motivate future investigations to refine our understanding of the evolutionary patterns which underlie the diversification of this fascinating group of organisms. 


\title{
Appendix
}

\section{A brief review of metazoan phylogeny and future prospects in Hox-research}

\author{
Reprinted with permission from Integrative and Comparative Biology \\ (formerly American Zoologist)
}


AMER. ZOOL., 41:629-639 (2001)

\title{
A Brief Review of Metazoan Phylogeny and Future Prospects in Hox-Research ${ }^{1}$
}

\author{
Kenneth M. HalanyCh ${ }^{2}$ and Yale PassamaneCK ${ }^{3}$ \\ Woods Hole Oceanographic Institution, Biology Department MS 33, Woods Hole, Massachusetts 02543
}

\begin{abstract}
SYNOPSIS. Underlying any analysis on the evolution of development is a phylogenetic framework, whether explicitly stated or implied. As such, differing views on phylogenetic relationships lead to variable interpretations of how developmental mechanisms have changed through time. Over the past decade, many long-standing hypotheses about animal evolution have been questioned causing substantial changes in the assumed phylogenetic framework underlying comparative developmental studies. Current hypotheses about early metazoan history suggest that three, not two, major lineages of bilateral animals originated in the Precambrian: the Deuterostomes (e.g., seastars, acorn worms, and vertebrates), the Ecdysozoans (e.g., nematodes and arthropods), and the Lophotrochozoans (e.g., annelids, mollusks, and lophophorates). Although information in Hox-genes bears directly on our understanding of early metazoan evolution and the formation of body plans, research effort has been focused primarily on two taxa, insects and vertebrates. By sampling a greater diversity of metazoan taxa and taking advantage of biotechnological advances in genomics, we will not only learn more about metazoan phylogeny, but will also gain valuable insight as to the key evolutionary forces that established and maintained metazoan bauplans.
\end{abstract}

Approximately 35 fundamentally different body plans (or "phyla") are recognized among extant metazoans. Understanding how, when, and why metazoan body plans diversified have been longstanding and challenging questions for biologists. "EvoDevo" research (or research on the evolution of developmental mechanisms) seeks to integrate our understanding of evolutionary history with the observed variation in developmental patterns and mechanisms to help answer some of these questions. Because of their role in regionalization and fate specification along the anteroposterior axis (Akam, 1995) and their ability to cause homeotic mutations (Lawrence, 1992; Gehring, 1994), Hox genes have been a central focus of developmental research examining patterns of body plan formation (e.g., Akam, 1995; Carroll, 1994, 1995; Davidson et al., 1995; Degnan and Morse, 1993; Holland, 1998). These genes are he-

\footnotetext{
' From the Symposium HOX Clusters and the Evolution of Morphology presented at the Annual Meeting of the Society for Integrative and Comparative Biolo-

gy, 4-8 January 2000 at Atlanta, Georgia.

2E-mail: khalanych@whoi.edu

3.E-mail: yale@whoi.edu
}

lix-turn-helix transcription factors that act on downstream gene cascades. They are linked in a cluster(s) along chromosomes and are arranged and expressed in a colinear fashion. Generally, genes that are the most similar are next to each other. The Hox gene cluster has been examined (to some extent) in a wide range of metazoans (from sponges to arthropods to vertebrates; e.g., Kaufman et al., 1990; Akam et al., 1994; Degnan et al., 1995; Holland and Garcia-Fernandez, 1996; Popadic et al., 1998). Within non-chordate metazoans, a single Hox cluster is known to range in size from the 3 gene $12 \mathrm{~Kb}$ cluster in cnidarians (Finnerty and Martindale, 2001) to the 10 gene . $500 \mathrm{~Kb}$ cluster in the sea urchin Strongylocentrotus purpuratus (Martinez et al., 1999). In comparison, the Hox cluster in $C$. elegans appears highly modified, as it contains only 6 Hox genes with an inversion, and $D$. melanogaster's cluster contains a large intergenic region (de Rosa et al., 1999).

The purpose of this communication is to provide a phylogenetic context to developmental patterns observed across major metazoan lineages, and to highlight, from 
the evolutionary perspective, future directions of evo-devo study. To this end, we will first review the current understanding of metazoan phylogeny helping to clarify the comparative framework for studies across major metazoan lineages. Then, the sampling of Hox-related genes will be discussed in relation to this framework. In particular, of the three great bilaterian clades, Lophotrochozoans encompass the greatest diversity of metazoan body plans, but have received the least research effort focused on developmental issues. We argue that model systems should be developed in annelids and/or mollusks to develop a more accurate understanding of the evolution of body plans.

\section{Metaozoan Phylogeny}

The first formal phylogeny of the Metazoa, and the origin of the term "phylogeny" itself, was published by Haeckel in 1866. Subsequent phylogenetic hypotheses were also based on the comparative morphological and developmental work of invertebrate biologists. In particular, Libbie Hyman's (1940-1967) influence on metazoan systematics cannot be understated. Phylogenetic hypotheses in many modern Invertebrate texts (e.g., Brusca and Brusca, 1990; Meglitsch and Schram, 1991) clearly echo ideas from her 1940 diagram (her Fig. 5. Vol. 1, p. 38). Interestingly, on the same pages as her "hypothetical diagram of the relationships of the phyla," Hyman states that she will "attempt to arrange the phyla in general according to their grade of construction while at the same time avoiding the separation of allied phyla" (p. 39). It is ironic that this researcher, who laid an important corner stone of invertebrate phylogeny, emphasized "grade[s] of construction" (or complexity) over evolutionary history. However, in her defense, Hyman stated her diagram was meant to be a convenient tool and not a rigorous phylogenetic hypothesis.

This emphasis on complexity has lead to delineations within the metazoans based on mesodermal features. The presence/absence of mesoderm is used to distinguish between diploblasts and triploblasts. How the mesoderm is arranged internally to form body cavities or coeloms (i.e., acoel, pseudocoel, schizocoel and enterocoel) was used to divide triploblasts into major lineages (acoels, aschelminths, protostomes and deuterostomes, respectively). Thus, as Figure 1 portrays, metazoan phylogeny has classically been thought to progress from less complex to more complex (body) forms. However, traditional assumptions that complexity has increased over the course of metazoan evolution (sensu Hyman, 1940) have recently been called into question (McShea, 1996, 1998). (Willmer [1990] provides a good review of hypotheses based on complexity.)

Following Hyman, the advent of SEM and TEM provided a suite of ultrastructural characters that were utilized in comparative studies. By hypothesizing homology between ultrastructural features from different taxa, workers were able to glean a novel understanding of metazoan relationships (e.g., Barnes, 1985; Nielsen, 1985, 1987). Ultrastructural information also lead to revisions in our understanding about the evolutionary plasticity of morphology. For example, Ruppert (1991) draws on data from microscopy studies and asserts that body cavity types are more evolutionarily labile than previously believed.

The introduction of cladistics methods (Hennig, 1966), nucletoide sequencing, and computers provided powerful new tools, and marked the beginning of a new era of more rigorous phylogenetic investigation. Figure 2 shows a revised view of evolutionary relationships among major groups of metazoans. Sponges and diploblasts (cnidarians and ctenophures) are basal to the triploblastic metazoans (e.g., Eernisse et al., 1992; Eernisse, 1997; Aguinaldo et al., 1997; Aguinaldo and Lake, 1998; Winnipenninckx et al., 1998b; Kim et al., 1999). When taken together, the two triploblast "superclades" Ecdysozoa (Aguinaldo et al., 1997) and Lophotrochozoa (Halanych et al., 1995) are usually referred to as the Protostomia (e.g., Aguinaldo and Lake, 1998). The Deuterostomia consists of only three recognized "phyla" (chordates, hemichordates and echinoderms). Most major rearrangements in our understanding of metazoan phylogeny were initially based on 18S rDNA data. Criticisms of this particular 


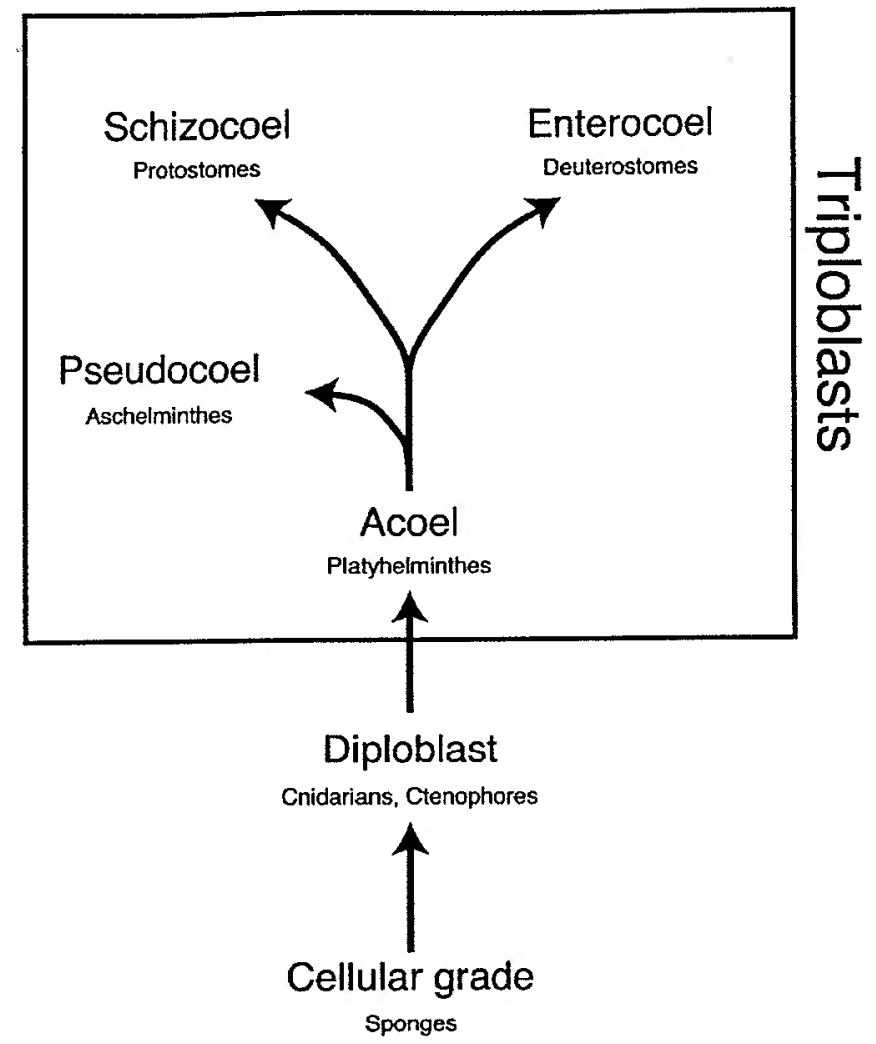

FIG. 1. Traditional concept of the evolution of complexity. Metazoan classification and assumptions about phylogeny have been largely shaped by this hypothesized progression from "simple" to "complex" which is formulated mainly on mesodermal patterns. Examples of taxa typically associated with each category are shown. Current understanding of metazoan phylogeny suggests the triploblast categories are environmental, not phylogenetic, in nature.

marker (Phillipe et al., 1994; Maley and Marshall, 1997; Abouief et al., 1998) have largely been muted as independent data have confirmed the $18 \mathrm{~S}$ based findings. In particular, phylogenetic inference based on Hox gene orthologs (de Rosa et al., 1999) and mitochondrial gene rearrangement data (e.g., Boore and Brown, 1998; Boore, 1999; Stechmann and Schlegel, 1999) support the Ecdysozoan and Lophotrochozoan superclades.

Based on 18S rDNA data, Aguinaldo et al. (1997) were the first to hypothesize that the pseudocoelomate nematodes are closely related to the arthropods in a monophyletic clade termed the Ecdysozoa. The name Ecdysozoa means "molting animal," in ref- erence to the fact that all the organisms Aquinaldo et al. (1997) identified as being within the clade undergo ecdysis. Further support for the ecdysozoan hypothesis has been provided by the identification of clade-specific Hox paralog groups (de Rosa et al., 1999), and recent evidence of a characteristic triplicate repeat in the b-Thymosin homologues of arthropods and nematodes (Manuel et al., 2000).

Other organisms placed in the Ecdysozoa include kinorhynchs, priapulids, nematomorphs, onychophorans and tardigrades (Aguinaldo et al., 1997). Because chaetognaths appear to be allied to nematodes (Halanych, 1996), they are also presumably ecdysozoans. Although ecdysis has not 


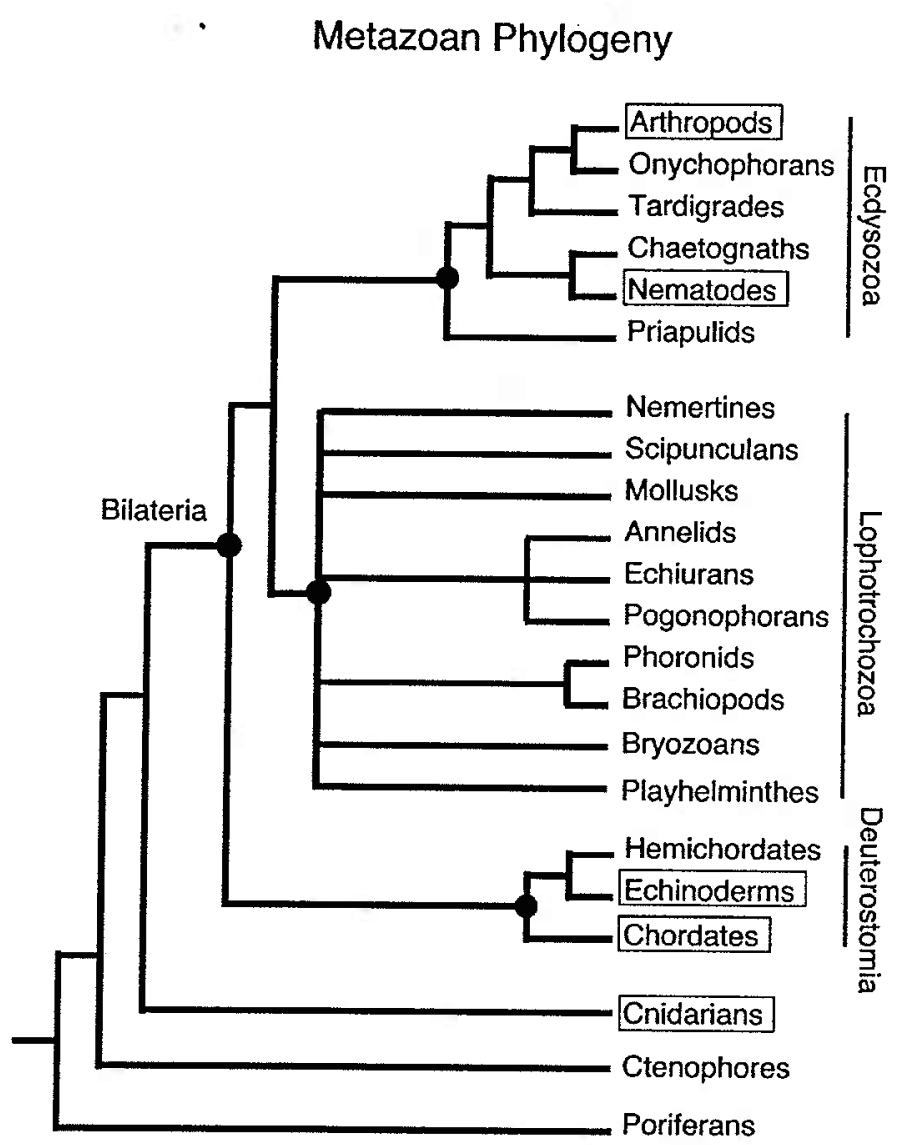

FIo. 2. Current understanding of metazoan phylogeny. Drawing on information from several different sources (e.g., Eernisse et al., 1992; Halanych et al., 1995; Aguinaldo et al., 1997; Eernisse, 1997; de Rosa et al., 1999; see text for additional references), this topology represents a consensus illustrating the relationships between major metazoan taxa. Many lesser-known "phyla" (e.g., gastrotrichs, acanthocephalans, placozoans, nematomorphs, etc.) were not included for simplicity or because their phylogenetic affinities are not clear. Taxa in which the Hox cluster has been completely sequenced are boxed. The echinoderm and cnidarian projects are currently underway. A genome project has just been initiated for a flatworm, but since it is not clear when the Hox cluster will be sequenced, it is not boxed here. Also echiurids and pogonophorans are within the annelids (shown separate for simplicity). See text for details.

been reported in chaetognaths, its occurrence in all other members of the Ecdysozoa suggests that this feature was present in the last common ancestor of the clade (Aguinaldo et al., 1997), and predicts that conserved ecdysis mechanisms may be found. Further investigation is necessary to determine whether the cuticle and process of ecdysis are in fact homologous across the Ecdysozoa.

The Ecdysozoa hypothesis has important ramifications, as it means two model organ- isms (Drosophila and Caenorhabditis) are more closely related than previously believed. The traditional view of metazoan evolution, which placed the less complex pseudocoelomate nematodes basal to the protostome/deuterostome split, suggested that developmental features common to Caenorhabditis and Drosophila were likely present in the common coelomate ancestor allowing extrapolation to other coelomates (most notably Homo sapiens). However, commonalities between these model organ- 
isms must now be interpreted with more caution as they may have arisen following the divergence of the Ecdysozoa.

Analysis of $18 \mathrm{~S}$ rDNA sequences has also led to the grouping of the lophophorates (brachiopods, bryozoans, and phoronids) with annelids and molluscs in a clade termed the Lophotrochozoa (Halanych et al., 1995). Earlier analyses (Field et al., 1988; Ghiselin, 1988; Lake, 1990) employing only a single partial brachiopod sequence also hinted at this association. The phylogenetic position of lophophorates has been a matter of some debate, with differing interpretations of developmental and morphological traits leading to their assignment as protostomes (Gutmann et al., 1978), deuterostomes (Zimmer, 1973), intermediates between the two groups (Salvini-Plawen, 1982; Siewing, 1976, 1980), or an independent radiation (Willmer, 1990). However, their placement as derived protostomes reveals that embryological features (blastopore fate, type of eucoelom formation, cleavage patterns, larval type) are more evolutionarily labile than traditionally believed (Halanych et al., 1995; Valentine, 1997; also see Halanych, 1996).

The lophotrochozoan clade (defined as all the descendents of the last common ancestor of lophophorates, mollusks, and annelids) is more inclusive than originally suspected. (It should be noted that the terms Eutrochozoa [sensu Gheslin, 1988] and Spiralia, sensu stricto, are less inclusive than Lophotrochozoa, and the terms should not be confused.) Sipunculids have been associated with both mollusks (Scheltema, 1993) and annelids (Boore and Staton, 2001), and echiurids and pogonophorans appear to be annelids (McHugh, 1997; Halanych et al., 1998). Mackey et al.'s (1996) report suggests that the pseudocoelomate entoprocts are lophotrochozoans. The nemerteans are also members of the clade, given associations in $18 \mathrm{~S}$ rDNA topologies (Turbeville et al., 1992). Hox evidence has also placed dicyemid mesozoans (Kobayashi et al., 1999) in the clade. Molecular studies have also provided evidence for the inclusion of platyhelminthes within the Lophotrochozoa. The platyhelminth flatworms were traditionally considered to be basal tri- ploblasts because they had no coelom (Hyman, 1951; reviewed in Willmer, 1990). Analysis of both $18 \mathrm{rDNA}$ and Hox genes (Balavoine and Telford, 1995; Balavoine, 1997) suggest that some platyhelminthes are members of the Lophotrochozoan clade which have undergone secondary simplification (Balavoine, 1998). Recent analysis has also suggested that platyhelminthes may be polyphyletic and that the acoels may be basal bilaterians (Carranza et al., 1997; Ruiz-Trillo et al., 1999; see also Eernisse, 1997), but it is likely that the acoel finding is an artifact of long-branch attraction (hinted at in Campos et al., 1998, Berney et al., 2000). Lastly, Garey and Schmidt-Rhaesa (1998) have proposed that a clade consisting of platyhelminthes, gnathostomulids, rotifers, and acanthocephalans (and probably cycliophorans-Winnepenninckx et al., 1998a) is sister to the Lophotrochozoa. Although based on their relative position to bryozoans (which has yet to be determined), these taxa might be within the Lophotrochozoa. In comparison, Eernisse (1997) finds many of these groups, as well as gastrotrichs, are placed as basal bilaterians. Clearly, the status of several traditional "aschelminthes" groups awaits further confirmation.

de Rosa et al. (1999) have found that all presumptive Lophotrochozoans surveyed (annelids, molluscs, brachiopods, platyhelminthes, and nemerteans) possess a set of medial and posterior Hox genes not present in either Ecdysozoans or Deuterostomes. The homeodomains of these Hox genes (Lox5, Lox2, Lox4, Post1, and Post2) possess diagnostic peptide motifs which have been conserved throughout the members of the clade. Comparatively ecdysozoans contain 2 diagnostic Hox genes ( $U b x$ and $A b d$ $B)$. However, Telford (2000) argues that others have over interpreted the diagnostic "signatures" of some Hox genes, and that unique amino acid motifs should be treated as unpolarized characters, rather than synapomorphies, when an outgroup is lacking. Such diagnostic features provide a powerful tool for examination of taxonomic inclusion of these major clades.

In contrast to the Lophotrochozoans, the deuterostomes have been shrinking. Into the 
early 1990s most researchers and evidence suggested that the deuterostomes were composed of chordates, hemichordates, echinoderms, chaetognaths, and lophophorates (although most placed the lophophorates as basal to the true deuterostomes; Willmer, 1990). The placement of the lophophorates has already been discussed above. Chaetognaths, commonly called arrow worms, were considered deuterostomes based on their tripartite coelom and the retention of the blastopore to form the anus. However, two independent 18S rDNA studies (Telford and Holland, 1993; Wada and Satoh, 1994) showed that chaetognaths were not closely related to other deuterostome taxa suggesting that coelomic patterns and blastopore fate are not representative of the relationships of major metazoan lineages (Halanych, 1996). Nielsen's (1995) hypothesis of deuterostome affinities for the ctenophores is inconsistent with available data (Eernisse et al., 1992; Schram, 1991; Eernisse, 1997; Kim et al., 1997; Winnepenninckx et al., 1998b).

Of the three recognized deuterstome phyla, echinoderms and hemichordates appear to be the most closely related (Turbeville et al., 1994; Cameron et al., 2000). Metschnikoff (1881) termed an echinoderm-hemichordate group the Ambulacraria drawing attention to similar features in the larvae (Halanych, 1995). Swalla and her collegues (2000) have recently examined chordate origins. Their report that urochordates are comprised of 4 discrete lineages holds interesting implications for understanding the evolution of tadpole morphology and chordate life history.

\section{Surveying the Hox Cluster}

Two aspect of Hox genes have peaked the interest of phylogeneticists. First, their conservative nature holds information on phylogenetic relationships among major metazoan groups. Although earlier workers alluded to this potential (Ruddle et al., 1994; Dick, 1997), it was not until more recently that researchers began to exploit this information (e.g., Balavoine and Telford, 1995; Balavoine, 1997; Grenier et al., 1997; de Rosa et al., 1999; Anderson et al., 1999; Kobyashi et al., 1999). Secondly, since the discovery that Hox genes cause homeotic mutations, there has been a hope that Hox genes may provide information on how and why metazoan body plans diversify. Earlier work (e.g., Lawrence, 1992; Gehring, 1994) focused on homeotic mutations and mainly compared wildtype to mutated individuals. With the development of molecular and phylogenetic methods, comparative studies were undertaken comparing Hox expression across lineages in a phylogenetic framework. Unfortunately, most of this comparative work has focused on a selective group of taxa (e.g., vertebrates-Holland and Garcia-Fernandez, 1996, and arthropods, esp. insects-Carroll, 1994, 1995; Akam et al., 1994; Akam, 1995, 1998).

In Figure 2, the taxa for which the Hox cluster has been sequenced are boxed. Because of genome projects, the cluster information will be available for Drosophila, Caenorhabditis and several chordates. Current work on the Hox clusters of the cnidarian Nematostella vectensis (Finnetry and Martindale, 1997, 2001) and the sea urchin Strongylocentrotus purpuratus (Martinez et al., 1999) should also soon be available. Therefore, physical maps and cis-acting regulatory elements that are in close proximity to the cluster will be known for representatives of the Ecdysozoa, Deuterostomes, and Diploblasts.

With little doubt the study of developmental mechanisms has received far less attention in Lophotrochozoans than in Ecdysozoans and Deuterostomes. Most Lophotrochozoan Hox studies have been limited to PCR surveys for genes (e.g., Webster and Mansour, 1992; Dick and Buss, 1994; Balavoine and Telford, 1995; Irvine et al., 1997; Kmita-Cunisse et al., 1998; de Rosa et al., 1999) and, to the best of the our knowledge and with the exception of leeches, few studies have actually examined Hox gene expression patterns in lophotrochozoans (e.g., flatworms-Bayascas et al., 1997; polychaete-Irvine and Martindale, 2000). Note studies by Bayascas et al. (1998) and Degnan and Morse (1993) of RNA transcription levels in flatworms and gastropods, respectively, did not examine the patterns of expression in the organism. 


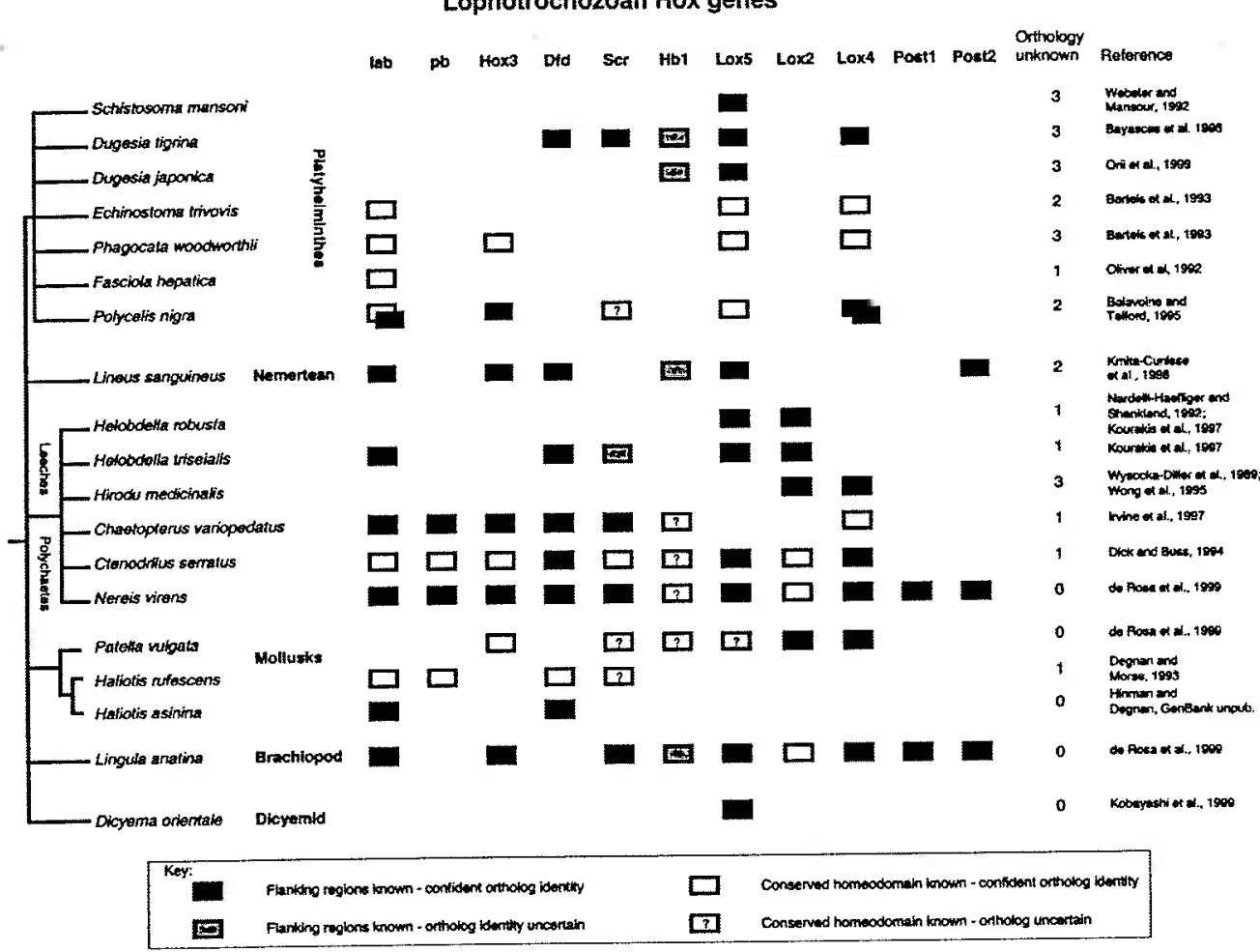

Fig. 3. Compilation of published Lophotrochozoan Hox gene sequences in GenBank as of February 2001. Boxes representing each sequence are aligned under their orthology group. Each sequence is coded according to whether regions flanking the homeodomain are known and whether assignment of orthology is confident. Numbers of homeodomain sequences published, but of unknown orthology, are also listed, though not represented graphically.

Some information has been gathered on the expression of transcription factors associated with segmentation and regeneration in oligochaete annelids (Bely and Wray, 2000). Shankland's group has done excellent work on exploring leech development (e.g., Nardelli-Haeflinger and Shankland, 1992; Nardelli-Haeflinger et al., 1994; Kourakis et al., 1997; Shankland and Bruce, 1998), but Irvine and Martindale (2000) point out some of the shortcomings of leeches as a model for other Lophotrochozoans (including direct development and "missing" Hox orthologs). Our knowledge on the mechanics of how Hox genes aid pattern formation of Lophotrochozoan organisms is in its infancy.

Of interest, NIH and the World Health Organization (WHO) have recently begun genome projects on Schistosoma japonica, and $S$. mansoni. Although Schistosoma Hox genes have been the focus of previous research (Webster and Mansour, 1992), it is not clear if Schistosoma will be representative of the Lophotrochozoa. Currently, platyhelminth evolution is in question; the monophyly, origins, and phylogeny of the group are hotly debated (Balavoine and Telford, 1995: Balavoine, 1997; Campos et al., 1998; Carranza et al., 1996, 1997; RuizTrillo et al., 1999; Berney et al., 2000).

Figure 3 summarizes all available information (i.e., sequences in GenBank as of February 2001) for Hox genes in Lophotrochozoans. Although the information is presented in a manner similar to standard Hox cluster illustrations for Drosophila or chordates, no gene mapping information exists 
for lophotrochozoan Hox clusters. Furthermore, the presence of genes was determined by either PCR screening with degenerate homeobox primers or by screening cDNA libraries. Thus, the spatial arrangement of the genes is merely speculation inferred from other organisms. The information in Figure 3 suggests that the ancestral lophotrochozoan Hox cluster probably consisted of at least 8-10 genes (de Rosa et al., 1999; Irvine and Martindale, 2000). The polychaete Nereis virens, perhaps the most thoroughly surveyed Lophotrochozoan, contains at least 11 Hox genes. Although we know some of the genes in the cluster, we do not know their arrangement, cis-acting regulatory elements, and if additional genes and/or clusters are present.

Gellon and McGinnis (1998) reviewed Hox transcription mechanisms and concluded that "evolutionary variation of Hox cisregulatory elements has played a major role in the emergence of novel body plans." For example, fly Hox genes share few regulatory regions in comparison to the mouse, where sharing of regulatory elements could help explain conservation of the cluster. Because the unsampled lophotrochozoan taxa have the most diversity in terms of body plans, the group will provide a powerful test of Gellon and McGinnis's hypothesis about the role of regulatory elements in body-plan diversi Ecation.

\section{FutURE RESEARCH}

In order to gain a more complete understanding of the evolution of the Hox cluster, future research must begin to employ genomic approaches and must incorporate a greater diversity of organisms. Most Hox genes have been identified using either PCR-based surveys or cDNA library screens coupled with comparisons of sequence similarity. Thus, little positional information or information on cis-acting regulatory elements is retrieved. Biotechnological advances have now made sequencing the entire Hox cluster possible even for smaller laboratories (as opposed to major genome centers), and developments in microarray technology will facilitate examination of timing and levels of expression for several genes simultaneously (initially this will only be feasible in model organisms). The combination of sequencing and microarray technology will open up a new realm of experimental studies that not only explore the evolution of the open-reading frame, but the evolution of the entire gene system (ORF, regulatory element, recognition sites, pleiotropic effects, etc.).

Lastly, to understand the evolution of the cluster and how it has shaped body plan evolution, more studies comparing Hox data across taxa must be undertaken. The comparative framework for such studies is phylogeny. However, at present most Hox studies focus on a single species with evolutionary considerations relegated to comparisons to previously published reports. A more desirable and objective approach is to examine multiple species in a single study and then use explicit methods to test alternative hypotheses (e.g., likelihood tests, Huelsenbeck and Rannala, 1997). Such an approach would also provide a context for determining which hypotheses are significantly better than alternatives. As mentioned above, phylogentic representation of Hox genes has been biased with Lophotrochozoans receiving little attention despite having the greatest diversity of recognized body plans. The use of explicit methods for evolutionary comparisons forces us to consider the most appropriate taxa, not just which taxa were most convenient, for the question being addressed.

\section{ACKNOWLEDGMENTS}

The authors wish to thank the efforts and time of the symposium organizers, Jeff Ram and Billie Swalla. Helpful comments from two anonymous reviewers are gratefully acknowledged. Support from The Richard B. Sellars Endowed Research Fund and The Andrew W. Mellon Foundation Endowed Fund for Innovative Research was kindly provided. This work is contribution number 10441 to Woods Hole Oceanographic Institution.

\section{REFERENCES}

Abouheif, E., R. Zardoya, and A. Meyer. 1998. Limitations of metazoan 18S rRNA sequence data: Implications for reconstructing a phylogeny of the 
animal kingdom and inferring the reality of the Cambrian explosion. J. Mol. Evol. 47:394- 405.

Aguinaldo, A. M. A. and J. A. Lake. 1998. Evolution of multicellular animals. Amer. Zool. 38:878-887.

Aguinaldo, A. M. A., J. M. Turbeville, L. S. Linford, M. C. Rivera, J. R. Garey, R. A. Raff, and J. A. Lake. 1997. Evidence for a clade of nematodes, arthropods and other moulting animals. Nature 387:489- 493 .

Akam, M. 1995. Hox genes and the evolution of diverse body plans. Phil. Trans. R. Soc. London B 349:313-319.

Akam, M. 1998. Hox genes in arthropod development and evolution. Biol. Bull. 195:373-374.

Akam, M., M. Averof, J. Castelli-Gair, R. Dawes, F Falciani, and D. Ferrier. 1994. The evolving role of Hox genes in arthropods. Development 1994 Suppl.:209-215

Anderson, C. I. and E. U. Canning. 1998. A triplobast origin for Myxozoa? Nature 392:346-347.

Balavoine, G. 1997. The early emergence of platyhelminths is contradicted by the agreement between 18S rRNA and Hox genes data. C. R. Acad. Sci. 320:83-94.

Balavoine, G. 1998. Are platyhelminthes coelomates without a coelom? An argument based on evolution of Hox genes. Amer. Zool. 38:843-858.

Balavoine, G. and M. J. Telford. 1995. Identfication of planarian homeobox sequences indicates the antiquity of most Hox/homeotic gene subclasses. Proc. Natl. Acad. Sci. U.S.A. 92:7227-7231.

Barnes, R. D. 1985. Current perspectives on lower invertebrates. In S. Conway Morris, J. D. George, R. Gibson, and H. M. Platt (eds.), The origins and relationships of lower invertebrates, pp. 361-367. Clarendon Press, Oxford.

Bartels, J. L., M. T. Murtha, and F. H. Ruddle. 1993 Multiple Hox/HOM-class homeoboxes in platyhelminthes. Mol. Phylogen. Evol. 2:143-151.

Bayascas, J. R., E. Castillo, A. M. Munoz-Marmol, and E. Salo. 1997. Planarian Hox genes: Novel patterns of expression during regeneration. Development 124: 141-148.

Bayascas, J. R., E. Castillo, and E. Salor 1998. Platyhelminthes have a Hox code differentially activated auring regeneration, with genes closely related to those of spiralian protostomes. Dev. Genes Evol. 208:467-473.

Bely, A. E. and G. A. Wray. 2000. Expresion of homeobox genes during regeneration and asexual reproduction in an annelid. Amer. Zool. 39:Abstract 65.

Berney, C., J. Pawlowski, and L. Zaninetti. 2000 Elongation factor 1 -alpha sequences do not support an early divergence of the Acoela. Mol Biol Evol. 17:1032-1039.

Boore, J. L. 1999. Animal mitochondrial genomes. Nucl. Acid. Res. 27:1767-1780.

Boore, J. L. and W. M. Brown. 1998. Big trees from little genomes; mitochondrial gene order as a phylogenetic tool. Curr. Opin. Gen. and Dev. 8:668674.

Boore, J. L. and J. L. Staton. 2001. The mitochondrial genome of the sipunculid Phascolopsis gouldii supports its association with Annelida rather than Mollusca. Mol. Biol. Evol. (In press)

Brusca, R. C. and G. J. Brusca. 1990. Invertebrates. Sinauer Associates, Inc., Sunderland, Massachusetts.

Cameron, C. B., J. R. Garey, and B. J. Swalla. 2000. Evolution of the chordate body plan: New insights from phylogenetic analyses of deuterostome phyla. Proc. Nat. Acad. Sci. U.S.A. 97:4469-4474.

Campos, A., M. P. Cummings, J. L. Reyes, and J. P. Laclette. 1998. Phylogenetic relationships of platyhelminthes based on $18 \mathrm{~S}$ ribosomal gene sequences. Mol. Phylogen. Evol. 10:1-10.

Carranza, G., G. Giribet, C. Ribera, J. Baguna, and M. Riutort. 1996. Evidence that two types of $18 \mathrm{~S}$ rDNA coexist in the genome of Dugesia (Schmidtea) mediterranea (Platyhelminthes, Turbellaria, Tricladida). Mol. Biol. Evol. 13:824-832.

Carranza, S. J. Bagurfa and M. Riutort. 1997. Are the Platyhelminthes a monophyletic primitive group? An assessment using 18S rDNA sequences. Mol. Biol. Evol. 14:485- 497 .

Carroll, S. B. 1994. Developmental regulatory mechanisms in the evolution of insect diversity. Development 1994 Suppl.:217-223.

Carroll, S. B. 1995. Homeotic genes and the evolution of arthropods and chordates. Nature 376:479- 485 .

Davidson, E. H., K. J. Peterson, and R. A. Cameron. 1995. Origin of bilaterian body plans: evolution of developmental regulatory mechanisms. Science 270:1319-1325

Degnan, B. M. and D. E. Morse. 1993. Identification of eight homeobox containing transcripts expressed during larval development and at metamorphosis in the gastropod mollusc Haliotis rufescens. Mol. Mar. Biol. Biotech. 2:1-9.

Degnan, B. M., S. M. Degnan, A. Giusti, and D. E. Morse. 1995. A hox/hom homeobox gene in sponges. Gene 155:175-177.

de Rosa, R., J. K. Grenier, T. Andreeva, C. E. Cook, A. Adoutte, M. Akam, S. B. Carroll, and G. Balavoine. 1999. HOX genes in brachiopods and priapulids and protostome evolution. Nature 399: $772-776$.

Dick, M. H. 1997. Hox genes and annelid-arthropod relationships. In R. A. Fortey and R. H. Thomas (eds.), Arthropod relationships, pp. 35-41. Chapman and Hall, London.

Dick, M. H. and L. W. Buss. 1994. A PCR-based survey of homeobox genes in Ctenodrilus serratus (Annelida: Polychaeta). Mol. Phy. Evol. 3:146158.

Eernisse, D. J. 1997. Arthropod and annelid relationships re-examined. In R. A. Fortey and R. H. Thomas (eds.), Arthropod relationships, pp. 4356. Chapman and Hall, London.

Eernisse, D. J., J. S. Albert, and F. E. Anderson. 1992. Annelida and Arthropoda are not sister taxa: A phylogenetic analysis of spiralian metazoan phylogeny. Syst. Biol. 41:305-330.

Field, K. G., G. J. Olsen, D. J. Lane, S. J. Giovannoni, M. T. Ghiselin, E. C. Raff, N. R. Pace, and R. A. Raff. 1988. Molecular phylogeny of the animal kingdom. Science 239:748-753. 
Finnerty, J, R. and M. Q. Martindale. 1997. Homeoboxes in sea anemones (Cnidaria:Anthozoa): A PCR-based survey of Nematostella vectensis and Metridium senile. Biol. Bull. 193:62-76.

Finnerty J. R. 2001. Cnidarians reveal intermediate stage in the evolution of Hox clusters and axial complexity. Amer. Zool. 41:608-620.

Garey, J. R. and A. Schmidt-Rhaesa. 1998. The essential role of "minor" phyla in molecular studies of animal evolution. Amer. Zool. 38:907-917.

Gehring, W. J. 1994. A history of the homeobox. In D. Duboule (ed.), Guidebook to the homeobox genes, pp. 3-10. Oxford University Press, Oxford.

Gellon, G. and W. McGinnis. 1998. Shaping animal body plans in development and evolution by modulation of Hox expression patterns. BioEssays 20: 116-125.

Ghișelin, M. T. 1988. The origin of molluscs in the light of molecular evidence. Oxford Surv. Evol. Biol. 5:66-95.

Grenier, J. K., T. L. Garber, R. Warren, P. M. Whitington, and S. Carroll. 1997. Evolution of the entire arthropod Hox gene set predated the origin and radiation of the onychophoran/arthropod clade. Curr. Biol. 1997:547-553.

Gutmann, W. F., K. Vogel, and H. Zorn. 1978. Brachiopods: Biomechanical interdependances governing their origin and phylogeny. Science 199: 890-893.

Haeckel, E. 1866. Generelle Morphologie der Organismen: Allgemeine Grundzuge der organischen Formen-Wissenschaft, mechanisch begrundet durch die von Charles Darwin reformirte Descendenz-Theorie. Georg Riemer, Berlin.

Halanych, K. M. 1995. The phylogenetic position of the pterobranch hemichordates based on $18 \mathrm{~S}$ rDNA sequence data. Mol. Phylogen. Evol. 4:7276.

Halanych, K. M. 1996. Testing hypotheses of chactognath origins: Long branches revealed by $18 \mathrm{~S}$ ribosomal DNA. Syst. Biol. 45:223-246.

Halanych, K. M., J. D. Bacheller, A. M. A. Aguinaldo, S. M. Liva, D. M. Hillis, and J. A. Lake. 1995 Evidence from 18S ribosomal DNA that the 10phophorates are protostome animals. Science 267 1641-1643.

Halanych, K. M., R. A. Lutz, and R. C. Vrijenhoek 1998. Evolutionary origins and age of vestimentiferan tube-worms. Cah. Biol. Mar. 39:355-358.

Hennig, W. 1966. Phylogenetic systematics. English version published by University of Illinois Press, Urbana.

Holland, P. W. H. 1998. Major transitions in animal evolution: A developmental genetic perspective. Amer. Zool. 38:829-842.

Holland, P. W. H. and J. Garcia-Fernąndez. 1996. Hox genes and chordate evolution. Dev. Biol. 173 382-395.

Huelsenbeck, J. P. and B. Rannala. 1997. Phylogenetic methods come of age: Testing hypothesis in a phylogenetic context. Science 276:227-232.

Hyman, L. H. 1940. The invertebrates: Protozoa through Ctenophora, Vol. 1. McGraw-Hill, New York.
Hyman, L. H. 1940-1967. The invertebrates. McGraw-Hill, New York.

Hyman, L. H. 1951. The Invertebrates: Platyhelminths and Rhynchocoela, Vol. 2. McGraw-Hill, New York.

Irvine, S. Q., S. A. Warinner, J. D. Hunter, and M. Q. Martindale. 1997. A survey of homeobox genes in Chaetopterus variopedatus and analysis of polychaete homeodomains. Mol. Phylogen. Evol. 7:331-345.

Irvine, S., and M. Martindale. 2000. Expression patterns of anterior Hox genes in the polychaete Chaetopterus: Correlation with morphological bouderies. Dev. Biol. 217:333-351.

Kaufman, T. C., M. A. Seeger, and G. Olsen. 1990 Molecular and genetic organization of the antennapedia gene complex of Drosophila melanogaster. Adv. Genet. 27:309-62.

Kim, J., W. Kim, and C. W. Cunningham. 1999. A new perspective on lower metazoan relationships form 185 rDNA sequences. Mol. Biol. Evol. 16:423427.

Kmita-Cunisse, M., F. Loosli, J. Bierne, and W. J. Gehring. 1998. Homeobox genes in the ribbonworm Lineus sanguineus: Evolutionary implications. Proc. Natl. Acad. Sci. U.S.A. 95:30303035.

Kobayashi, M., H. Furuya, and P. W. H. Holland. 1999 Dicyemids are higher animals. Nature 401:762.

Kourakis, M. J., V. A. Master, D. K. Lokhorst, D. Nardelli-Haefliger, C. J. Wedeen, M. Q. Martindale, and M. Shankland. 1997. Conserved anterior boundaries of Hox gene expression in the central nervous system of the leech Helobdella. Dev. Biol. 190:284-300.

Lake, J. A. 1990. Origin of Metazoa. Proc. Natl. Acad. Sci. U.S.A. 87:763-766.

Lawrence, P. A. 1992. The making of a fly. Blackwell Scientific Press, London.

Mackey, L. Y., B. Winnepennickx, R. De Wachter, T Beckeljau, P. Emschermann, and J. R. Garey. 1996. 18S rRNA suggests that Entoprocta are protostomes, unrelated to Ectoprocta. J. Mol. Evol. 42:552-559.

Maley, L. E. and C. R. Marshall. 1998. The coming of age of molecular systematics. Science 279:505506.

Manuel, M., M. Kruse, W. E. G. Muller, and Y. Le Parco. 2000. The comparison of ${ }^{\circ}$-Thymosin homologues among Metazoa supports an arthropodnematode clade. J. Mol. Evol. 51:378-381.

Martinez, P., J. P. Rast, C. Arenas-Mena, and E. H. Davidson. 1999. Organization of an echinoderm Hox gene cluster. Proc. Natl. Acad. Sci. U.S.A. 96: 1469-1474.

McHugh, D. 1997. Molecular evidence that echiurans and pogonophorans are derived annelids. Proc. Nat. Acad. Sci. U.S.A. 94:8006-8009

McShea, D. W. 1996. Metazoan complexity and evoIution: Is there a trend? Evolution 50:477-492.

McShea, D. W. 1998. Possible largest-scale trends in organismal evolution: Eight "live hypotheses" Annu. Rev. Ecol. Syst. 29:293-318.

Meglitsch, P. A. and F. R. Schram. 1991. Invertebrate 
zoology. 3rd ed. Oxford University Press, New York.

Metschnikoff, V. E. 1881. Bber die systematische Stellung von Balanoglossus. Zool. Anzeiger 4:139157.

Nardelli-Haefliger, D., A. E. Bruce, and M. Shankland. 1994. An axial domain of HOM/Hox gene expression is formed by morphogenetic alignment of independently specified cell lineages in the leech Helobdella. Development 120:1839- 49.

Nardelli-Haefliger, D. and M. Shankland. 1992. Lox2. a putative leech segment identity gene, is expressed in the same segmental domain in different stem cell lineages. Development 116:697-710.

Nielsen, C. 1985. Animal phylogeny in the light of the trochaea theory. Biol. J. Linn. Soc. 25:243-299.

Nielsen, C. 1987. Structure and function of metazoan ciliary bands and their phylogenetic signifcance. Acta Zool. 68:205-262.

Nielsen, C. 1995. Animal evolution; Interrelationships of the living phyla. Oxford University Press, New York.

Oliver, G., M. Vispo, A. Mailhos, C. Martinez, B. Sosa-Pineda, W. Fielitz, and R. Ehrlich. 1992. Homeoboxes in flatworms. Gene 121:337-342.

Orii, H., K. Kato, Y. Umesono, T. Sakurai, K. Agata, and K. Watanabe. 1999. The planarian HOM/ HOX homeobox genes (Plox) expressed along the anteroposterior axis. Dev. Biol. 210:456-468.

Philippe, H., A. Chenuil, and A. Adouette. 1994. Can the Cambrian explosion be inferred through molecular phylogeny? Development 1994 Suppl.:1525.

Popadic, A., A. Abzhanov, D. Rusch, and T. C. Kaufman. 1998. Understanding the genetic basis of morphological evolution: The role of homeotic genes in the diversification of the arthropod bauplan. Int. J. Dev. Biol. 42:453-61.

Ruddle, F. H., J. L. Bartels, K. L. Bentley, C. Kappen, M. T. Murtha, and J. W. Pendleton. 1994. Evolution of Hox genes. Annu. Rev. Genet. 28:423442 .

Ruiz-Trillo, I., M. Riutort, T. J. Littlewood, E. A. Herniou, and J. Bagurfa. 1999. Acoel flatwoms: Earliest extant bilaterian metazoans, not members of platyhelminthes. Scienze 283:1919-1923.

Ruppert, E. E. 1991 Introduction to the aschelminth phyla: A consideration of mesoderm, body cavities, and cuticle. In F. W. Harrison and E. E. Ruppert (eds.), Microscopic anatomy of invertebrate, Vol. 4, Aschelminthes, pp. $1 \pm 17$. Wiley-Liss, New York.

Salvini-Plawen, L. v. 1982. A paedomorphic origin of the oligomerous animals? Zool. Scripta 11:77-81.

Scheltema, A. 1. H. 1993. Aplacophora as progenetic aculiferans and the coelomate origin of mollusks as the sister taxon of Sipuncula. Biol. Bull. 184: 57-78.

Schram, F. R. 1991 Cladistic analysis of metazoan phyla and the placement of fossil problematica. In A. M. Simonetta and S. Conway-Morris (eds.), The early evolution of Metazoa and the significance of problematic taxa, pp. 35- 46. Cambridge University Press, New York.
Shankland, M., and A. E. Bruce. 1998. Axial patterning in the leech: Developmental mechanisms and evolutionary implications. Biol. Bull. 195:370372.

Siewing, R. 1976. Probleme und neuere Erkentnisse in der Gross-systematik der Wirbellosen. Verhandl. Disch. Zool. Ges. Stuttgart 1976:59-83.

Siewing, R. 1980. Das Archicoelomatenkonzept. Zool Jb. Syst. 103:439- 482 .

Stechmann, A., and M. Schlegel. 1999. Analysis of the complete mitochondrial DNA sequence of the brachiopod Terebratulina retusa places Brachiopoda within the protostomes. Proc. Roy. Soc. London Ser. 266:2043.

Swalla, B. J., C. B. Cameron, L. S. Corley, and J. R. Garey. 2000. Urochordates are monophyletic within the deuterostomes. Syst. Biol. 49:52-64.

Telford, M. J. 2000. Turning Hox "signatures" into synapomorphies. Evol. Devel. 2:360-264.

Telford, M. J. and P. W. H. Holland. 1993. The phylogenetic af AEnitiesof the chaetognaths: A molecular analysis. Mol. Biol. Evol. 10:660- 676.

Turbeville, J. M., J. R. Schulz, and R. A. Raff. 1994 Deuterostome phylogeny and the sister group of the chordates: Evidence from molecules and morphology, Mol. Biol. Evol. 11:648- 655

Turbeville, J. M., K. G. Field, and R. A. Raff. 1992. Phylogenetic position of phylum Nermertini, inferred from 18S rRNA sequences: Molecular dataloggers as a test of morphological character homology. Mol. Biol. Evol. 9:235-249.

Valentine, J. W. 1997. Cleavage patterns and the to pology of the metazoan tree of life. Proc. Nat. Acad. Sci. U.S.A. 94:8001-8005.

Wada, H. and N. Satoh. 1994. Details of the evolutionary history from invertebrates to vertebrates, as deduced from the sequences of $18 \mathrm{~S}$ rDNA. Proc. Nat. Acad. Sci. U.S.A. 91:1801-1804.

Webster P. J. and T. E. Mansour. 1992. Conserved classes of homeodomains in Schistosoma mansoni, an early bilateral metazoan. Mech. Dev. 38:25-32.

Willmer, P. 1990. Invertebrate relationships, patterns in animal evolution. Cambridge University Press, New York.

Winnepenninckx, B. M. H., T. Backeljau, and R. M Kristensen. 1998a. Relations of the new phylum Cycliophora. Nature 393:636 \pm 638 .

Winnepenninckx, B. M. H., Y. Van de Peer, and T Backeljau. 1998b. Metazoan relationships on the basis of 18S sequences: A few years later... Amer. Zool. 38:888-906.

Wong, V. Y., G. O. Aisemberg, W. B. Gan, and E. R Macagno. 1995. The leech homeobox gene Lox 4 may determine segmental differentiation of identified neurons. J. Neurosci. 15:5551-5559.

Wysocka-Diller, J. W., G. O. Aisember, M. Baumgarten, M. Levine, and E. R. Macagno. 1989. Characterization of a homologue of bithorax-complex genes in the leech Hirudo medicinalis. Nature $341: 760-763$

Zimmer, R. L. 1973. Morphological and developmental affinities of the Lophophorates. In G. P. Larwood (ed.), Living and fossil Bryozoa, pp. 593599. Academic Press, New York. 


\section{BIBLIOGRAPHY}

Abouheif E., Akam M., Dickinson W.J., Holland P.W., Meyer A., Patel N.H., Raff R.A., Roth V.L., Wray G.A. (1997) Homology and developmental genes. Trends. Genet. 13:432-433.

Abouheif E., Zardoya R., Meyer A. (1998) Limitations of metazoan 18S rRNA sequence data: Implications for reconstructing a phylogeny of the animal kingdom and inferring the reality of the Cambrian explosion. J Mol Evol. 47:394-405.

Aguinaldo A.M.A., Turbeville J.M., Linford L.S., Rivera M.C., Garey J.R., Raff R.A., Lake J.A. (1997) Evidence for a clade of nematodes, arthropods and other moulting animals. Nature. 387:489-493.

Ahlrichs W.H. (1995) Seison annulatus und Seison nebaliae - Ultrastruktur und Phylogenie. Verh Dtsch Zool Ges. 88:115.

Arendt D., Technau U., Wittbrodt J. (2001) Evolution of the bilaterian larval foregut. Nature. 409:81-5.

Balavoine G. (1996) Identification of members of several homeobox genes in a planarian using a ligation-mediated polymerase chain reaction technique. Nucleic Acids Res. 24:1547-1553.

Balavoine G. (1997) The early emergence of platyhelminths is contradicted by the agreement between 18S rRNA and Hox genes data. C. R. Acad. Sci. 320:83-94.

Balavoine G., Adoutte A. (1998) One or three Cambrian radiations? Science. 280:397398.

Balavoine G., de Rosa R., Adoutte A. (2002) Hox clusters and bilaterian phylogeny: Mol Phyl Evol. 24:366-373.

Boore J.L., Brown W.M. (1998) Big trees from little genomes: mitochondrial gene order as a phylogenetic tool. Curr Opin Genet Dev. 8:668-74.

Boore J.L., Brown W.M. (2000) Mitochondrial genomes of Galathealinum, Helobdella, and Platynereis: Sequence and gene arrangement comparisons indicate that Pogonophora is not a phylum and Annelida and Arthropoda are not sister taxa. Mol. Biol. Evol. 17:87-106.

Boore J.L., Staton J.L. (2002) The Mitochondrial Genome of the Sipunculid Phascolopsis gouldii Supports Its Association with Annelida Rather than Mollusca. Mol Biol Evol. 19:127-137.

Boyer B.C., Henry J.Q., Martindale M.Q. (1998) The cell lineage of a polyclad 
turbellarian embryo reveals close similarity to coelomate spiralians. Develop Biol. 204:111-123.

Brusca R.C., Brusca G.J. (1990) Invertebrates. Sinauer Associates, Sunderland, Mass.

Cavalier-Smith T. (1998) A revised six-kingdom system of life. Biol. Rev. Camb. Philos. Soc. 73:203-66.

de Rosa R., Grenier J.K., Andreeva T., Cook C.E., Adoutte A., Akam M., Carroll S.B., Balavoine G. (1999) HOX genes in brachiopods and priapulids and protostome evolution. Nature. 399:772-776.

Eernisse D.J., Albert J.S., Anderson F.E. (1992) Annelida and Arthropoda are not sister taxa: a phylogenetic analysis of spiralian metazoan phylogeny. Systematic Biology. 41:305-330.

Eernisse D.J. (1997) Arthropod and annelid relationships re-examined. In: Fortey RA, Thomas RH (eds) Arthropod Relationships. Chapman and Hall, London, p 43-56.

Erber A., Riemer D., Bovenschulte M., Weber K. (1998) Molecular phylogeny of metazoan intermediate filament proteins. J. Mol. Evol. 47:751-762.

Felsenstein J. (1978) Cases in which parsimony or compatibility methods will be positively misleading. Sys. Zool. 27:401-410.

Field K.G., Olsen G.J., Lane D.J., Giovannoni S.J., Ghiselin M.T., Raff E.C., Pace N.R., Raff R.A. (1988) Molecular phylogeny of the animal kingdom. Science. 239:748753.

Finnerty J.R., Martindale M.Q. (1998) The evolution of the Hox cluster: insights from outgroups. Current Opinion in Genetics and Development. 8:681-687.

Funch P., Kristensen R.M. (1995) Cycliophora is a new phylum with affinities to Entoprocta and Ectoprocta. Nature. 378:711-714.

Funch P., Kristensen R.M. (1997) Cycliophora. In: Harrison FW (ed) Microscopic Anatomy of the Invertebrates. Wiley-Liss, New York, p 409-474.

Garey J.R., Near T.J., Nonnemacher M.R., Nadler S.A. (1996) Molecular evidence for Acanthocephala as a subtaxon of Rotifera. J. Mol. Evol. 43:287-292.

Gilbert J.J. (1989) Rotifera. In: Adiyodi KG, Adiyodi RG (eds) Reproductive Biology of Invertebrates. John Wiley and Sons, New York, p 179-199.

Giribet G., Distel D.L., Polz M., Sterrer W., Wheeler W.C. (2000) Triploblastic relationships with emphasis on the acoelomates and the position of Gnathostomulida, Cycliophora, Plathelminthes and Chaetognatha: A combined 
approach of 18S rDNA sequences and morphology. Syst. Biol. 49:539-562.

Giribet G. (2002) Current advances in the phylogenetic reconstruction of metazoan evolution. A new paradigm for the Cambrian explosion? Mol Phyl Evol. $24: 345-357$.

Grobben K. (1908) Die systematische Einteilung des Tierreiches. Verh. Zool. Bot. Ges. Wien. 58:491-511.

Gutmann W.F., Vogel K., Zorn H. (1978) Brachiopods: biomechanical interdependances governing their origin and phylogeny. Science. 199:890-893.

Haeckel E. (1874) The gastraea-theory, the phylogenetic classification of the animal kingdom and the homology of the germ.lamellæ. (Translated by E. Percival Wright, F.L.S., Sec. R.I.A., Professor of Botany, Trin. Coll., Dublin. With PI. VII). Journal of Microscopical Science. 14. New ser.:142-165.

Halanych K.M., Bacheller J.D., Aguinaldo A.M.A., Liva S.M., Hillis D.M., Lake J.A. (1995) Evidence from 18S ribosomal DNA that the lophophorates are protostome animals. Science. 267:1641-1643.

Halanych K.M. (1996) Convergence in the feeding apparatuses of lophophorates and pterobranch hemichordates revealed by $18 \mathrm{~S}$ rDNA: An interpretation. Biol. Bull. 190:1-5.

Halanych K.M. (1998) Considerations for reconstructing metazoan history: Signal, resolution, and hypothesis testing. Amer. Zool. 38:929-941.

Halanych K.M., Passamaneck Y. (2001) A brief review of metazoan phylogeny and future prospects in Hox-research. Amer. Zool. 41:629-639.

Haszprunar G. (2000) In the Aplacophora monophyletic? A cladistic point of view. Am. Malac. Bull. 15:115-130.

Hatschek B. (1878) Studien ber Entwicklungsgeschichte der Anneliden. Ein Beitrag zur Morphologie der Bilaterien. Arbeiten aus dem Zoologischen Institute der Universita"t Wien und der Zoologischen Station in Triest. 1:277-404.

Hennig W. (1966) Phylogenetic Systematics. University of Illinois Press, Urbana.

Henry J.Q. (2002) Conserved mechanism of dorsoventral axis determination in equalcleaving spiralians. Dev Biol. 248:343-355.

Hillis D.M., Dixon M.T. (1991) Ribosomal DNA: Molecular evolution and phylogenetic inference. Quarterly Review of Biology. 66:411-453. 
Huelsenbeck J.P., Ronquist F. (2001) MRBAYES: Bayesian inference of phylogenetic trees. Bioinformatics. 17:754-755.

Hyman L.H. (1940-1967) The Invertebrates. McGraw Hill Book Company, Inc., New York.

Hyman L.H. (1951) The Invertebrates: Acanthocephala, Aschelmithes, and Entoprocta. McGraw-Hill, New York.

Hyman L.H. (1959) The invertebrates: smaller coelomate groups, Chaetognatha, Hemichordata, Pogonophora, Phoronida, Ectoprocta, Brachiopoda, Sipunculida, the coelomate Bilateria. McGraw-Hill, New York.

Ivanov D.L. (1996) Origin of the Aculifera and problems of monophyly of higher taxa in molluscs. In: Taylor JD (ed) Origin and evolutionary radiation of the Mollusca. Oxford Science Publications, London, p 59-65.

Jägersten G. (1972) The evolution of the metazoan life cycle. Academic Press, New York.

Jenner R.A. (2001) Bilaterian phylogeny and uncritical recycling of morphological data sets. Syst Biol. 50:730-42.

Kourakis M.J., Master V.A., Nardelli-Haefliger D., Wedeen C.J., Shankland M., Martindale M.Q. (1997) Conserved anterior boundaries of Hox gene expression in the central nervous system of the leech Helobdella. Dev Biol. 190:284-300.

Kurabayashi A., Ueshima R. (2000) Complete sequence of the mitochondrial DNA of the primitive opisthobranch gastropod Pupa strigosa: systematic implication of the genome organization. Mol. Biol. Evol. 17:266-277.

Lake J.A:(1990) Origin of Metazca. Proc. Natl. Acad. Sci. USA. 87:763-766.

Lake J.A. (1994) Reconstructing evolutionary trees from DNA and protein sequences: paralinear distances. Proc Natl Acad Sci U S A. 91:1455-1459.

Lehmann U., Hillmer G. (1983) Fossil Invertebrates. Cambridge University Press, Cambridge.

Lockhart P.J., Steel M.A., Hendy M.D., Penny D. (1994) Recovering evolutionary trees under a more realistic model of sequence evolution. Mol Biol Evol. 11:605-612.

Mackey L.Y., Winnepennickx B., De Wachter R., Beckeljau T., Emschermann P., Garey J.R. (1996) 18S rRNA suggests that Entoprocta are protostomes, unrelated to Ectoprocta. J. Mol. Evol. 42:552-559.

Maddison D.R., Maddison W.P. (2000) MacClade. Sinauer Associates, Sunderland, Mass 
Maidak B.L., Cole J.R., Lilburn T.G., Parker C.T.J., Saxman P.R., Farris R.J., Garrity G.M., Olsen G.J., Schmidt T.M., Tiedje J.M. (2001) The RDP-II (Ribosomal Database Project). Nucleic Acids Research. 29:173-174.

Maley L.E., Marshall C.R. (1998) The coming of age of molecular systematics. Science. 279:505-506.

Mallatt J., Winchell C.J. (2002) Testing the new animal phylogeny: first use of combined large-subunit and small-subunit rRNA gene sequences to classify the protostomes. Mol Biol Evol. 19:289-301,

Medina M., Collins A.G., Silberman J.D., Sogin M.L. (2001) Evaluating hypotheses of basal animal phylogeny using complete sequences of large and small subunit rRNA. Proc Natl Acad Sci U S A. 98:9707-12.

Meglitsch P.A., Schram F.R. (1991) Inverebrate Zoology. Oxford University Press, New York.

Muse S.V., Kosakovsky Pond S.L. (2001) HYPHY. Hypothesis Testing Using Phylogenies.

Nielsen C. (1971) Entoproct life cycles and the entoproct/ectoproct relationship. Ophelia. 9:209-341.

Nielsen C. (1985) Animal phylogeny in the light of the trochaea theory. Biol. J. Linn. Soc. 25:243-299.

Nielsen C. (1987) Structure and function of metazoan ciliary bands and their phylogenetic significance. Acta Zool. 68:205-262.

Nielsen C., Riisgård H.U. (1998) Tentacle structure and filter-feeding in Crisia eburnea and other cyclostomatous bryozoans, with a review of upstream-collecting mechanisms. Mar Ecol Prog Ser. 168:163-186.

Nielsen C. (2001) Animal Evolution: Interrelationships of the Living Phyla. Oxford University Press, Oxford.

Peterson K.J., Eernisse D.J. (2001) Animal phylogeny and the ancestry of bilaterians: inferences from morphology and $18 \mathrm{~S}$ rDNA gene sequences. Evolution \& Development. 3:170-205.

Philippe H., Lopez P., Brinkmann H., Budin K., Germot A., Laurent J., Moreira D., Muller M., Le Guyader H. (2000) Early-branching or fast-evolving eukaryotes? An answer based on slowly evolving positions. Proc. R. Soc. Lond. B Biol. Sci. 267:1213-1221. 
Posada D., Crandall K.A. (1998) Modeltest: testing the model of DNA substitution. Bioinformatics. 14

Rawlings T.A., Collins T.M., Bieler R. (2001) A major mitochondrial rearrangement among closely related species. Mol Biol Evol. 18:1604-1609.

Regier J.C., Shultz J.W. (2001) Elongation factor-2: a useful gene for arthropod phylogentics. Mol Phyl Evol. 20:136-148.

Ruiz-Trillo I., Paps J., Loukota M., Ribera C., Jondelius U., Baguñà J., Riutort M. (2002) A phylogenetic analysis of myosin heavy chain type II sequences corroborates that Acoela and Nemertodermatida are basal bilaterians. Proc Natl Acad Sci U S A. 99:11246-11251.

Runnegar B., Pojeta J.J. (1974) Molluscan phylogeny: the paleontological viewpoint. Science. 186:311-317.

Runnegar B., Pojeta J.J. (1985) Origin and diversification of the Mollusca. In: Trueman ER, Clarke MR (eds) The Mollusca. Academic Press, New York, p 1-57.

Salvini-Plawen L.v. (1972) Zur Morphologie und Phylogenie der Mollusken: Die Beziehung der Caudofaveataa und Solenogastres als Aculifera, als Mollusca und als Spiralia. Z. wiss. Zool. 184:205-394.

Salvini-Plawen L.v. (1980) A reconstruction of systematics in the Mollusca (phylogeny and higher classification). Malacologia. 19:249-278.

Salvini-Plawen L.v. (1982) A paedomorphic origin of the oligomerous animals? Zool. Scripta. 11:77-81.

Salvini-Plawen L.v. (1985) Early evolution and the primitive groups. In: Trueman ER, Clarke MR (eds) The Mollusca. Academic Press, New York, p 59-150.

Salvini-Plawen L.v., Steiner G. (1996) Synapomorphies and plesiomorphies in higher classification of Mollusca. In: Taylor JD (ed) Origin and evolutionary radiation of the Mollusca. Oxford Science Publications, London, p 29-51.

Scheltema A.H. (1993) Aplacophorans as progenetic Aculiferans and the coelomate origin of mollusks as the sister taxon of the Sipuncula. Biol. Bull. 184:57-78.

Scheltema A.H. (1996) Phylogenetic position of the Sipuncula, Mollusca and the progenetic Aplacophora. In: Taylor JD (ed) Origin and evolutionary radiation of the Mollusca. Oxford Science Publications, London, p 53-58.

Shimodaira H., Hasegawa M. (1999) Multiple comparisons of log-likelihoods with 
applications to phylogenetic inference. Mol Biol Evol. 16:1114-1116.

Siewing R. (1976) Probleme und neuere Erkentnisse in der Gross-systematik der Wirbellosen. Verhandl. Dtsch. Zool. Ges. Stuttgart. 1976:59-83.

Siewing R. (1980) Das Archicoelomatenkonzept. Zool. Jb. Syst. 103:439-482.

Stechmann A., Schlegel M. (1999) Analysis of the complete mitochondrial DNA sequence of the brachiopod Terebratulina retusa places Brachiopoda within the protostomes. Proc. R. Soc. Lond. B. 266:2043-2052.

Steiner G., Müller M. (1996) what can 18S rDNA do for bivalve phylogeny? J. Mol. Evol. 43:58-70.

Steiner G., Hammer S. (2000) Molecular phylogeny of the Bivalvia inferred from 18S rDNA sequences with particular reference to the Pteriomorpha. In: Harper EM, Taylor JD, Crame JA (eds) The evolutionary biology of the Bivalvia. Geological Society, London, p 11-29.

Stiller J.W., Hall B.D. (1999) Long-branch attraction and the rDNA model of early eukaryotic evolution. Mol. Biol. Evol. 16:1270-1279.

Swofford D.L., Olsen G.J., Waddell P.J., Hillis D.M. (1996) Phylogenetic inference. In: Hillis DM, Moritz C, Mable BK (eds) Molecular Systematics. Sinauer Associates, Inc., Sunderland, Mass, p 407-514.

Swofford D.L. (2002) PAUP*. Phylogenetic Analysis Using Parsimony (*and Other Methods). Version 4. Sinauer Associates, Sunderland, Mass

Tamura K., Nei M. (1993) Estimation of the number of nucleotide substitutions in the control region of mitochondrial DNA in humans and chimpanzees. Mol Biol Evol. 10:512-526.

Telford M.J. (2000a) Evidence for the derivation of the Drosophila fushi tarazu gene from a Hox gene orthologous to lophotrochozoan Lox5. Current Biology. 10:349352.

Telford M.J. (2000b) Turning Hox "signatures" into synapomorphies. Evol. Devel. 2:360-264.

Thompson J.D., Higgins D.G., Gibson T.J. (1994) CLUSTAL W: improving the sensitivity of progressive multiple alignment through sequence weighting, position specific gap penalties and weight matrix choice. Nucleic Acids Research. 22:46734680.

Tomita K., Yokobori S., Oshima T., Ueda T., Watanabe K. (2002) The cephalopod 
Loligo bleekeri mitochondrial genome: multiplied noncoding regions and transportation of tRNA genes. J. Mol. Evol. 54:486-500.

Valentinè J.W. (1974) Late Precambrian bilaterians:-grades and clades. Proc. Natl. Acad. Sci. USA. 91:6751-6757.

Valentine J.W. (1997) Cleavage Patterns and the Topology Of the Metazoan Tree Of Life. Proceedings Of The National Academy Of Sciences Of The United States Of America. 94:8001-8005.

Waller T.R. (1998) Origin of the molluscan class Bivalvia and the phylogeny of major groups. In: Johnston PA, Haggart JW (eds) Bivalves: An eon of evolution paleobiological studies honoring Norman D. Newell. University of Calgary Press, Calgary, p 1-45.

Wilding C.S., Mill P.J., Grahame J. (1999) Partial sequence of the mitochondrial genome of Littorina saxatilis: relevance to gastropod phylogenetics. J. Mol. Evol. 48:348359.

Willmer P. (1990) Invertebrate relationships, Patterns in animal evolution. Cambridge University Press, New York.

Winchell C.J., Sullivan J., Cameron C.B., Swalla B.J., Mallatt J. (2002) Evaluating Hypotheses of Deuterostome Phylogeny and Chordate Evolution with New LSU and SSU Ribosomal DNA Data. Mol Biol Evol. 19:762-76.

Wingstrand K.G. (1985) On the anatomy and relationships of recent Monoplacophorans. Galathea Rep. 16:7-94.

Winnepenninckx B., Backeljau T., De Wachter R. (1995) Phylogeny of protostome worms derived from 48 S rRNA sequences. Mol. Biol. Evol. 12:641-649.

Winnepenninckx B., Backeljau T., De Wachter R. (1996) Investigation of molluscan phylogeny on the basis of 18S rRNA sequences. Mol Biol Evol. 13:1306-17.

Winnepenninckx B.M.H., Backeljau T., Kristensen R.M. (1998) Relations of the new phylum Cycliophora. Nature. 393:636-638.

Wray G.A. (1996) Parallel evolution of nonfeeding larvae in echinoids. Syst. Biol. 45:308-322.

Wray G.A., Abouheif E. (1998) When is homology not homology? Current Opinion in Genetics and Development. 8:675-680.

Zimmer R.L. (1973) Morphological and developmental affinities of the Lophophorates. In: Larwood GP (ed) Living and Fossil Bryozoa. Academic Press, New York, $p$ 
593-599.

Zrzavy J., Mihulka S., Kepka P., Bezdek A., Tiez D. (1998) Phylogeny of the Metazoa based on morphological and $18 \mathrm{~S}$ ribosomal DNA evidence. Cladistics. 14:249-285. 